EFFECTS OF COLLARS ON SCOUR REDUCTION AT BRIDGE ABUTMENTS

ABDULLAH ERCÜMENT DOĞAN

DECEMBER 2008 
EFFECTS OF COLLARS ON SCOUR REDUCTION AT BRIDGE ABUTMENTS

A THESIS SUBMITTED TO

THE GRADUATE SCHOOL OF NATURAL AND APPLIED SCIENCES

$\mathrm{OF}$

MIDDLE EAST TECHNICAL UNIVERSITY

BY

ABDULLAH ERCÜMENT DOĞAN

IN PARTIAL FULFILLMENT OF THE REQUIREMENTS

FOR

THE DEGREE OF MASTER OF SCIENCE

IN

CIVIL ENGINEERING

DECEMBER 2008 
Approval of the Thesis;

\section{EFFECTS OF COLLARS ON SCOUR REDUCTION AT BRIDGE ABUTMENTS}

submitted by A. ERCÜMENT DOĞAN in partial fulfillment of the requirements for the degree of Master of Science in Civil Engineering, Middle East Technical University by,

Prof. Dr. Canan Özgen

Dean, Graduate School of Natural and

Applied Sciences

Prof. Dr. Güney Özcebe

Head of Department, Dept. of Civil Engineering

Prof. Dr. Mustafa Göğüş

Supervisor, Dept. of Civil Engineering, METU

\section{Examining Committee Members:}

Prof. Dr. Nevzat Yıldırım ( $\left.{ }^{*}\right)$

Civil Engineering Dept., GAZI UNI.

Prof. Dr. Mustafa Göğüş ${ }^{* *}$ )

Civil Engineering Dept., METU

Assoc. Prof. Dr. İsmail Aydın

Civil Engineering Dept., METU

Dr. Mete Köken

Civil Engineering Dept., METU

Dr. Ş. Yurdagül Kumcu

Technical Research and Quality Control Dept., DSI

Date: $\quad 05.12 .2008$

(*) Head of Examining Committee

$\left({ }^{* *}\right)$ Supervisor 
I hereby declare that all information in this document has been obtained and presented in accordance with academic rules and ethical conduct. I also declare that, as required by these rules and conduct, I have fully cited and referenced all material and results that are not original to this work.

Name, Last name $\quad$ : A. Ercüment DOĞAN

Signature 


\author{
ABSTRACT \\ EFFECTS OF COLLARS ON SCOUR REDUCTION AT BRIDGE \\ ABUTMENTS \\ Doğan, Abdullah Ercüment \\ M.S., Department of Civil Engineering \\ Supervisor: Prof. Dr. Mustafa Göğüş
}

December 2008, 104 pages

Bridge failures are generally resulted from scour of the bed material around bridge piers and abutments during severe floods. In this study, scour phenomenon around bridge abutments and collars, located at abutments as scour countermeasures, were experimentally studied.

The experimental study was carried out under clear-water scour conditions with uniform non-cohesive sediment (having a grain size diameter of $d_{50}=0.90 \mathrm{~mm}$ ). The experimental flume is a rectangular channel of $30 \mathrm{~m}$ long and $1.5 \mathrm{~m}$ wide filled with this erodible bed material. 
Based on the results of 97 experiments conducted during the study, the efficiency of various sizes of collars, which were used to reduce the local scour depth, located at different elevations around the abutments was determined. The results obtained were compared with previous studies, and the effect of the sediment grain size on the performance of abutment collars was emphasized. It was noticed that when the collar width was increased and placed at or below the bed level, the reduction in scour depth increases considerably. It was also found out that the change of the sediment size did not affect the optimum location of the collar at the abutment, which yields the maximum scour reduction around the abutment.

Keywords: Scour, Bridges, Abutments, Collar, Scour Countermeasures 


\title{
ÖZ
}

\section{KÖPRÜ YAN AYAKLARI ÜZERINE YERLEŞTİIILEN PLAKALARIN OYULMAYA ETKİSI}

\author{
Doğan, Abdullah Ercüment \\ Yüksek Lisans, İnşaat Mühendisliği Bölümü \\ Tez Yöneticisi: Prof. Dr. Mustafa Göğüş
}

Aralık 2008, 104 sayfa

Köprü yıkılmaları genel olarak köprü orta ve yan ayakları etrafındaki yatak malzemesinin şiddetli taşkınlarla aşınması ve oyulmasından kaynaklanmaktadır. Bu çalışmada, köprü yan ayakları etrafındaki oyulmalar ve bunlara önlem olarak ayak üzerine yerleştirilen plakalar deneysel olarak çalışılmıştır.

Deneysel çalışma, temiz su oyulması koşulları altında üniform ve koheziv olmayan sediment malzemesiyle (tane çap $1 \mathrm{~d}_{50}=0.90 \mathrm{~mm}$ olan) yapılmıştır. Deney kanalı, dikdörtgen kesitli bir kanal olup, 30 m uzunluğunda ve 15 m genişliğinde bahsi geçen oyulabilir yatak malzemesi doldurulmuştur. 
Çalışma esnasında yapılan 97 deneyin sonuçlarına dayanılarak yersel oyulma derinliğini azaltmak amacı ile köprü yan ayağının etrafına farklı derinliklere yerleştirilen değişik boyutlardaki plakaların verimleri belirlenmiştir. Elde edilen sonuçlar önceki çalışmalarla karşılaştırılmış ve sediment tane büyüklüğünün yan ayağa yerleştirilen yatay levha davranışları üzerindeki etkisi vurgulanmıştır. Plakanın genişliğinin artması halinde ve plakanın kum seviyesine veya kum seviyesinin altına yerleştirilmesi durumunda, oyulma derinliğindeki azalmanın arttığı dikkat çekmiştir. Ayrıca, sediment çapının değişiminin, plakaların yan ayak üzerinde yerleştirildiği ve ayak çevresindeki oyulmanın azalmasına en fazla derecede etki ettiği optimum seviyelerin üzerinde bir etkisi olmadığı sonucu çıkarılmıştır.

Anahtar Kelimeler: Oyulma, Köprüler, Köprü Yan Ayakları, Plakalar, Oyulma Tedbirleri 
TO MY FAMILY 


\section{ACKNOWLEDGMENTS}

This study was suggested and has been completed under the supervision of Prof. Dr. Mustafa GÖĞÜŞ in the Middle East Technical University (METU) in Ankara, Turkey.

I would like to express my sincere thanks and deep sense of gratitude to my supervisor Prof. Dr. Mustafa GÖĞÜŞ for his invaluable guidance, continued interest, patience and encouragement throughout this study. His wealth of knowledge and enthusiasm to share them with me is most appreciated.

I would like to extend my thankful feelings to State Hydraulic Works for offering all of its possibilities without any reciprocal throughout the experimental studies.

My special gratitude goes to my colleague, Dr. Ş. Yurdagül KUMCU for her invaluable help, support and patience for my frequent disturbances.

I am grateful to Ahmet GÜVENÇ and Abidin TEKE for their assistance and help throughout the laboratory program of my research. 
Finally, I would like to thank my family for their "all the time" love, understanding, support, encouragement and patience, which gave me the strength, the motivation and the inspiration to complete this study. I always try to merit you. 


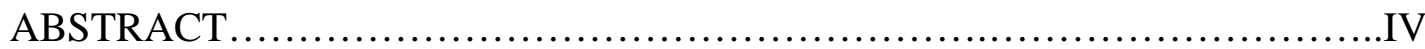

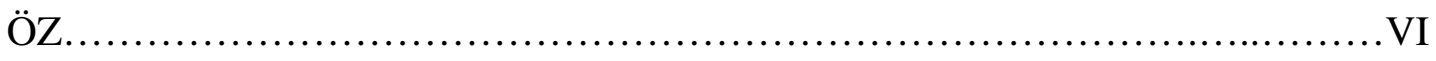

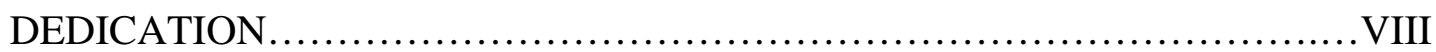

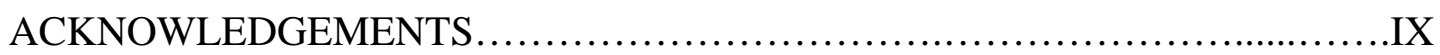

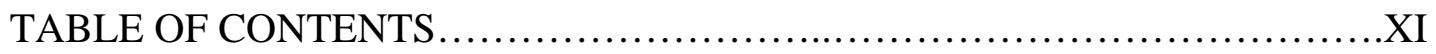

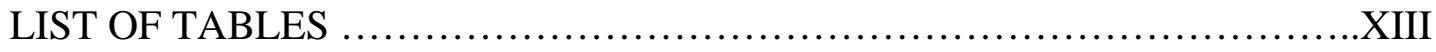

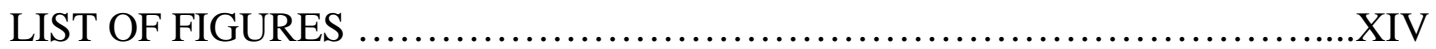

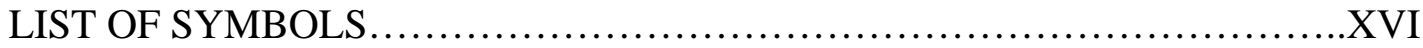

CHAPTERS

1. INTRODUCTION........................................................

1.1 GENERAL REMARKS................................................

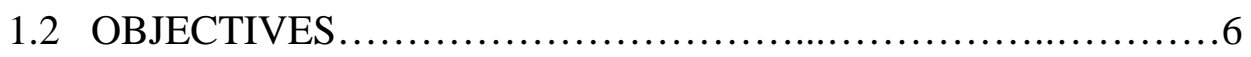

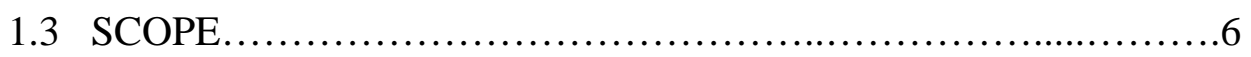

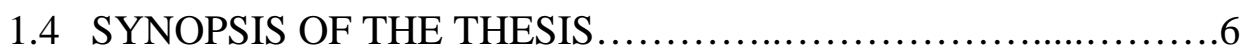

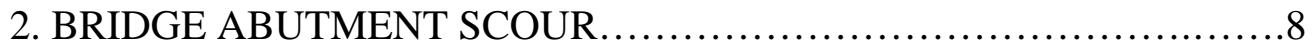

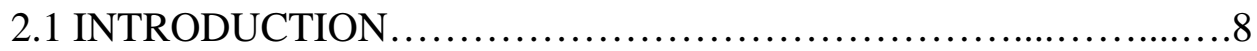

2.2 BRIDGE ABUTMENT SCOUR MECHANISM.........................

2.3 PARAMETERS INFLUENCING LOCAL SCOUR AT ABUTMENTS..........................................................

2.3.1 Time Evolution..........................................12

2.3.2 The Effect of Flow Velocity.............................13

2.3.3 The Effect of Flow Depth ...............................14

2.3.4 The Effect of Sediment Size ...........................14

2.3.5 The Effect of Sediment Gradation ......................16

2.3.6 The Effect of Abutment Length .............................17

2.3.7 The Effect of Abutment Shape ............................17 
2.3.8 The Effect of Abutment Skewness ......................18

2.4 CLOSURE ....................................................... 18

3. BRIDGE ABUTMENT SCOUR COUNTERMEASURES..................19

3.1 GENERAL REMARKS............................................19

3.2 GROUPS OF COUNTERMEASURES.............................21

3.3 ABUTMENT SCOUR COUNTERMEASURES....................22

3.4 CONCLUSION.............................................24

4. EXPERIMENTAL SETUP .........................................25

4.1 THE FLUME.................................................25

4.2 THE ABUTMENT MODEL.......................................26

4.3 SAND MATERIAL..............................................26

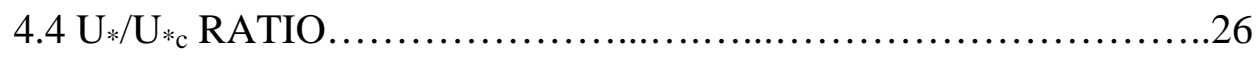

4.5 MEASUREMENT AND DEVICE............................27

5. APPLICATION OF COLLAR TO CONTROL SCOURING AROUND

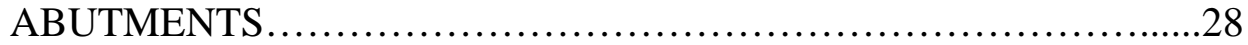

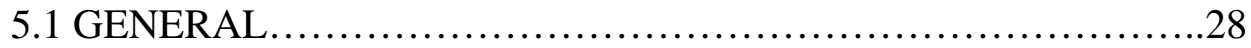

5.2 LITERATURE REVIEW ......................................28

5.3 DIMENSIONAL ANALYSIS....................................

5.4 EXPERIMENTAL PROCEDURE......................................32

5.5 SCOUR MECHANISM..........................................35

5.6 DISCUSSION OF RESULTS..................................36

5.6.1 Scour Profiles around the Abutment with and without Collar...36

5.6.2 Maximum Scour Reductions around the Abutments with Collars.....................................................62

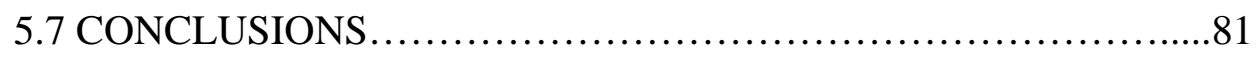

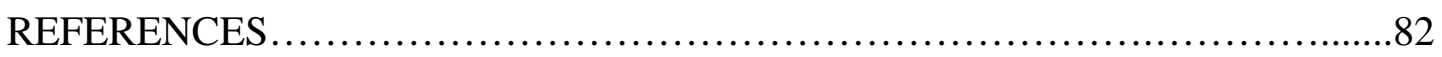

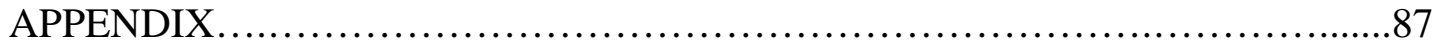




\section{LIST OF TABLES}

\section{TABLE}

Table 2.1 Parameters influencing local scour at abutments................... 11

Table 3.1 Advantages and disadvantages of various countermeasures.......... 23

Table 5.1 Abutment and collar sizes used in the tests........................ 34

Table 5.2 Experimental data for $\mathrm{Q}=0.017 \mathrm{~m}^{3} / \mathrm{s}, \mathrm{y}=4.25 \mathrm{~cm}$ and $\mathrm{B}_{\mathrm{a}}=10 \mathrm{~cm} \ldots \ldots .63$

Table 5.3 Optimum design parameters of an abutment-collar arrangement...... 72

Table A.1 Cross-sections (profiles) of the scour hole for $\mathrm{L}_{\mathrm{a}}=7.5 \mathrm{~cm} \ldots \ldots \ldots \ldots . .87$

Table A.2 Cross-sections (profiles) of the scour hole for $\mathrm{La}=15 \mathrm{~cm} . \ldots \ldots \ldots \ldots . . . .89$

Table A.3 Cross-sections (profiles) of the scour hole for $\mathrm{La}=20 \mathrm{~cm} \ldots \ldots \ldots \ldots . .93$

Table A.4 Cross-sections (profiles) of the scour hole for $\mathrm{La}=25 \mathrm{~cm} . \ldots \ldots \ldots \ldots . .97$

Table A.5 Cross-sections (profiles) of the scour hole for $\mathrm{La}=35 \mathrm{~cm} . \ldots \ldots \ldots \ldots . . .101$ 


\section{LIST OF FIGURES}

\section{FIGURE}

Figure 2.1 Flow patterns around a wing-wall abutment............... 10

Figure 2.2 Time development of clear-water and live-bed scour......... 13

Figure 4.1 The longitudinal cross-section of the experimental setup...... 26

Figure 5.1 Definition sketch of collar-abutment arrangement........... 31

Figure 5.2(a) Bed profiles around the bridge abutment of $L_{a}=7.5 \mathrm{~cm}$ with and without collars $\left(\mathrm{L}_{\mathrm{a}} / \mathrm{B}_{\mathrm{c}}=0.75\right) \ldots \ldots \ldots \ldots \ldots \ldots \ldots \ldots \ldots \ldots \ldots \ldots \ldots \ldots \ldots$

Figure 5.2(b) Bed profiles around the bridge abutment of $\mathrm{L}_{\mathrm{a}}=7.5 \mathrm{~cm}$ with

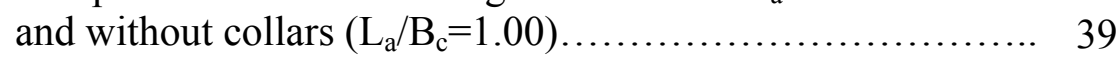

Figure 5.2(c) Bed profiles around the bridge abutment of $L_{a}=7.5 \mathrm{~cm}$ with

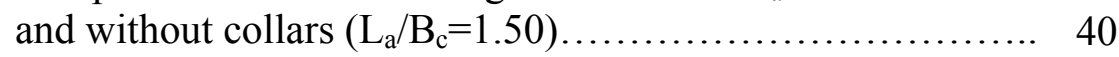

Figure 5.2(d) Bed profiles around the bridge abutment of $L_{a}=7.5 \mathrm{~cm}$ with

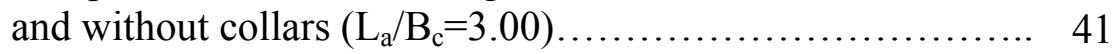

Figure 5.3(a) Bed profiles around the bridge abutment of $\mathrm{L}_{\mathrm{a}}=15 \mathrm{~cm}$ with

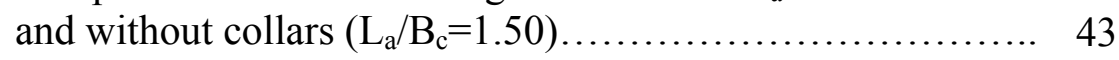

Figure 5.3(b) Bed profiles around the bridge abutment of $\mathrm{L}_{\mathrm{a}}=15 \mathrm{~cm}$ with

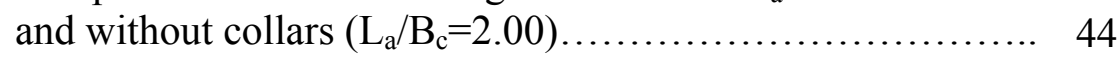

Figure 5.3(c) Bed profiles around the bridge abutment of $\mathrm{L}_{\mathrm{a}}=15 \mathrm{~cm}$ with

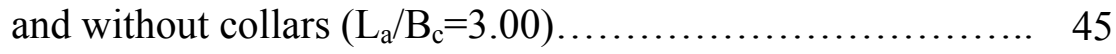

Figure 5.3(d) Bed profiles around the bridge abutment of $\mathrm{L}_{\mathrm{a}}=15 \mathrm{~cm}$ with

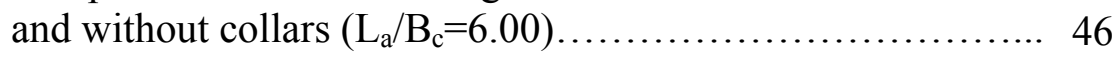

Figure 5.4(a) $\begin{aligned} & \text { Bed profiles around the bridge abutment of } \mathrm{L}_{\mathrm{a}}=20 \mathrm{~cm} \text { with } \\ & \text { and without collars }\left(\mathrm{L}_{\mathrm{a}} / \mathrm{B}_{\mathrm{c}}=2.00\right) \ldots \ldots \ldots \ldots \ldots \ldots \ldots \ldots \ldots \ldots \ldots \ldots \ldots \ldots \ldots \ldots\end{aligned}$

Figure 5.4(b) Bed profiles around the bridge abutment of $\mathrm{L}_{\mathrm{a}}=20 \mathrm{~cm}$ with

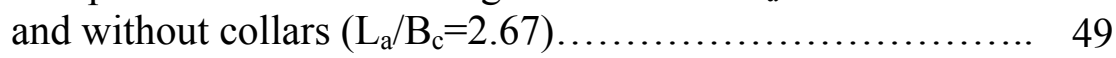

Figure 5.4(c) Bed profiles around the bridge abutment of $\mathrm{L}_{\mathrm{a}}=20 \mathrm{~cm}$ with

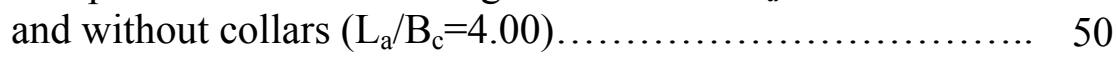

Figure 5.4(d) $\begin{aligned} & \text { Bed profiles around the bridge abutment of } \mathrm{L}_{\mathrm{a}}=20 \mathrm{~cm} \text { with } \\ & \text { and without collars }\left(\mathrm{L}_{\mathrm{a}} / \mathrm{B}_{\mathrm{c}}=8.00\right) \ldots \ldots \ldots \ldots \ldots \ldots \ldots \ldots \ldots \ldots \ldots \ldots \ldots \ldots \ldots \ldots \ldots \ldots\end{aligned}$

Figure 5.5(a) Bed profiles around the bridge abutment of $\mathrm{L}_{\mathrm{a}}=25 \mathrm{~cm}$ with and without collars $\left(\mathrm{L}_{\mathrm{a}} / \mathrm{B}_{\mathrm{c}}=2.50\right)$ 
Figure 5.5(b) Bed profiles around the bridge abutment of $\mathrm{L}_{\mathrm{a}}=25 \mathrm{~cm}$ with

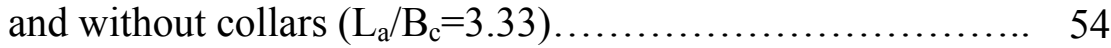

Figure 5.5(c) Bed profiles around the bridge abutment of $\mathrm{L}_{\mathrm{a}}=25 \mathrm{~cm}$ with

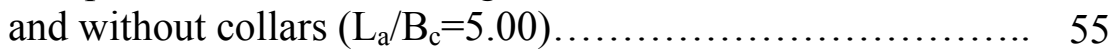

Figure 5.5(d) Bed profiles around the bridge abutment of $\mathrm{L}_{\mathrm{a}}=25 \mathrm{~cm}$ with

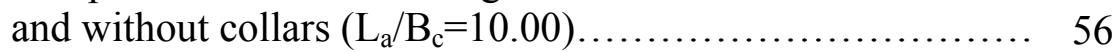

Figure 5.6(a) Bed profiles around the bridge abutment of $\mathrm{L}_{\mathrm{a}}=35 \mathrm{~cm}$ with

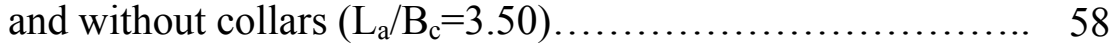

Figure 5.6(b) Bed profiles around the bridge abutment of $\mathrm{L}_{\mathrm{a}}=35 \mathrm{~cm}$ with

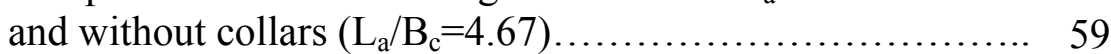

Figure 5.6(c) Bed profiles around the bridge abutment of $\mathrm{L}_{\mathrm{a}}=35 \mathrm{~cm}$ with

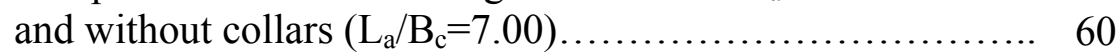

Figure 5.6(d) Bed profiles around the bridge abutment of $\mathrm{L}_{\mathrm{a}}=35 \mathrm{~cm}$ with

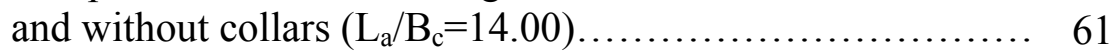
Effect of collar size and elevation on the maximum scour

Figure 5.7 depth around the abutments of various lengths $(\mathrm{Q}=0.017$ $\mathrm{m}^{3} / \mathrm{s}, \mathrm{y}=4.25 \mathrm{~cm}, \mathrm{~d}_{50}=0.90 \mathrm{~mm}$ ).

Effect of collar size and elevation on the maximum scour

Figure 5.8 depth around the abutments of various lengths $(\mathrm{Q}=0.050$ $\left.\mathrm{m}^{3} / \mathrm{s}, \mathrm{y}=10 \mathrm{~cm}, \mathrm{~d}_{50}=1.48 \mathrm{~mm}\right)($ Kayatürk, 2005)...

Variation of $\left\lfloor\left(d_{s}\right)_{\max , c} / y\right\rfloor_{o p t}$ with $\theta\left(\mathrm{Q}=0.017 \mathrm{~m}^{3} / \mathrm{s}, \mathrm{y}=4.25\right.$

Figure 5.9

$\left.\mathrm{cm}, \mathrm{Fr}=0.41, \mathrm{U} * / \mathrm{U}_{*}=0.90, \mathrm{~d}_{50}=0.90 \mathrm{~mm}\right)$

Variation of $\left[\left(d_{s}\right)_{\max , c} / y\right\rfloor_{o p t}$ with $\theta\left(\mathrm{Q}=0.050 \mathrm{~m}^{3} / \mathrm{s}, \mathrm{y}=10 \mathrm{~cm}\right.$,

Figure 5.10

$\left.\mathrm{Fr}=0.34, \mathrm{U}_{*} / \mathrm{U}_{*_{\mathrm{c}}}=0.90, \mathrm{~d}_{50}=1.48 \mathrm{~mm}\right)($ Kayatürk, 2005).......

Figure 5.11 Variation of $\left\lfloor\left(d_{s}\right)_{\max , c} / y\right\rfloor_{o p t}$ with $\sqrt{\theta\left(L_{a} / B_{c}\right)} \ldots \ldots \ldots \ldots \ldots . . \ldots 7$

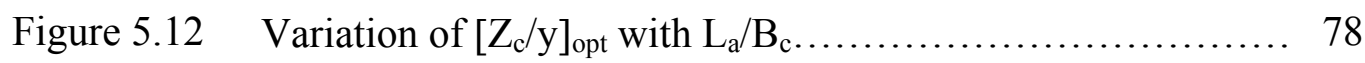

Figure 5.13 Variation of $[\% \text { Reduction }]_{\text {opt }}$ with $\mathrm{L}_{\mathrm{a}} / \mathrm{B}_{\mathrm{c}} \ldots \ldots \ldots \ldots \ldots \ldots \ldots . . . \ldots$ 


\section{LIST OF SYMBOLS}

\section{SYMBOLS}

$\mathrm{A}_{\text {total }}$

A abutment

B

$\mathrm{B}_{\mathrm{a}}$

$\mathrm{B}_{\mathrm{c}}$

$\mathrm{B}_{\mathrm{t}}$

C

$\mathrm{C}_{\mathrm{u}}$

$d_{s}$

$\left(\mathrm{d}_{\mathrm{s}}\right)_{\max }$

$\left(d_{s}\right)_{\max , \mathrm{c}}$

$\mathrm{d}_{50}$

$\mathrm{d}_{84}$

$\mathrm{d}_{84.1}$

$\mathrm{d}_{60}$

$\mathrm{d}_{16}$

$\mathrm{d}_{15.9}$
Total area of the abutment with collar

Abutment area on the horizontal plane

Channel width

Abutment width

Collar width around the abutment

Total width of the abutment width and collar width on horizontal

Cohesiveness

Uniformity coefficient

Local scour depth at the abutment at any time

Maximum scour depth at the abutment at the end of the given time duration

Maximum scour depth at the abutment with collar

Median size of sediment

Sediment size for which $84 \%$ of the sediment finer

Sediment size for which $84.1 \%$ of the sediment finer

Sediment size for which $60 \%$ of the sediment finer

Sediment size for which $16 \%$ of the sediment finer

Sediment size for which $15.9 \%$ of the sediment finer 


\begin{tabular}{|c|c|}
\hline $\mathrm{d}_{10}$ & Sediment size for which $10 \%$ of the sediment finer \\
\hline $\mathrm{F}_{\mathrm{r}}$ & Froude number of flow \\
\hline g & Gravitational acceleration \\
\hline $\mathrm{K}_{\mathrm{a}}$ & Shape factor of abument \\
\hline $\mathrm{K}_{\mathrm{G}}$ & Approach channel geometry factor \\
\hline $\mathrm{L}_{\mathrm{a}}$ & Projecting length of abutment, perpendicular to the flow \\
\hline $\mathrm{L}_{\mathrm{c}}$ & Projecting length of collar, perpendicular to the flow \\
\hline $\mathrm{R}^{2}$ & Correlation coefficient \\
\hline $\operatorname{Re}^{*}$ & Particle Reynolds number \\
\hline Q & Discharge of the flow \\
\hline $\mathrm{S}_{0}$ & Slope of the channel \\
\hline $\mathrm{S}_{\mathrm{e}}$ & Energy slope of flow \\
\hline $\mathrm{S}_{\mathrm{p}}$ & Particle shape factor \\
\hline $\mathrm{S}_{\mathrm{s}}$ & Specific gravity \\
\hline $\mathrm{T}_{\mathrm{c}}$ & Collar thickness \\
\hline $\mathrm{t}$ & Time \\
\hline $\mathrm{U}$ & Mean approach flow velocity \\
\hline $\mathrm{U}_{\mathrm{c}}$ & The value of the $U$ at the threshold of grain motion \\
\hline $\mathrm{U}_{*}$ & Shear velocity of the approach flow \\
\hline $\mathrm{U}_{*_{\mathrm{C}}}$ & The value of the $U_{*}$ at the threshold of grain motion \\
\hline $\mathrm{X}$ & Axis in the direction of flow \\
\hline $\mathrm{y}$ & Normal flow depth \\
\hline $\mathrm{y}_{\mathrm{c}}$ & Critical flow depth at the threshold of grain motion \\
\hline $\mathrm{w}$ & Sediment fall velocity \\
\hline
\end{tabular}


$\mathrm{Z}_{\mathrm{c}} \quad$ Collar level on the abutment with reference to bed level

$\theta$

Ratio of total area of the abutment and collar to the abutment area on horizantal plane

$\theta_{\mathrm{a}}$

Abutment skewness

Shield's entrainment factor, dimensionless critical shear

$\theta_{\mathrm{c}}$

factor

$\sigma_{\mathrm{g}} \quad$ Standart deviation of particle-size distribution

$\varphi$

Angle of repose

$\rho$

Fluid density

$\rho_{\mathrm{s}}$

Sediment density

$\mu$

Dynamic viscosity of fluid

$\tau_{0}$

Bed shear stress

$\tau_{\mathrm{C}}$

Critical shear stress for sediment particles to move 


\section{CHAPTER 1}

\section{INTRODUCTION}

\subsection{GENERAL REMARKS}

In today's modern world, the meaning of a civilized country is related with the strength of a competitive and growing economy. And to achieve such an economy requires several components working effectively both by themselves and as parts of a larger, interconnected whole. One of these components is transportation. Transportation facilities are constructed because they provide benefits to society as a whole or as individuals. The efficient operation of a transportation system has great economic significance. Therefore, having a proper and efficient infrastructural approach is becoming more and more important day by day. Thinking about the roads, highways, bridges etc. as being parts of such an infrastructural system, their physical condition are quite important. Deficiencies and damages in one of those can affect the whole transportation system, and, as a result, the whole economy and community. One of the important components of a land transport facility is the bridges. 
There are several studies related to the causes of bridge failures. Almost all of them lead to the same result. Most of the bridge failure cases were caused by flood/scourrelated problems. Some results of these studies are given below:

- In a survey of 823 bridge failures in the USA since 1950, Shirhole and Holt (1991) found that $60 \%$ of the failures were associated with the effects of hydraulics, including both channel bed scour around bridge foundations and channel instability.

- Over 1000 bridge failures have occurred in the United States over the last 30 years. Over $60 \%$ of bridge failures in the U.S. were due to scour of the bridge foundations. More than 85,000 bridges in the U.S. are vulnerable to scour (about 80,000 being scour-susceptible and about 7,000 scour-critical) (Sümer et al., 2002).

- Over 500 failures of bridge structures in the United States between 1989 and 2000 were studied. The age of the failed bridges ranged from 1 year (during construction) to 157 years, with an average of 52.5 years. The most frequent causes of bridge failures were attributed to floods and collisions. Flood and scour, with the major flood disaster in 1993, contributed to the frequency peak of bridge failures (almost 53\% of all failures). Bridge overload and lateral impact forces from trucks, barges/ships, and trains constitute $20 \%$ of the total bridge failures. Other frequent principal causes are design, detailing, construction, material, and maintenance (Wardhana and Hadipriono, 2003). 
- Federal Highway Administration of USA stated that during the spring floods of 1987, 17 bridges in New York and New England were damaged or destroyed by scour (FHWA, 2001).

According to given studies and researches above, the term "scour" becomes more meaningful, and to understand it provides a wider perspective to prevent from the bridge failures. By the U.S. FHWA, scour can be defined as erosion or removal of streambed or bank material from bridge foundations due to flowing water, usually considered as long-term bed degradation, contraction, and local scour. As noted in the definition, the scour concept has three main components: a long-term streambed elevation changes due to natural or human-induced causes as General Scour, Contraction Scour as a result from the acceleration of the flow due to either a natural or bridge contraction, and finally, Local Scour around piers, abutments, spurs and embankments due to the acceleration of the flow and the development of vortex systems induced by these obstructions to the flow. Among these components, local scour is the most effective cause to the bridge failures. According to U.S. FHWA (2001), depths of local scour are much larger than general or contraction scour depths, often by a factor of ten. Thus, most of the studies are focused on the local scour concept. Local scour shows itself as pier scour and abutment scour, in reality. There are numerous works, experiments and case studies given in the literature about pier scour and abutment scour concept. The statistical researches show that in a bridge failure case, the main reason of the failure is most probably the abutment scour. Some of these studies are: 
- A study of U.S. FHWA (1973) concludes that $75 \%$ of a number of 383 bridge failures are due to abutment scour and the rest is produced by pier scour.

- According to Melville (1992), of the 108 bridge failures surveyed in New Zealand during the period of $1960-1984$, 29 were attributed to abutment scour. Melville also mentioned that $70 \%$ of the expenditure on bridge failures in New Zealand was due to abutment scour.

- Kandasamy and Melville (1998) found that 6 of 10 bridge failures that occurred in New Zealand during Cyclone Bola were related to abutment and approach scour.

- One other U.S. FHWA study (2001) reveals that the 1993 flood in the upper Mississippi basin caused 23 bridge failures for an estimated damage of $\$ 15$ million. The modes of bridge failures were 14 from abutment scour, 2 from pier scour, 3 from pier and abutment scour, and 2 from lateral bank migration, 1 from debris load and 1 from an unknown cause.

Although the statistics given above present the problem clearly, it is not easy to handle it. Since the nature of the local scour phenomenon is quite complex, the studies can be conducted by making assumptions and simplifications. This leads to different approaches causing different results for different cases. So, one can not come up with a universal solution, which has included all conditions about flow type, bridge structure, and river characteristics. In general, the methods used in local scour 
research can be listed as physical modeling, field observation and numerical simulation. The physical modeling, i.e., laboratory experiments, is used to find the correlations between the parameters affecting local scour. These correlations and results are tried to be verified by field observations. But, the less the amount of the field observations, the more important the experimental studies become. And that is what it is today. Recent development in computational fluid dynamics enables the researchers to study the local scour based on the rules of hydrodynamics.

In the vicinity of these truths, it is obvious that, in literature, it is easy to find many studies related with the pier scour and its countermeasures. Some of these are Laursen (1958, 1963), Neill (1973), Richardson et al. (1975, 1999, 2001), Bresusers et al. (1977), Ettema (1980), Jones (1989), Dargahi (1990), Chiew (1992), Johnson (1994), Melville (1997), Mueller et al. (1999), Lagasse et al. (2001), Singh (2001), Mashahir and Zarrati (2002), and Zarrati et al. (2004). For bridge pier countermeasures, the NCHRP 24-7 (1998) project final report named “Countermeasures to Protect Bridge Piers from Scour” has reviewed nearly all the literature in this aspect and also has given recommendations and design suggestions for a number of countermeasures. Also the Federal Highway Administration has developed several comprehensive technical manuals (HEC-18, HEC-20 and HEC23) for dealing with the problem of bridge scour. Moreover, a field survey of pier countermeasures was carried out across the United States (Li, Kuhnle, and Barkdoll, 2006).

However, the scour at bridge abutments has received less attention, and especially the future works on countermeasures for abutment scour are greatly needed. 


\subsection{OBJECTIVES}

The aim of this study is to investigate the effect of collars, which are placed around abutments, on the development of local scour at the base of abutments in comparison with the doctoral thesis study of Kayatürk (2005). For this reason, a series of experiments were conducted at the laboratory under clear-water flow conditions with vertical abutments and collars of various sizes using almost uniform sand of $d_{50}=0.90$ $\mathrm{mm}$.

The main difference between this study and the Kayatürk’s (2005) one is the grain size of the uniform cohesionless bed material. In the discussion part, the results obtained from Kayatürk’s (2005) study and this one will be compared and interpreted from this point of view.

\subsection{SCOPE}

The study reported herein is based on experiments carried out at the State Hydraulic Works’s Technical Research and Quality Control Department in Ankara, Turkey using a physical hydraulic model. The study was confined to uniform cohesionless material and clear-water flow conditions with vertical abutments and collars of various sizes.

\subsection{SYNOPSIS OF THE THESIS}

In Chapter 2, the background and current state of knowledge of abutment scour, and the literature related to it are covered. Chapter 3 describes the countermeasures against abutment scour and the concerned studies in literature. Chapter 4 gives a description of the experimental apparatus and model. Presentation, analysis and 
discussion of results are presented in Chapter 5. Also, the principal conclusions drawn from the comparison of the results of this study and Kayatürk’s (2005) one are provided. 


\section{CHAPTER 2}

\section{BRIDGE ABUTMENT SCOUR}

\subsection{INTRODUCTION}

As pointed in the previous chapter, abutment scour seems to be the primary reason for a bridge to fail and so for loss of life and property. In order to take some precautions, there is a necessity to understand the mechanism of the abutment scour. The parameters related with it should be identified clearly so that the precautions taken will be releavant. Therefore, in this chapter, the abutment scour mechanism and the parameters that affect local scour at bridge abutments will be investigated intensively, as possible.

\subsection{BRIDGE ABUTMENT SCOUR MECHANISM}

The flow field at an abutment embedded vertically in a loose sediment bed of an open channel is complex in nature; and the complexity increases with the development of a scour hole involving separation of flow to form a threedimensional vortex flow system at the base of the abutment. The downflow and the principal vortex at the upstream corner of the abutment, together with the secondary vortices at the middle part of the abutment and the wake vortices at the downstream 
corner of the abutment, cause complex interactions between the fluids and the bed material and are mainly responsible for the scour at abutments.

Ettema, Nakato and Muste (2003) explain the mechanism as given: the flow field at an abutment typically comprises an acceleration of flow from the upstream approach to the most contracted cross section somewhere at or just downstream of the head of the abutment, followed by a deceleration of flow. A flow-separation region forms immediately downstream of the abutment, and flow expands around the flow separation region until it fully re-establishes across the compound channel. Just upstream of the abutment, a flow-separation point and a small eddy may develop. The size of the upstream eddy depends on the length and alignment of the abutment. The curvature of the flow along the interface between the stagnation region and the flow causes a secondary current that, together with the flow leads to a spiral motion or vortex motion like flow through a channel bend. The vortex in flow around an abutment head is more localized and it has a strong scouring action. The vortex erodes a groove along its path and it also induces a complex system of secondary vortices.

"In addition to the vortex systems, other mechanisms may exist to cause local scour. Hagerty and Parola (1992) reported that seepage effects could be very important to interact with turbulent vortices to aggravate local scour. The fluctuating pressure differences induced by the flow separation at abutments cause seepage into and out of the abutment foundation; seepage forces cause ejection of sediment particles from the bed where seepage emerges beside the abutment" (Li, Kuhnle, and Barkdoll, 2006). 
Observations of flow patterns around abutments derived from flow visualization techniques using dye injection, dye crystals strategically placed on the sand bed, paper floats, smoke tunnel experiments by various researchers including Liu (1961), and Gill (1970) are summarized in Figure 2.1.

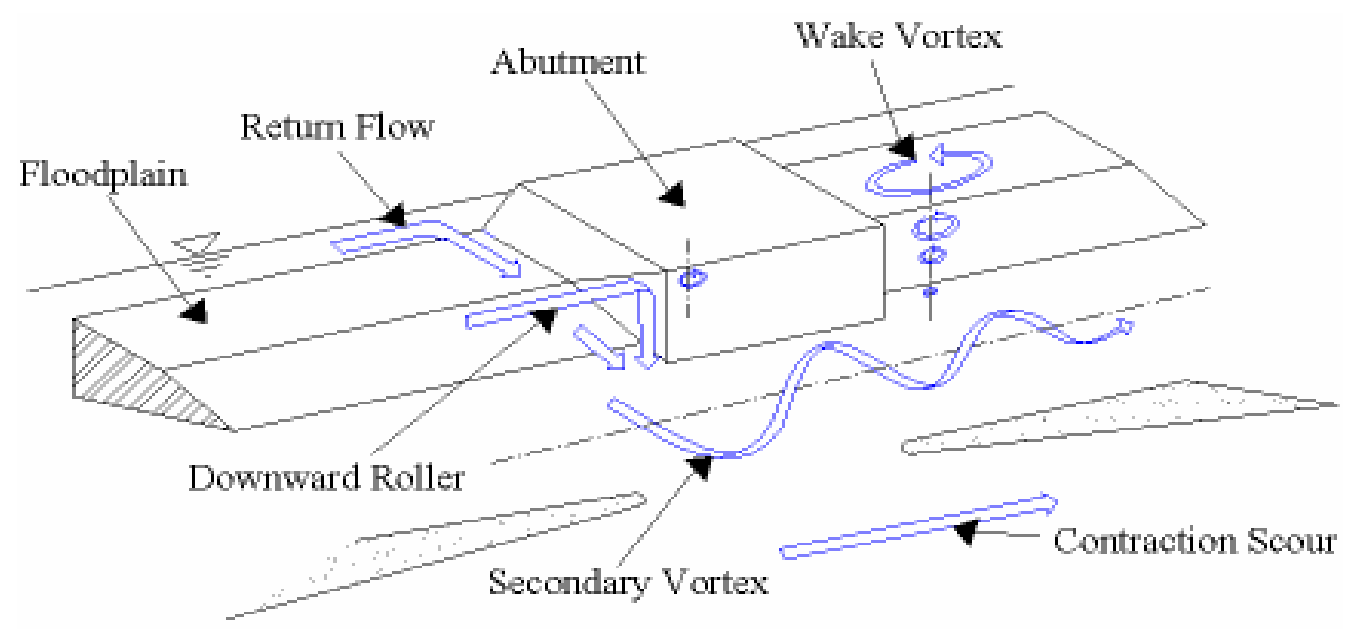

Figure 2.1. Flow patterns around a wing-wall abutment (after Li, Kuhnle, and Barkdoll, 2006)

\subsection{PARAMETERS INFLUENCING LOCAL SCOUR AT ABUTMENTS}

The parameters affecting the local scour at abutments can be grouped as fluid parameters, flow parameters, channel parameters, bed material parameters, abutment parameters and time as independent variable. In literature, the researchers are specified the same parameters most of the time in their studies, but according to the topic of investigation, some other parameters are chosen additionaly. Therefore, a list of commonly used parameters is given in Table 2.1: 
Table 2.1 Parameters influencing local scour at abutments

\begin{tabular}{|c|c|c|}
\hline Parameter Name & Symbols & Attribution \\
\hline Density & $\rho$ & \multirow{2}{*}{ FLUID } \\
\hline Dynamic Viscosity & $\mu$ & \\
\hline $\begin{array}{l}\text { Gravitational } \\
\text { Acceleration }\end{array}$ & $\mathrm{g}$ & \multirow{4}{*}{ FLOW } \\
\hline Normal Flow Depth & $\mathrm{y}$ & \\
\hline $\begin{array}{l}\text { Mean Approach } \\
\text { Velocity }\end{array}$ & $\mathrm{U}$ & \\
\hline $\begin{array}{c}\text { Energy Slope of } \\
\text { Flow } \\
\end{array}$ & $\mathrm{S}_{\mathrm{e}}$ & \\
\hline Width of Channel & $\mathrm{B}$ & \multirow{3}{*}{ CHANNEL } \\
\hline Slope of Channel & $\mathrm{S}_{0}$ & \\
\hline Geometry of Channel & $\mathrm{K}_{\mathrm{G}}$ & \\
\hline Median Size & $\mathrm{d}_{50}$ & \multirow{9}{*}{ BED MATERIAL } \\
\hline Specific Gravity & $\mathrm{S}_{\mathrm{S}}$ & \\
\hline Standard Deviation & $\sigma_{g}$ & \\
\hline Fall Velocity & $\mathrm{W}$ & \\
\hline Particle Shape Factor & $\mathrm{S}_{\mathrm{p}}$ & \\
\hline Angle of Repose & $\varphi$ & \\
\hline Cohesiveness & $\mathrm{C}$ & \\
\hline $\begin{array}{c}\text { Dimensionless } \\
\text { Critical Shear Stress }\end{array}$ & $\theta_{\mathrm{c}}$ & \\
\hline $\begin{array}{c}\text { Particle Reynolds } \\
\text { Number }\end{array}$ & $\operatorname{Re}^{*}$ & \\
\hline Length of Abutment & $\mathrm{L}_{\mathrm{a}}$ & \multirow{3}{*}{ ABUTMENT } \\
\hline Skewness & $\theta_{\mathrm{a}}$ & \\
\hline Shape of Abutment & $\mathrm{K}_{\mathrm{a}}$ & \\
\hline Time & $\mathrm{t}$ & TIME \\
\hline
\end{tabular}

By making use of these parameters, the local scour depth $\left(d_{s}\right)$ at bridge abutment can be written as a function of them as given:

$$
\begin{gathered}
d_{s}=f\left(\rho, \mu, g, y, U, S_{e}, B, S_{0}, K_{G}, d_{50}, S_{s}, \sigma_{g}, w, S_{p}, \varphi,\right. \\
\text { C, } \left.\theta_{c}, R^{*}, L_{a}, \theta_{a}, K_{a}, t\right)
\end{gathered}
$$

Some of these variables can be neglected under certain circumstances. By doing so and non-dimensionalizing the remaining, the following variables are believed to be 
most important in influencing the scour at abutments: time $t$, velocity $\left(U / U_{c}\right)$, flow depth $\left(y / L_{a}\right)$, sediment size $\left(L_{a} / d_{50}\right)$, sediment gradation $\sigma_{g}$, abutment shape $K_{a}$, abutment length $\left(\mathrm{L}_{\mathrm{a}} / \mathrm{y}\right)$, abutment skewness $\theta_{\mathrm{a}}$ and channel geometry $\mathrm{K}_{\mathrm{G}}$. An understanding of these variables is quite important to design a countermeasure against abutment scour. To achieve that some of these variables are discussed further in this chapter.

\subsubsection{Time Evolution}

To estimate the maximum scour depth has a great importance in foundation design stage of a bridge structure. But, the main difficulty is to estimate the time needed for the scour depth to reach its maxima. Also, an additional question emerges in this stage whether the time needed for this maximum is longer or shorter in duration of a known time-to-peak value design flood. In other words, whether the equilibrium time reached in laboratory conditions represents the real time for a design flood or not. The answers of these questions are directly affecting the total cost of the construction in reality. Therefore, there is a great need of understanding the temporal development of scour depth in order not to make over-designs and to save the funds. Also, scour depth at a certain moment of a flood hydrograph could be predicted with the help of the scour time evolution curve. Figure 2.2 shows a schematic diagram of the timevariation of scour depth at a cylindrical pier (after Chabert \& Engeldinger 1956). Time to reach equilibrium scour depth varies widely, ranging from a day to a fortnight. 


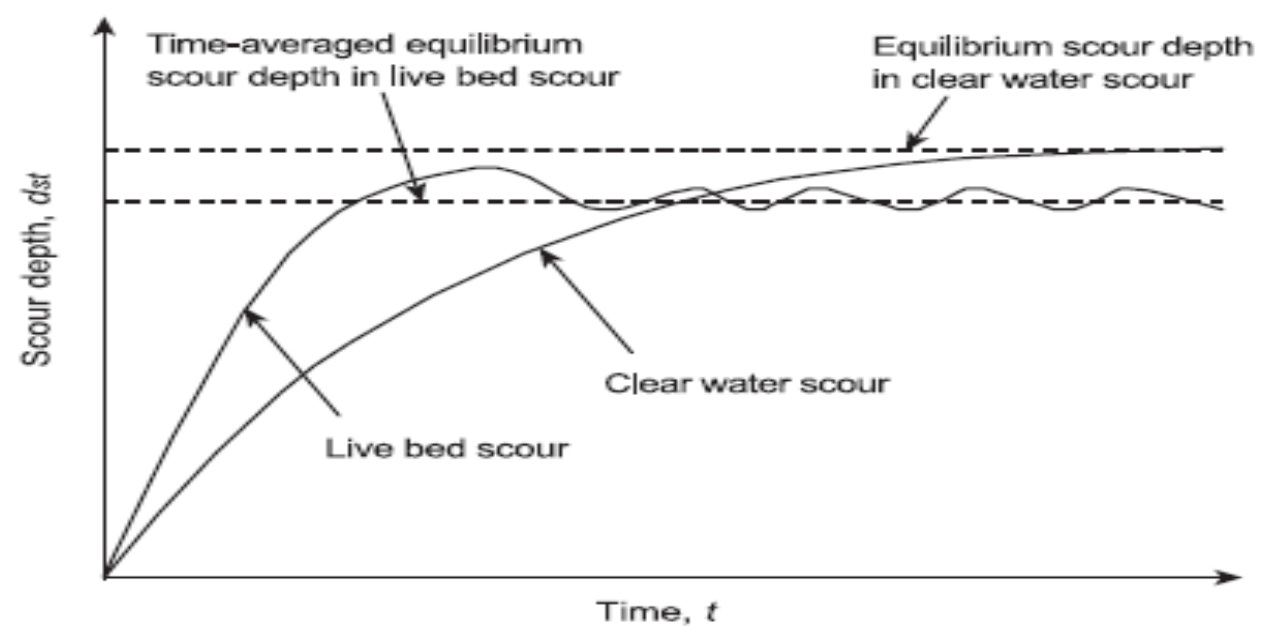

Figure 2.2. Time development of clear-water and live-bed scour (after Chabert \& Engeldinger, 1956)

“Time development of scour was first studied in Laursen's (1952) pioneering research on scour by jets. Laursen argued that clear-water scour is an asymptotic process in which scour depth increases linearly with the logarithm of time" (FHWARD-99-156, 2004).

“Rouse (1965), Gill (1972), Rajaratnam \& Nwachukwu (1983), Dargahi (1990), Ettema (1980), Kohli \& Hager (2001), Oliveto \& Hager (2002) and Coleman et al (2003) think that the variation of scour depth with time is logarithmic. Ahmad (1953), Franzetti et al (1982), Kandasamy (1989), Whitehouse (1997), Cardoso \& Bettess (1999) and Ballio \& Orsi (2000) propose an exponential time-variation of scour; while Breusers (1967) and Cunha (1975) give a power law distribution" (Barbhuiya and Dey, 2004).

\subsubsection{The Effect of Flow Velocity}

"The effect of approaching flow velocity, $\mathrm{U}$, is incorporated in the scour predicting formulae in the form of flow Froude number, Fr, or shear velocity, $U_{*}$. Garde et al 
(1961), Zaghloul \& McCorquodale (1975), Zaghloul (1983), Rajaratnam \& Nwachkwu (1983) and Froehlich (1989) included the flow Froude number in their analyses. Garde et al (1961) concluded that the flow Froude number for the normal channel flow adequately represents the effect of approaching flow velocity on the maximum scour depth. Kandasamy (1989) showed that the scour depth increases with increase in flow depth due to incorporation of the flow Froude number" (Barbhuiya and Dey, 2004).

\subsubsection{The Effect of Flow Depth}

Dey \& Barbhuiya (2004) reported that, according to Laursen (1952), the approaching flow depth, y, is an important factor to determine scour depth. Experimental results of Gill (1972), Wong (1982), Tey (1984) and Kandasamy (1989) indicate that for constant value of the shear velocity ratio $U_{*} / U_{*_{c}}$, the maximum scour depth increases with increase in approaching flow depth. It is also observed that the maximum scour depth increases at a decreasing rate with increase in approaching flow depth. Dey \& Barbhuiya (2004) also reported that for smaller flow depths, the equilibrium scour depth increases significantly with increase in, y; where as for higher flow depths, equilibrium scour depth is independent of flow depth.

\subsubsection{The Effect of Sediment Size}

Characteristics of the bed sediments are derived from particle size distribution curves. The two most commonly used parameters are median sediment diameter $\mathrm{d}_{50}$ and geometric standard deviation $\sigma_{\mathrm{g}}\left[=\left(\mathrm{d}_{84} / \mathrm{d}_{16}\right)^{0.5}\right]$ of particle size distribution. Breusers and Raudkivi (1991) set the limit of the geometric standard deviation beyond which a mixture can be considered to be non-uniform as 1.35. Moreover, the 
coefficient of uniformity, i.e. $C_{u}$, which is equal to $\left(d_{60} / d_{10}\right)$, is also a parameter to identify a sediment sample's uniformity. If the value of $C_{u}$ is less than 3.0 the sediment mixture can be defined as uniform.

"It is important to distinguish between clear-water and live-bed scour when considering the effects of sediment size on scour. Under live-bed conditions, some early pier scour researchers argued that there is no significant effect of sediment size on local scour, but some others suggested that the scour depth decreases with an increase in the sediment size. For clear-water conditions, most studies have shown that sediment size has an effect on local scour" (Li, Kuhnle, and Barkdoll, 2006).

"Laursen (1960) found that maximum scour depth is affected by sediment size under clear-water scour but not under live-bed scour. Results of Gill (1972) for two sediment sizes $\left(\mathrm{d}_{50}=1.52 \mathrm{~mm}\right.$ and $\left.0.914 \mathrm{~mm}\right)$ indicate that for the same value of $\tau_{0} /$ $\tau_{\mathrm{c}}<1$, scour depth is greater with coarse sediments than with fine sediments, where $\tau_{\mathrm{c}}=$ critical shear stress for sediment particles. However, for the same value of absolute approaching bed shear stress, fine sediments produce greater scour depth" (Barbhuiya and Dey, 2004).

"The scour studies for piers by various researchers show that under clear-water conditions the scour depth increases with an increase in sediment size for finer sediments, while the reverse trend is true for coarser sediments. Dongol (1994) divided the sediment size relative to the abutment length into four groups on the basis of scour development for different values of $\mathrm{L}_{\mathrm{a}} / \mathrm{d}_{50}$ at the principal stage as follows: (1) $\mathrm{L}_{\mathrm{a}} / \mathrm{d}_{50}>100$ : fine sediment; (2) $100>\mathrm{L}_{\mathrm{a}} / \mathrm{d}_{50}>40$; intermediate 
sediment; (3) $40>\mathrm{L}_{\mathrm{a}} / \mathrm{d}_{50}>10$ : coarse sediment; (4) $10>\mathrm{L}_{\mathrm{a}} / \mathrm{d}_{50}$ : very coarse sediment" (Li, Kuhnle, and Barkdoll, 2006).

“Ettema's (1980) data for pier scour, together with abutment data obtained by Gill (1970), Wong (1982), Kwan (1987) and Kandasamy and Dongol are plotted by Kandasamy (1989). All data apply to threshold conditions and non-rippling sediments with $\sigma_{\mathrm{g}}<1.3$. The curves showed that the scour depth increases rapidly with sediment size to a peak at $\mathrm{L}_{\mathrm{a}} / \mathrm{d}_{50}>50$, for a constant pier diameter or abutment length, and then decreases. It needs to be noted that data by Gill and Wong were measured before equilibrium had been reached so that the scour depth may be smaller than otherwise it should be. But Dongol (1994) found that the relative equilibrium scour depth, $\mathrm{d}_{\mathrm{s}} / \mathrm{L}_{\mathrm{a}}$ decreases as $\mathrm{L}_{\mathrm{a}} / \mathrm{d}_{50}$ decreases below 40 . For large values of $\mathrm{L}_{\mathrm{a}} / \mathrm{d}_{50}$, the effect of sediment size is insignificant" (Li, Kuhnle, and Barkdoll, 2006).

\subsubsection{The Effect of Sediment Gradation}

River bed materials are generally nonuniform. A measure of the nonuniformity of the sediment is geometrical standard deviation $\sigma_{\mathrm{g}}$. For the log-normally distributed sediment, $\sigma_{\mathrm{g}}$ is given by

$$
\sigma_{g}=\sqrt{\frac{d_{84.1}}{d_{15.9}}}
$$

"The effect of sediment gradation on scour depth depends upon whether the scour occurs under clear-water or live-bed conditions. For sediment with the same $\mathrm{d}_{50}$ and under similar flow conditions, it is found that less scour is developed in nonuniform sediments than in uniform sediments. Scour depth is seen to decrease progressively 
with increasing $\sigma_{\mathrm{g}}$ (Ettema (1980), Wong (1982), Melville (1992) and Dongol (1994))" (Li, Kuhnle, and Barkdoll, 2006).

Dey \& Barbhuiya (2004) conducted experiments to study the effects of thinly armourlayer on scour depth at abutments. They concluded that the scour depth at an abutment with an armour-layer in clear-water scour condition under limiting stability of surface particles (approaching flow velocity nearly equaling critical velocity for threshold motion of surface particles) is always greater than that without an armourlayer for the same bed sediments.

\subsubsection{The Effect of Abutment Length}

Abutment length and contraction ratio have extensively been used in formulating the maximum scour depth at abutments. The inverse of the opening ratio is termed contraction ratio (Barbhuiya and Dey, 2004). Abutment length is one of the most important parameters influencing the scour process and depth at an abutment. Various experimental data have shown that the scour depth increases with increasing abutment length.

\subsubsection{The Effect of Abutment Shape}

"The shape of the abutment plays an important role on equilibrium scour depth. Streamlined bodies, such as semicircular (SC), spill-through (ST) and wing-wall (WW) abutments, produce vortice of feeble strength; while blunt obstructions, for example vertical-wall abutments, are capable of producing strong turbulent vortices. Consequently, a relatively large scour depth is observed at a blunt obstruction. From laboratory experimental data, Laursen \& Toch (1956), Liu et al (1961), Garde et al 
(1961) and Wong (1982) concluded that vertical-wall abutments produce greater scour depth in comparison with spill-through and wing-wall abutments" (Barbhuiya and Dey, 2004). In other words, the scour at streamlined abutments is less than that at the blunt shaped abutments (Li, Kuhnle, and Barkdoll, 2006).

\subsubsection{The Effect of Abutment Skewness}

"Ideally, bridges are constructed at a straight reach of the river channel and normal to the flow, giving the shortest span and eliminating skewness. However, skewness is likely, due to the existing road layout constraints and river channel geometry. Abutment skewness is defined as the inclination of the abutment to the mean flow direction and is denoted by $\theta_{\mathrm{a}}$ " ( $\mathrm{Li}$, Kuhnle, and Barkdoll, 2006), and this angle effects scour depth significantly.

“It was experimentally studied by Garde et al. (1961). Garde et al. (1961) reported that for the same flow, sediment and abutment conditions, the maximum scour depth is greatest for a spurdike with an inclination of $90^{\circ}$. For all other inclinations the scour depth is smaller" (Barbhuiya and Dey, 2004).

\subsection{CLOSURE}

In the above discussion we conclude that the local scour at bridge abutments is a very complex phenomenon to be fully understood. But basically, the downflow at the upstream face of an abutment and associated horse-shoe vortex with the secondary and wake vortices due to flow seperation are constructed the mechanism of the local scour at abutments. The parameters affecting this phenomenon are also listed and explained shortly. 


\section{CHAPTER 3}

\section{BRIDGE ABUTMENT SCOUR COUNTERMEASURES}

\subsection{GENERAL REMARKS}

From the previous chapters, it is easy to remind that the scour problem encountered in the bridge piers and abutments is the main cause for bridges to collapse. There has been several researchers and researches dealed with this phenomenon to understand its mechanism and dependency to other factors. All these efforts have been made to develop the scour resistant bridge design guidelines for the future-built bridges and also to develop countermeasures in order to save and rehabilitate the existing bridges from scour failures. In this chapter, the purpose of the study is to review the scour countermeasures, especially the ones related with the bridge abutments. While doing that the HEC-23 “Bridge Scour And Stream Instability Countermeasures Experience, Selection, and Design Guidance” (2001) (one of the FHWA's publications) will be referred several times throughout the chapter as being one of the most important document on this topic in literature.

As given by FHWA NJ's "Handbook of Scour Countermeasures Designs” Final Report in September 2005, a countermeasure is defined by HEC-23 as a measure 
incorporated at a stream/bridge crossing system to monitor, control, inhibit, change, delay, or minimize stream and bridge stability problems and scour. It is obvious from this definition that the selection of a countermeasure is directly dependent to the state of the problem. In FHWA's HEC-23 (March, 2001), this situation is related with the functional applications category, suitable river environment category and maintenance category of the countermeasures.

The functional applications category describes the type of scour or stream instability problem for which the countermeasure is prescribed. The five main categories of functional applications are local scour at abutments and piers, contraction scour, and vertical and lateral instability (HEC-23, 2001).

This suitable river environment category describes the characteristics of the river environment for which a given countermeasure is best suited or under which there would be a reasonable expectation of success. The river environment characteristics that can have a significant effect on countermeasure selection or performance are:

- River type

- Stream size (width)

- Bend radius

- Flow velocity

- Bed material

- Ice/debris load

- Bank condition

- Floodplain (width) (HEC-23, 2001) 
The maintenance category identifies the estimated level of maintenance that may need to be allocated to service the countermeasure (HEC-23, 2001).

Therefore, for an engineer to tackle the problem of scour at bridge elements, the very first act to do is to define and set the conditions of the problematic area of the bridge site. After that, it becomes easier to select the type of the countermeasure.

\subsection{GROUPS OF COUNTERMEASURES}

Beside these categories as aids to make the countermeasure selection, there are three main groups of countermeasures from functionality with respect to scour and stream instability as given in HEC-23 (2001). These are given below with their subgroups:

\section{Group 1. Hydraulic Countermeasures}

- Group 1.A: River training structures

— Transverse structures

— Longitudinal structures

- Areal structures

- Group 1.B: Armoring countermeasures

— Revetment and Bed Armor

+ Rigid

+ Flexible/articulating

_ Local armoring 


\section{Group 2. Structural Countermeasures}

- Foundation strengthening

- Pier geometry modification

\section{Group 3. Monitoring}

- Fixed Instrumentation

- Portable instrumentation

- Visual Monitoring

The detailed explanation and presentation of these groups are given in HEC-23 (2001).

\subsection{ABUTMENT SCOUR COUNTERMEASURES}

After giving the countermeasure groups, it is time to focus on the specific topic of this study, which is the abutment scour countermeasures. In Table 3.1, the countermeasures and their advantages and disadvantages against abutment scour are provided: 
Table 3.1. Advantages and disadvantages of various countermeasures (Handbook of Scour Countermeasures Designs, FHWA NJ, 2005)

\begin{tabular}{|c|c|c|}
\hline Countermeasure & Advantages & Disadvantages \\
\hline \multicolumn{3}{|c|}{ Local Scour at Abutment } \\
\hline Peak Flood Closure & Low initial cost & Limits access, constant monitoring \\
\hline Monitoring & Low initial cost & Does not prevent scour \\
\hline Riprap & $\begin{array}{c}\text { Familarity, relatively low cost } \\
\text { and maintenance, easy to } \\
\text { construct, ability to adjust to } \\
\text { minor scour }\end{array}$ & $\begin{array}{l}\text { Can wash out, disturbs channel } \\
\text { ecosystem until vegetation } \\
\text { reestablished }\end{array}$ \\
\hline Gabions & $\begin{array}{l}\text { Relatively low cost, ability to } \\
\text { adjust to minor scour }\end{array}$ & $\begin{array}{l}\text { Can be undermined, Stones can wash } \\
\text { out of wire mesh, disturbs channel } \\
\text { ecosystem }\end{array}$ \\
\hline Cable-tied Blocks & Will not wash out as easily & $\begin{array}{l}\text { More difficult to construct, higher } \\
\text { maintenance }\end{array}$ \\
\hline Tile Mats & Will not wash out as easily & $\begin{array}{l}\text { More difficult to construct, higher } \\
\text { maintenance, easier for water to lift }\end{array}$ \\
\hline Alarm Systems & Low initial cost & $\begin{array}{c}\text { Provides no scour protection, must } \\
\text { be checked periodically }\end{array}$ \\
\hline Articulated Mattress & $\begin{array}{l}\text { Coherent structure, individual } \\
\text { block will not wash out }\end{array}$ & $\begin{array}{l}\text { More difficult to construct, easier for } \\
\text { water to lift }\end{array}$ \\
\hline Concrete-filled Mattress & $\begin{array}{l}\text { Rocks will not wash out, } \\
\text { relative ease of construction }\end{array}$ & $\begin{array}{l}\text { Can be undermined, easy for water } \\
\text { to lift }\end{array}$ \\
\hline Locking Blocks & $\begin{array}{l}\text { Coherent structure, individual } \\
\text { block will not wash out }\end{array}$ & $\begin{array}{l}\text { More difficult to construct, easier for } \\
\text { water to lift }\end{array}$ \\
\hline Pavement & Conceptually appealing & $\begin{array}{l}\text { High cost and maintenance, can be } \\
\text { undermined, easy for water to lift }\end{array}$ \\
\hline Rock Bolting & Strong, low maintenance & $\begin{array}{l}\text { Costly, only for abutments on } \\
\text { bedrock }\end{array}$ \\
\hline Grouted Riprap & $\begin{array}{l}\text { Rocks will not wash out, } \\
\text { relative ease of construction }\end{array}$ & $\begin{array}{l}\text { Can be undermined, easy for water } \\
\text { to lift }\end{array}$ \\
\hline Sacrificial Piles & Conceptually appealing & Not effective, high cost \\
\hline Grout Bags & Ease of construction, low cost & Bags can wash out \\
\hline Sheet Piling & $\begin{array}{c}\text { Stops flow, helpful in } \\
\text { dewatering }\end{array}$ & $\begin{array}{l}\text { Scour can occur near sheet piling, } \\
\text { construction difficult, rust }\end{array}$ \\
\hline $\begin{array}{l}\text { Hinged-Slab/Tethered Block } \\
\text { System }\end{array}$ & $\begin{array}{l}\text { Will not erode under extreme } \\
\text { velocities }\end{array}$ & $\begin{array}{c}\text { Could be subject to edge } \\
\text { undermining }\end{array}$ \\
\hline \multicolumn{3}{|c|}{ River Control } \\
\hline Spur Dikes / Guide Banks & Proven effective & $\begin{array}{l}\text { Can wash out, need to protect guide } \\
\text { bank walls, obstructs navigation }\end{array}$ \\
\hline Submerged Vanes & $\begin{array}{l}\text { Elegant approach, not too } \\
\text { expensive, effective }\end{array}$ & $\begin{array}{l}\text { Obstructs navigation, possible debris } \\
\text { snags, construction difficult }\end{array}$ \\
\hline Collars & $\begin{array}{l}\text { Low cost and maintenance, } \\
\text { effective }\end{array}$ & $\begin{array}{l}\text { Does not eliminate scour, not much } \\
\text { experience }\end{array}$ \\
\hline Attached Vanes & $\begin{array}{l}\text { Low cost and maintenance, } \\
\text { effective }\end{array}$ & $\begin{array}{l}\text { Does not eliminate scour, not much } \\
\text { experience }\end{array}$ \\
\hline
\end{tabular}




\subsection{CONCLUSION}

To protect a bridge structure from collapse, in most of the cases, the necessary precautions should be taken against bridge components scour. For a designer, the most important step in design stage of a new structure or in rehabilitation of an existing structure is the detection of the site conditions, flow mechanisms and functional aspects. By stating these parameters precisely, the ideal countermeasure can be chosen to be designed for that particular situation. In literature, there are given and applied many countermeasure types for different cases. Some of them are used in common and some of them are not researched in details. As being a part of the last group, collars are not much in interest. That is the reason why this thesis study is objected to perform a series of experiments to develop a better understanding in making use of collar against abutment scour. The experimental setup and procedure are discussed in the next chapter. 


\section{CHAPTER 4}

\section{EXPERIMENTAL SETUP}

\subsection{THE FLUME}

Experimental investigations were performed in a channel at the Hydraulics Laboratory of State Hydraulic Works, in Ankara, which had been used during the doctoral thesis study of Dr. Kayatürk in year 2005.

During the investigation, a rectangular channel with transparent walls, $30 \mathrm{~m}$ length and 1.5 m width was filled with erodable uniform sediment and the channel slope was $S_{0}=0.001$. The depth and the length of the sand layer in the working reach were $0.50 \mathrm{~m}$ and $10 \mathrm{~m}$, respectively. The longitudinal cross-sectional view of the channel is shown in Figure 4.1. The flume had a closed-loop water system and the flow to the flume was supplied from a constant-head water tank by a pump. A gate was mounted at the tail end to adjust flow depths.

The longitudinal cross-section of the experimental setup is provided in Figure 4.1 given below: 


\section{Rectangular weir}

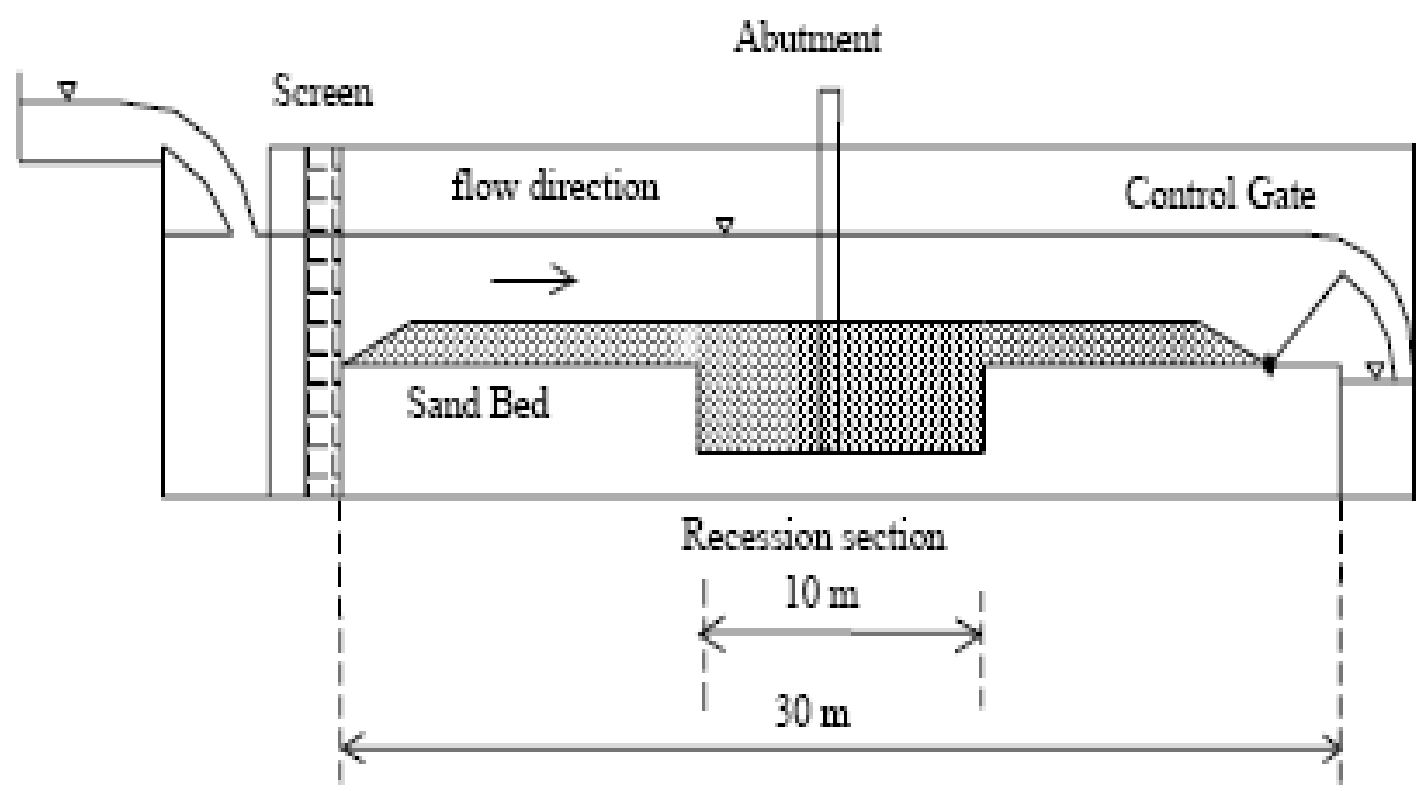

Figure 4.1 The longitudinal cross-section of the experimental setup

\subsection{THE ABUTMENT MODEL}

The abutment models used during the experiments had a constant width of $10 \mathrm{~cm}$ in each run. The abutment lengths used during this study were the same ones used in Kayatürk’s study (2005) as being 35 cm, 25 cm, 20 cm, 15 cm, and 7.5 cm.

\subsection{SAND MATERIAL}

The erodible uniform sand bed material was selected to have a median size diameter of $d_{50}=0.90 \mathrm{~mm}$ with geometric Standard deviation of particle size distribution ratio of $\sigma_{\mathrm{g}}=1.48$ and uniformity coefficient of $\mathrm{C}_{\mathrm{u}}=1.6$.

\subsection{U* / U $*_{\mathrm{c}}$ RATIO}

All tests were conducted under or near the clear water flow conditions at $U_{*} / U_{*_{\mathrm{c}}}=$ 0.90 , where $U *$ is the shear velocity of the approach flow and $U_{*_{c}}$ is the value of $U *$ at 
the threshold of grain motion. The threshold flow depth of bed material, $\mathrm{y}_{\mathrm{c}}=5.3 \mathrm{~cm}$, motion was calculated from the Shield's diagram. Then, the result for $y_{c}$ was confirmed with experimental observation when the abutment was not installed. It was concluded that the resultant flow depth from Shield's diagram gave almost the same flow depth determined by observetion for incipient sediment motion. During this procedure, threshold of bed material motion was defined as a condition for which finer materials may move, but the elevation of the bed would not be lower more than $1 \mathrm{~mm}$ to $2 \mathrm{~mm}$ during the test duration. Finally, the flow depth satisfying the ratio $\mathrm{U}_{*} / \mathrm{U}_{*_{\mathrm{c}}}=0.90$ was calculated as $\mathrm{y}=4.25 \mathrm{~cm}$, and the experiments were conducted by using this flow depth under clear water flow condition, which corresponds to upstream Froude and Reynolds numbers of 0.41 and 43439, respectively.

\subsection{MEASUREMENT AND DEVICE}

The flow discharge was measured with a sharp-crested rectangular weir having the width of $1 \mathrm{~m}$ and the height of $0.30 \mathrm{~m}$ mounted at the upstream section of the flume. By means of bricks and sheet-iron strainer, which placed between brick-walls, placed at the entrance of the channel as a filter, turbulance of the flow was reduced and the uniform flow conditions were maintained which were required for upstream head measurements. The scour depths were also measured with a pointgage to an accuracy of $\pm 1 \mathrm{~mm}$. The tip of the gage was painted with white paint and for each measurement the painted tip penetrated the sandy bottom of the scour hole until it could no longer be seen. 


\author{
CHAPTER 5
}

\title{
APPLICATION OF COLLAR TO CONTROL SCOURING AROUND ABUTMENTS
}

\subsection{GENERAL}

The main objective of this study is to compare the results of the conducted experiments with the ones concluded by Kayatürk (2005) and draw a conclusion about the effect of sediment particle size of the bed material on the performance of the collar against abutment scour.

\subsection{LITERATURE REVIEW}

The downflow and the principal vortex at the upstream corner of the abutment together with the secondary vortices and wake vortices at the middle part and the downstream corner of the abutment cause complex interaction between the fluid and the bed material. This vortex system is mainly responsible for the scour at abutments. The scouring power of this vortex can be reduced by creating a rigid obstacle around the abutment. In literature, collars were used to achieve such a goal. But, literature review shows that the researchers studied the collars mainly to reduce the local scour at bridge piers. Researchers like Dargahi (1990), Chiew (1992, (b)), Kapoor and 
Keana (1994), Kumar et. al. (1997), Singh et. al. (2001), Mashahir and Zarrati (2002), Zarrati et. al. (2004), and Borghei et al. (2004) were all investigated the reducing effect of collars on the local scour at bridge piers.

There are fewer researchers keen on studying the countermeasure effect of collars on bridge abutment scour. The doctoral study of Kayatürk (2005), which is also the fundamental study of this thesis, was dealing with the size of the collars as well as its elevation from the bed level, which is called $Z_{c}$, attached on the vertical wall abutment. Based on the results obtained, efficiency of a collar for preventing scour is a function of its size and its vertical location on the abutment. As the size of the collar increases the scour depth decreases. If $\mathrm{L}_{\mathrm{a}} / \mathrm{y}>1$, the efficiency of the collar increases with decreasing $\mathrm{L}_{\mathrm{a}} / \mathrm{B}_{\mathrm{c}}$ and the elevation of the collar shifts in downward direction from the bed level, as long as the clear water flow conditions are satisfied, regardless of the flow depth, that is $\mathrm{U}_{*} / \mathrm{U}_{*_{\mathrm{c}}}=0.90$. If $\mathrm{L}_{\mathrm{a}} / \mathrm{y}<1$, the collar, which is placed at the bed level $\left(Z_{\mathcal{c}} / y= \pm 0.00\right)$, gives higher performance than those having other $Z_{\mathrm{c}} / \mathrm{y}$ values. Instead of full-collars, partial collars can be used to provide maximum reduction in the scour depth from economical point of view (Kayatürk, 2005).

Li, Kuhnle and Barkdoll (2006) have conducted some laboratory experiments with collars at a vertical-face wingwall abutment placed at the main channel edge, an abutment configuration typical of older bridges on smaller streams. To mitigate abutment scour, flat, horizontal, steel collars were attached around a wing-wall abutment ending at the main channel edge under clear-water flow conditions in a laboratory flume channel. It was found that these collars were able to protect the 
bridge abutment efficiently by eliminating secondary vortices that ordinarily would cause local scour. The minimum collar dimensions that eliminated local scour were a flow perpendicular width of $0.23 \mathrm{~L}_{\mathrm{a}}\left(\mathrm{L}_{\mathrm{a}}\right.$ is the abutment length perpendicular to the flow direction) and a flow parallel length of 0.7 times the flow parallel abutment width. It was determined that a vertical location of $0.08 \mathrm{y}$ (where $\mathrm{y}$ is the main channel flow depth) below the mean bed sediment elevation gave the best results of scour reduction. In addition, the collar not only reduced scour magnitude near the abutment, but also retarded the development of the scour hole.

This review exposes that there is a huge gap in the literature related with collars' use against abutment scour. Although there are some studies conducted and presented, there should be put more efforts to investigate this phenomenon. Especially, the ones comparing existing studies with new ones are in great need. Therefore, the study presented in this chapter makes this comparison with the study of Kayatürk (2005) and tries to come up with some new information and understanding related with the collar application to the abutments against local scour.

\subsection{DIMENSIONAL ANALYSIS}

The dimensional analysis presented in the Kayatürk's (2005) study hold itself true for this study, as well. The maximum scour depth, $\left(\mathrm{d}_{\mathrm{s}}\right)_{\max , \mathrm{c}}$, at an abutment with a collar can be written as a function of the following parameters, for clear-water scour flow conditions,:

$$
\left(d_{s}\right)_{\max , c}=f\left\{\begin{array}{l}
L_{a}, B_{a}, B_{c}, Z_{c}, T_{c}, U, y, S_{0}, g, \\
\rho_{s}, \rho, \mu, d_{50}, \sigma_{g}, t, B
\end{array}\right\}
$$


where, $\mathrm{B}_{\mathrm{c}}=$ collar width, $\mathrm{Z}_{\mathrm{c}}=$ elevation of the collar with respect to the sand level, and $\mathrm{T}_{\mathrm{c}}=$ collar thickness. Figure 5.1 shows a definition sketch with a typical view of a collar-abutment arrangement.

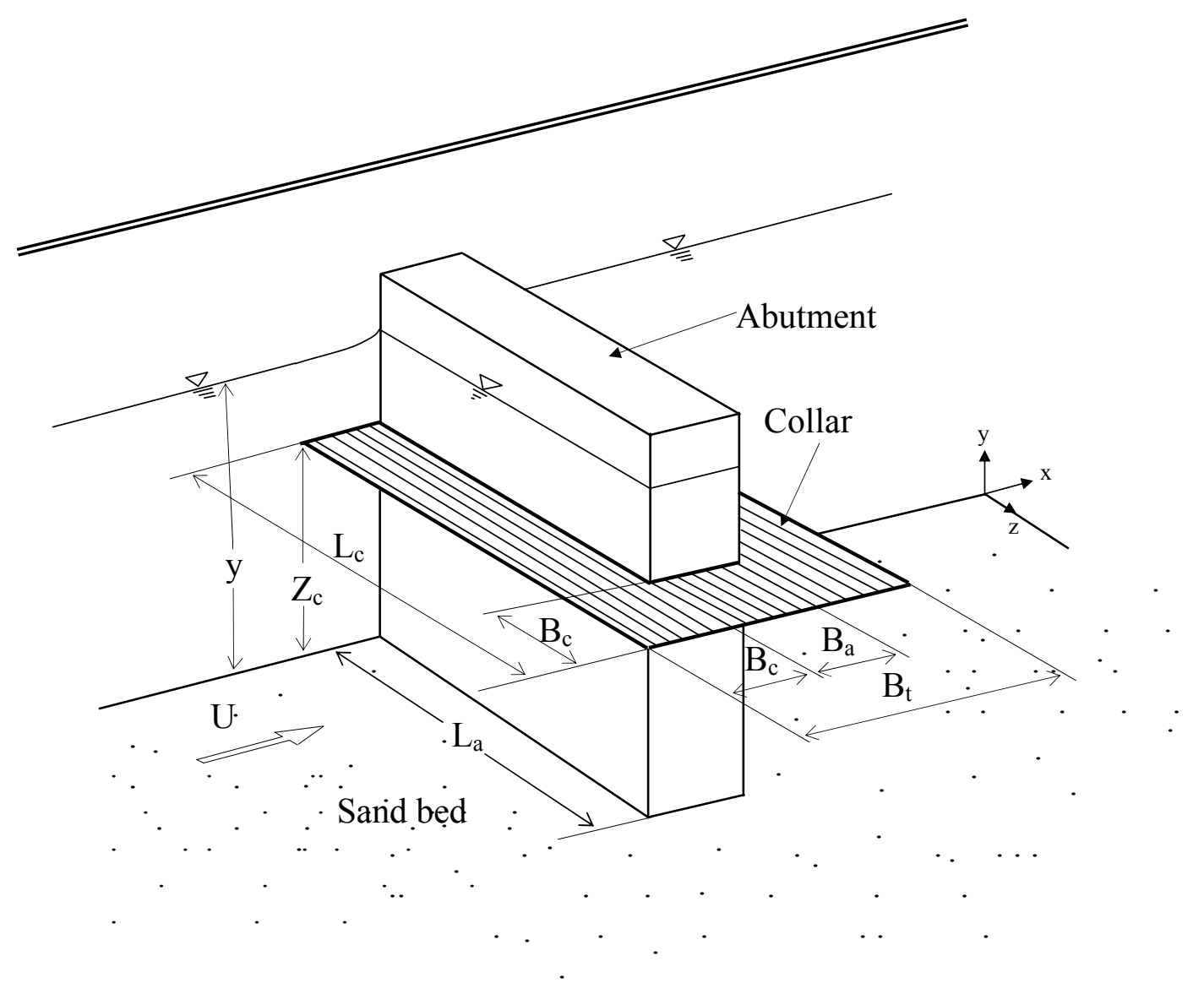

Figure 5.1. Definition sketch of collar-abutment arrangement

Buckingham's $\pi$ theorem gives the following dimensionless terms:

$$
\frac{\left(d_{s}\right)_{\max , c}}{\mathrm{y}}=\mathrm{f}\left\{\frac{L_{a}}{y}, \frac{\mathrm{B}_{\mathrm{a}}}{\mathrm{y}}, \frac{\mathrm{B}_{\mathrm{c}}}{\mathrm{y}}, \frac{\mathrm{Z}_{\mathrm{c}}}{\mathrm{y}}, \frac{\mathrm{T}_{\mathrm{c}}}{\mathrm{y}}, \frac{\rho_{\mathrm{s}}}{\rho}, \frac{\mathrm{U}}{\sqrt{\mathrm{gy}}}, \frac{\mathrm{B}}{\mathrm{y}}, \frac{\mu}{\mathrm{Uy} \rho}, \frac{\mathrm{Ut}}{\mathrm{y}}, \mathrm{S}_{0}, \sigma_{\mathrm{g}}, \frac{\mathrm{d}_{50}}{\mathrm{y}}\right\}
$$

Considering that the experiments are conducted with one sediment size and with 
constant parameters of bed slope, channel width, collar thickness, abutment width, duration of the experiment, flow depth and discharge, one can simplify Equation (5.2) as:

$\frac{\left(d_{s}\right)_{\max , c}}{y}=f\left(\frac{L_{a}}{B_{c}}, \frac{Z_{c}}{y}, \frac{L_{a}}{B_{a}}\right)$

The reduction in the scour depth around the bridge abutments as compared to the case without collar, $\left(\mathrm{d}_{\mathrm{s}}\right)_{\max }$, is

$$
\frac{\left(d_{s}\right)_{\max }-\left(d_{s}\right)_{\max , c}}{\left(d_{s}\right)_{\max }}=f\left(\frac{L_{a}}{B_{c}}, \frac{Z_{c}}{y}, \frac{L_{a}}{B_{a}}\right)
$$

Kayatürk (2005)

\subsection{EXPERIMENTAL PROCEDURE}

The same setup used by Kayatürk (2005) was used in this study. Collars were cut out of 3-mm thick plexi-glass sheet. The elevations and the widths of the collars were changed systematically. The abutments used were always rectangular in plan, having lengths of $\mathrm{L}_{\mathrm{a}}=7.5 \mathrm{~cm}, 15 \mathrm{~cm}, 20 \mathrm{~cm}, 25 \mathrm{~cm}$ and $35 \mathrm{~cm}$ and the width is kept constant at $B_{a}=10 \mathrm{~cm}$. Acording to Oliveto and Hager (2002), and Kayatürk (2005), the effect of the streamwise abutment length on the development of scour hole is small and can be neglected.

The experiments were started by filling the channel with water without disturbing the levelled surface of sediment bed until the water depth was adjusted to satisfy the 
ratio of $\mathrm{U}_{*} / \mathrm{U}_{*_{\mathrm{c}}}=0.90$, by making use of the control gate placed at the far downstream of the flume. When the corresponding flow depth $(y=4.25 \mathrm{~cm})$ and discharge $\left(\mathrm{Q}=0.017 \mathrm{~m}^{3} / \mathrm{s}\right)$ were achieved and the flow regime was checked as being uniform by making use of line meters attached to the glass- sidewalls of the flume, the experiment was started. The scour hole was obtained by performing a 6-hour continuous run under clear-water conditions and both maximum scour depth and scour formation at the abutment site were investigated. The maximum scour depth at the end of a 6-hour continued run was determined with the help of a mirror by estimating the distance between the zero level of the mirror and the current level of the channel bed. At the end of each experiment, the flume was carefully drained and sand bed level was straightened and compacted for the next experiment with a special apparatus, which was made of steel plate welded on a steel frame. Before the straightening and compaction of the channel bed, the longitudinal cross-sectional bed profile in front of the abutment face, where the maximum scour depth occured, was gauged and recorded in the flow direction (the records belonging to each experiment with and without collar are provided in the Appendix). The frame used for straightening could slide from the beginning to the end of the flume over steel rails, which were mounted, on the glass- sidewalls.

Four different collar widths $B_{c}=2.5 \mathrm{~cm}, 5.0 \mathrm{~cm}, 7.5 \mathrm{~cm}$ and $10 \mathrm{~cm}$ were used for all abutment types. As the efficiency of the collar is also a function of its vertical location on the abutment, collars of different sizes were placed at different elevations on the abutments as; at the bed level, $1.0 \mathrm{~cm}$ and $2.0 \mathrm{~cm}$ above the bed level and also $1.0 \mathrm{~cm}$ and $2.0 \mathrm{~cm}$ below the bed level. In Table 5.1, all collars used are classified considering their sizes and also abutment types. 
Table 5.1. Abutment and collar sizes used in the tests

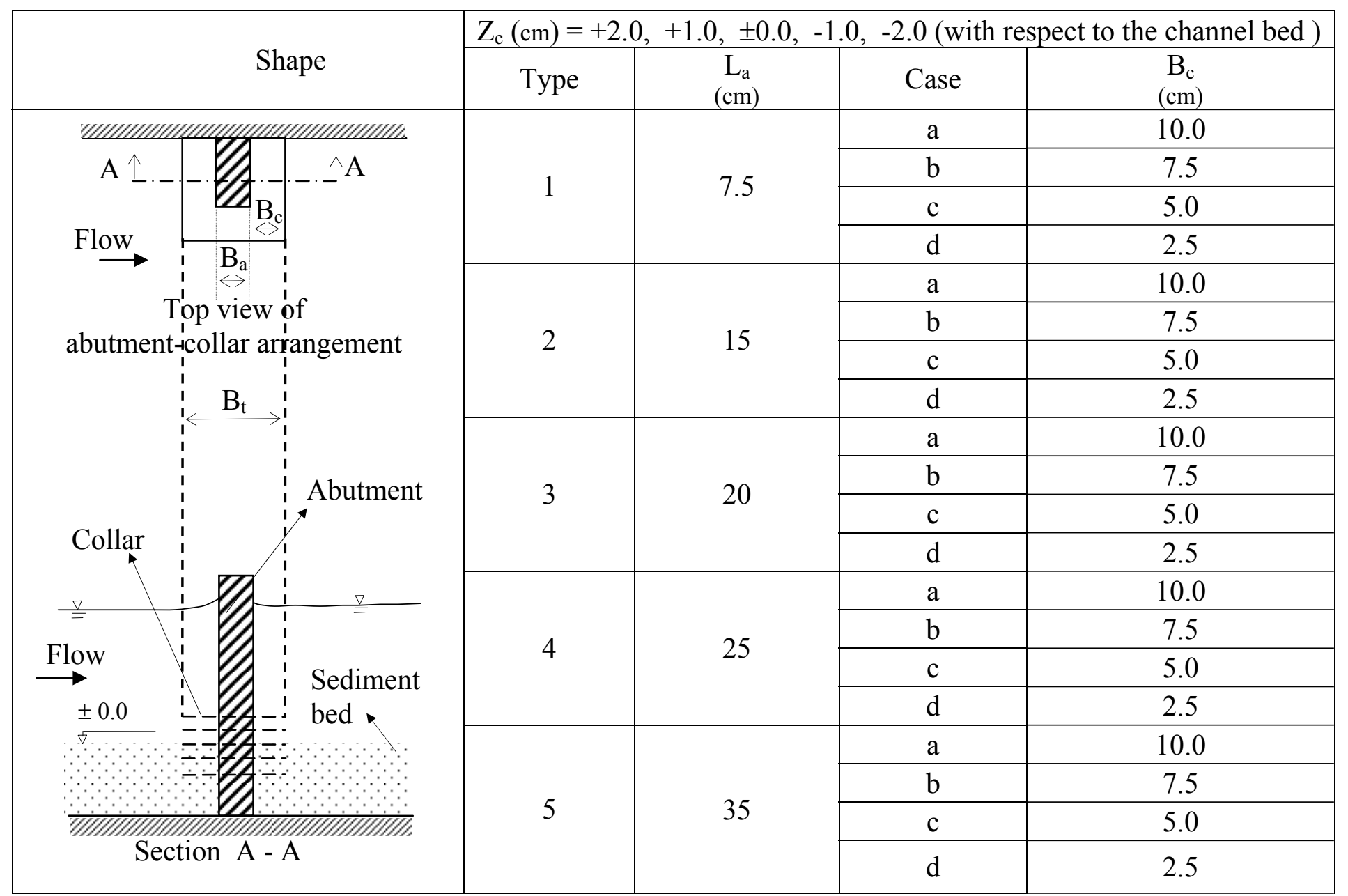


To conclude, the experimental setup, the abutment lengths and width, and the collar widths are kept constant in order to set up a base to compare the findings of this study and the one of Kayatürk (2005). The sediment particle size is different. And this leads the clear-water scour condition to be different. Accordingly, the approach flow depth is different. As it will be seen in the coming parts, the dimensionless term " $\mathrm{Z}_{\mathrm{c}} / \mathrm{y}$ " is used during the analysis. Here, $\mathrm{Z}_{\mathrm{c}}$ is the elevation of collar from the bed level and $y$ is the approach flow depth. In order to keep these ratios the same as the ones in Kayatürk's (2005) study, the elevations of collars are chosen as $1.0 \mathrm{~cm}$ and $2.0 \mathrm{~cm}$ above and below the bed level, as mentioned in the previous paragraph. So, the ratios of " $Z_{c} / y$ " become $\pm 0.25, \pm 0.50$ for Kayatürk's (2005) one and \pm 0.24 , \pm 0.47 for this study. The difference inbetween is negligible, so the base to comparison is setup fairly.

\subsection{SCOUR MECHANISM}

The causes of local scour at bridge abutments are the principal vortex due to downflow at the upstream corner of the abutment, the secondary vortices at the middle part of the abutment, and the wake vortices due to the separation of the flow at the downstream corner of the abutment. Although the main cause of the scour hole at the abutments is the downflow and resulting principal vortex, the interaction of these agents with the bed material leads to the local scour.

A collar at any level above the bed divides the flow into two regions; i.e. above and below the collar. For the region above the collar, it acts as an obstacle against the downflow in which the downflow looses its strength an impingement at the bed. For the region below the collar, the downflow and the principal vortex are reduced. 
However, the efficiency of a collar depends on its size and the location on the abutment with respect to the bed (Kayatürk, 2005).

\subsection{DISCUSSION OF RESULTS}

\subsubsection{Scour Profiles around the Abutment with and without Collar:}

In the following figures and paragraphs, the scour profiles obtained as the results of the performed experiments are presented. Later, the profiles of this study are compared with the ones obtained by Kayatürk (2005) and the result of this comparison is put in the words. But, the plots of Kayatürk (2005) are not presented here in order not to cause any mess or confusion. Furthermore, the main comparison material between two studies is given at the upcoming sections.

In Figure 5.2, the longitudinal profiles of the channel bed around the abutment of $\mathrm{L}_{\mathrm{a}}=7.5 \mathrm{~cm}$ tested without collar and with collars at different elevations are presented. Figures 5.2.(a) and 5.2.(b) show the cases when the largest collars, $B_{c}=10$ and $7.5 \mathrm{~cm}$ are placed around the abutment of $\mathrm{L}_{\mathrm{a}}=7.5 \mathrm{~cm}$. When these collars are placed at an elevation of $Z_{c} / y= \pm 0.0$, no scour is recorded during the test duration while a closer efficiency in scour reduction is observed at $Z_{c} / y=-0.24$. The maximum scour depth is observed at the upstream side of the abutment, and the bed material is swept away to the downstream of the abutment for all cases of collar widths and elevations. This tendency is similar to the observations in Kayatürk's (2005) study. The main difference observed inbetween is related to the collar performance. The collars' scour reduction performances are better for all cases of collar widths and elevations than those of the Kayatürk's (2005). As the collar width decreases, the most efficient collar elevation is seen when $Z_{\mathrm{c}} / \mathrm{y}= \pm 0.0$, but the relative performances of the collar at 
this elevation reduces as well. This result is the similar of the one concluded in Kayatürk's (2005) study. The Figures 5.2.(a), (b), (c), and (d) are provided in the next pages. 


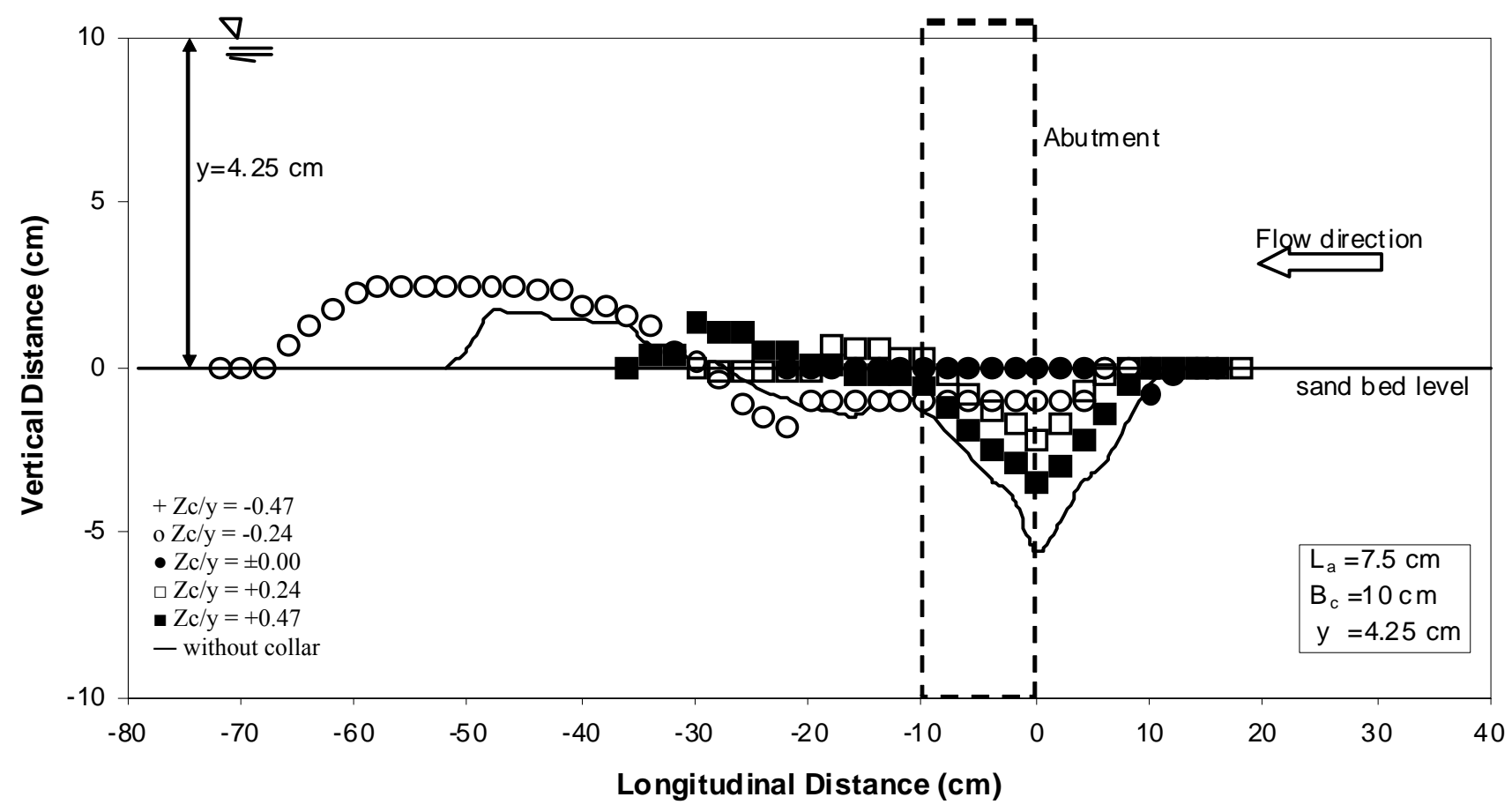

(a) $\mathrm{L}_{\mathrm{a}} / \mathrm{B}_{\mathrm{c}}=0.75$

Figure 5.2. Bed profiles around the bridge abutment of $\mathrm{L}_{\mathrm{a}}=7.5 \mathrm{~cm}$ with and without collars 


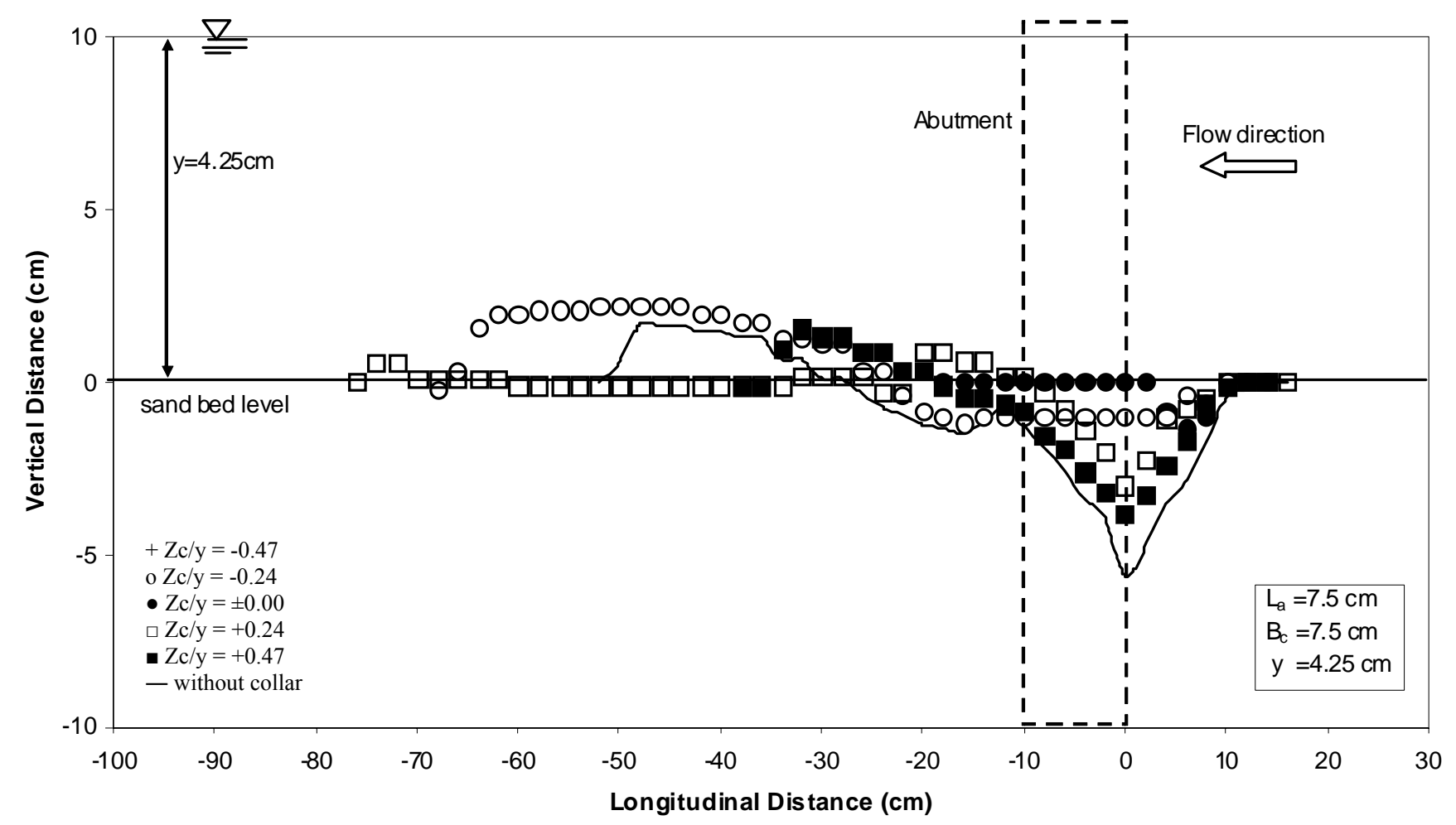

b) $\mathrm{L}_{\mathrm{a}} / \mathrm{B}_{\mathrm{c}}=1.0$

Figure 5.2. Bed profiles around the bridge abutment of $\mathrm{L}_{\mathrm{a}}=7.5 \mathrm{~cm}$ with and without collars 


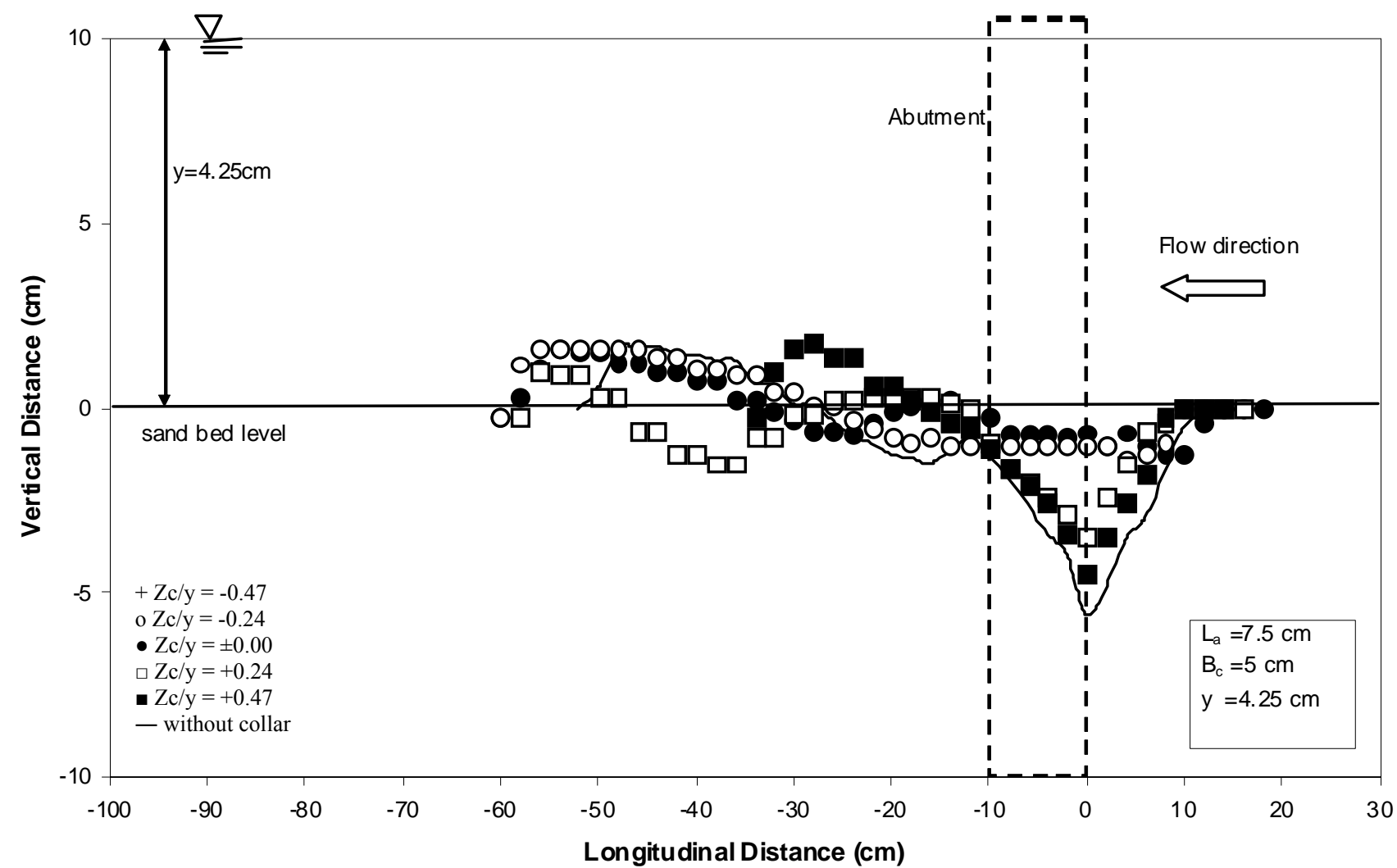

(c) $\mathrm{L}_{\mathrm{a}} / \mathrm{B}_{\mathrm{c}}=1.5$

Figure 5.2. Bed profiles around the bridge abutment of $\mathrm{L}_{\mathrm{a}}=7.5 \mathrm{~cm}$ with and without collars 


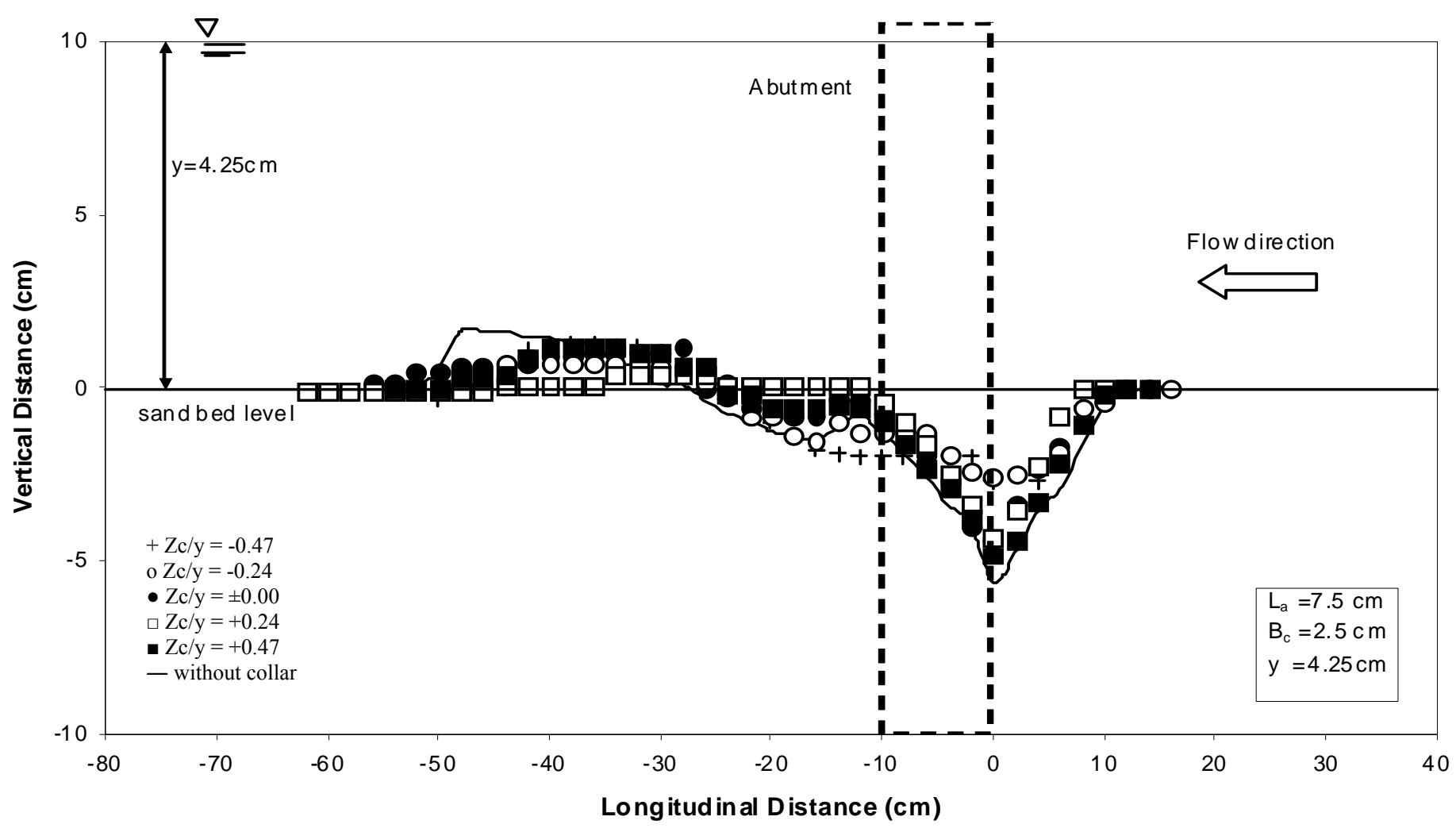

(d) $\mathrm{L}_{\mathrm{a}} / \mathrm{B}_{\mathrm{c}}=3.0$

Figure 5.2. Bed profiles around the bridge abutment of $\mathrm{L}_{\mathrm{a}}=7.5 \mathrm{~cm}$ with and without collars 
Figure 5.3.(a) shows the bed profiles at the abutment site for $L_{a}=15 \mathrm{~cm}$ with $B_{c}=10$ $\mathrm{cm}$. The maximum scour depth occurs at the upstream corner of the abutment. When the profiles for different collar elevations are checked, it is obvious that the scour does not penetrate below the collars at $Z_{c} / y=-0.47$ and -0.24 . But, the best performance is observed for the one at the $\mathrm{Z}_{\mathrm{c}} / \mathrm{y}= \pm 0.0$. The scour depth is $100 \%$ reduced (i.e., no scour observed). The main difference between this study and Kayatürk's (2005) one is the general performances for all collar elevations are better than the ones obtained by Kayatürk (2005). For Figure 5.3.(b) scour does not penetrate below the collar for $Z_{c} / y=-0.47$ although it does for the other cases of smaller collar widths. Collar performances are almost the same or better than those observed in Kayatürk's (2005) study, in general. Figures 5.3.(c) and 5.3.(d) reveal that the scour penetrates below the collar for all the collar elevations. This holds for Kayatürk (2005) true as well, but the general performances of the collars in this study are worse than those of obtained by Kayatürk (2005). Especially for the collar width of $B_{c}=2.5 \mathrm{~cm}$, the collars at elevations $Z_{c} / y \geq \pm 0.0$ have an increasing effect on scour depth.

In general for all Figures, the deposition shape and locations are similar to each other for both of the studies. The general tendency is for the sediment to deposit at the downstream region of the abutment. 


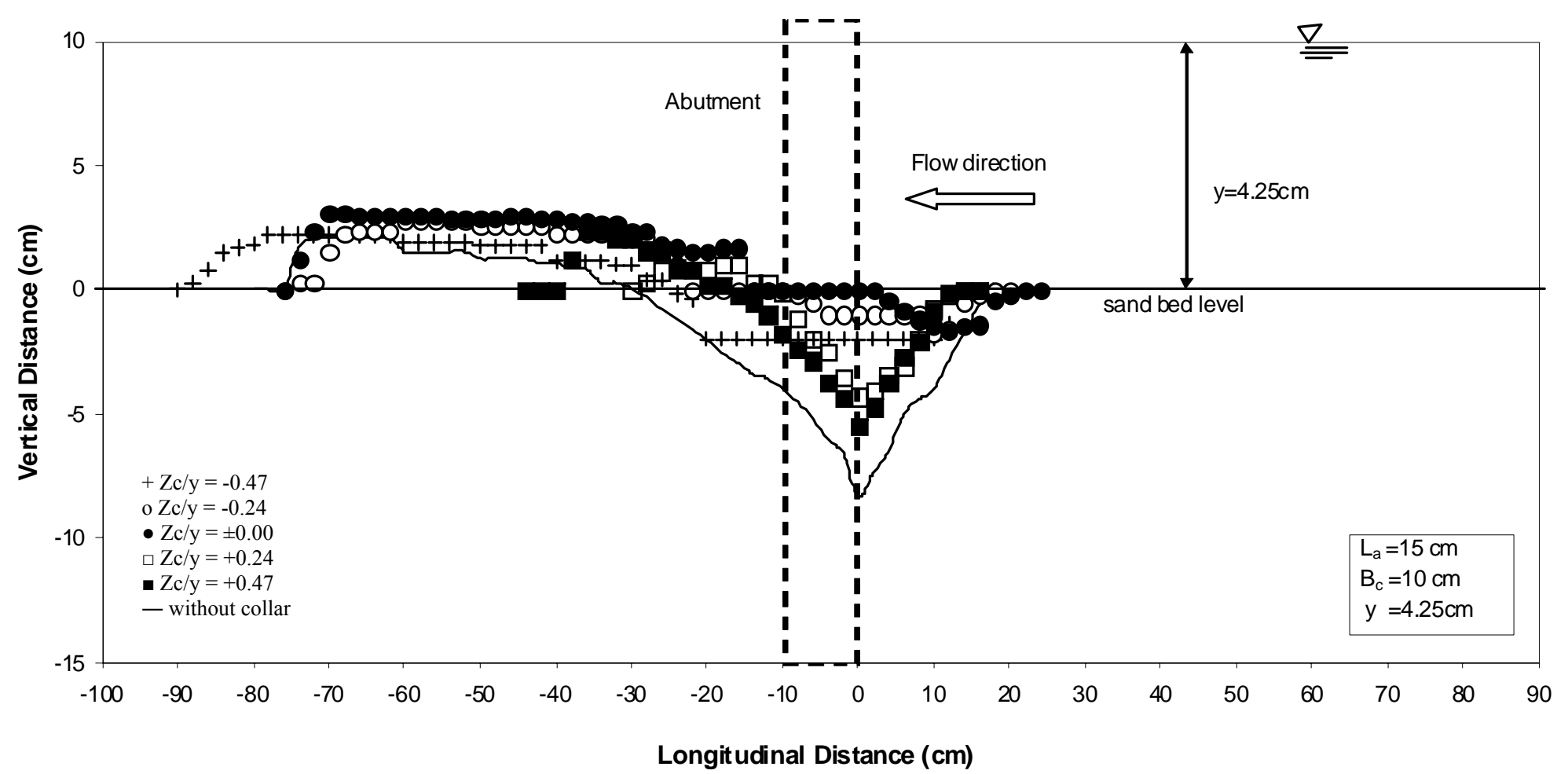

(a) $\mathrm{L}_{\mathrm{a}} / \mathrm{B}_{\mathrm{c}}=1.5$

Figure 5.3. Bed profiles around the bridge abutment of $\mathrm{L}_{\mathrm{a}}=15 \mathrm{~cm}$ with and without collars 


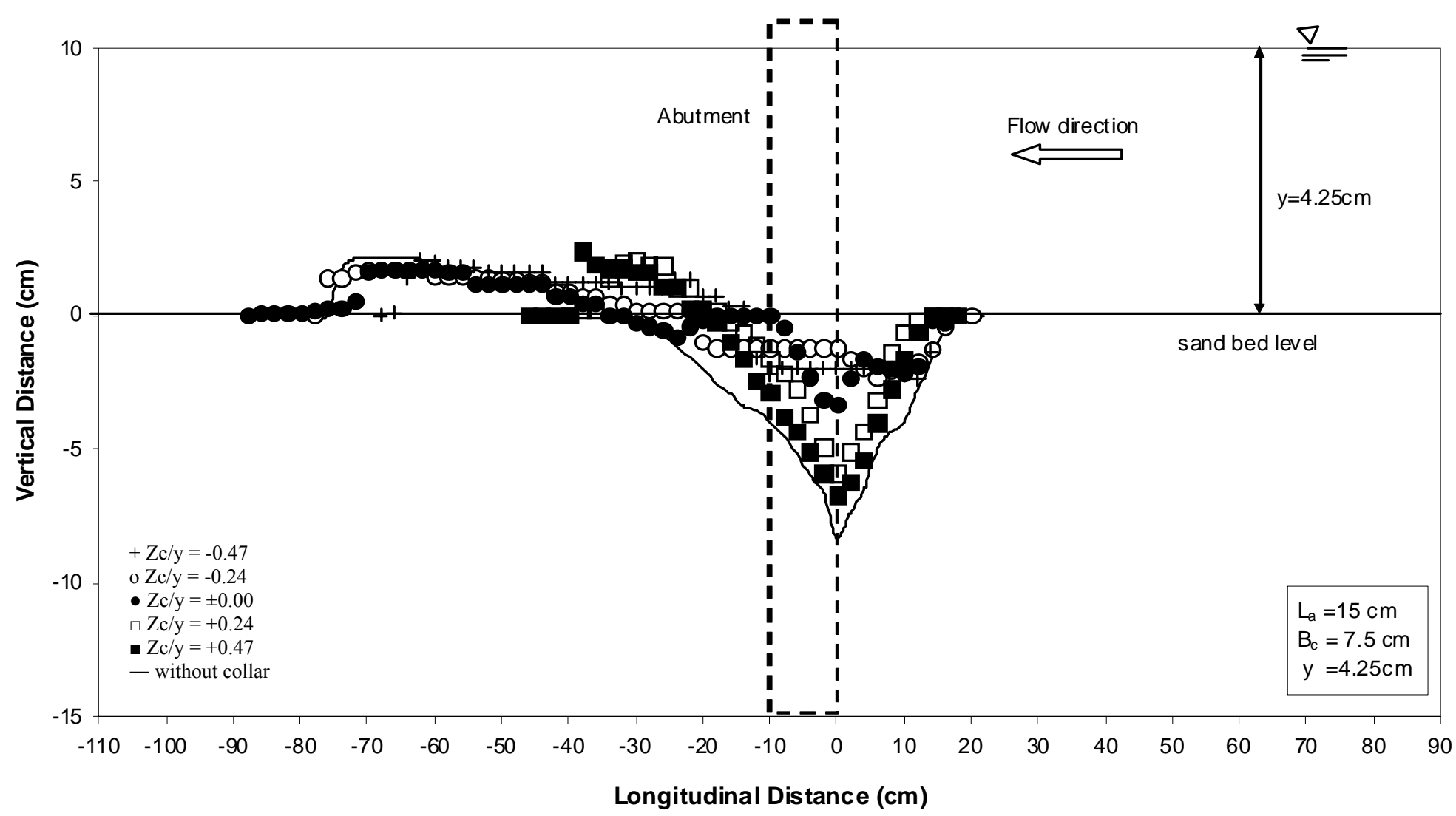

(b) $\mathrm{L}_{\mathrm{a}} / \mathrm{B}_{\mathrm{c}}=2.0$

Figure 5.3. Bed profiles around the bridge abutment of $\mathrm{L}_{\mathrm{a}}=15 \mathrm{~cm}$ with and without collars 


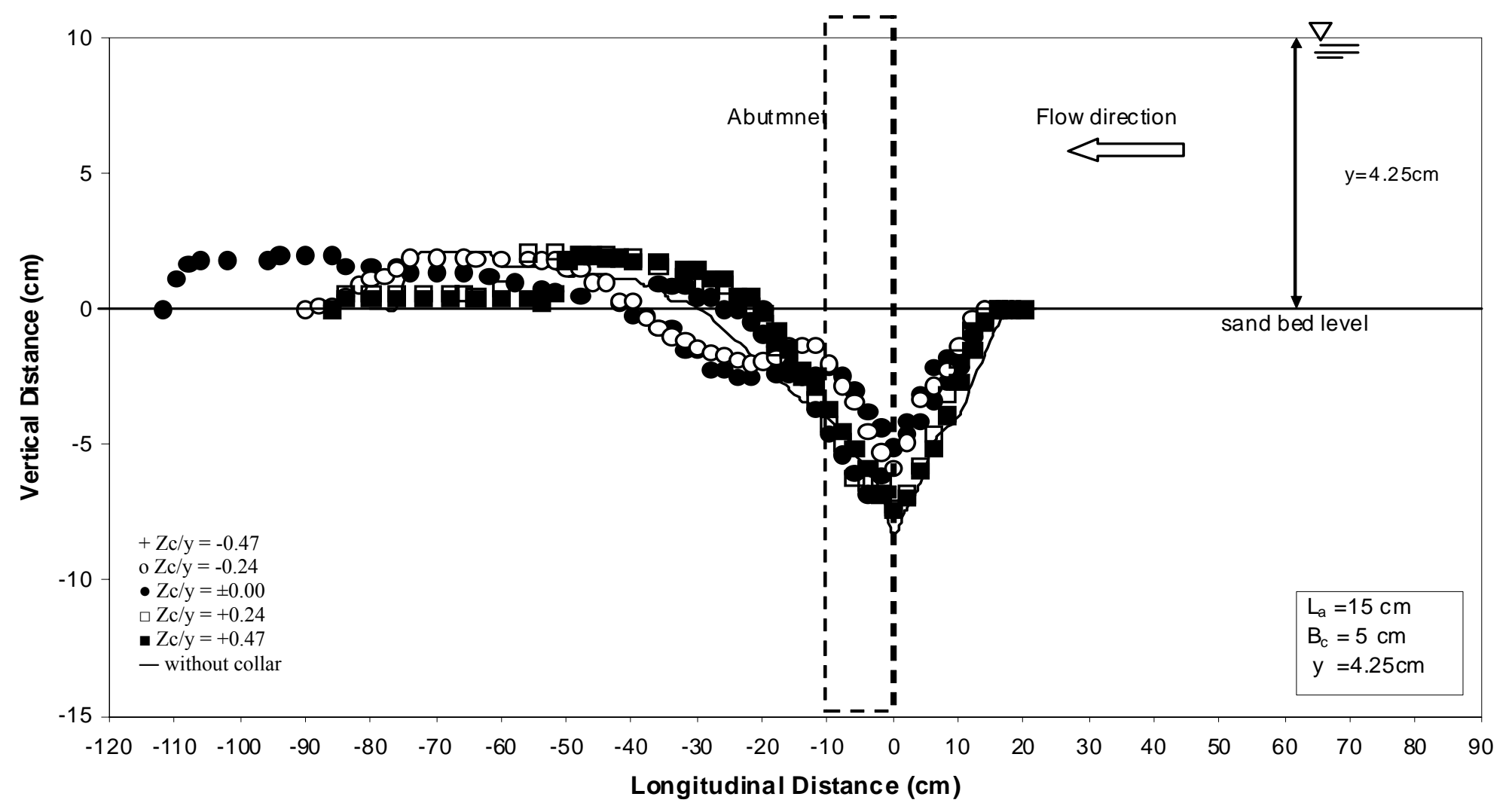

(c) $\mathrm{L}_{\mathrm{a}} / \mathrm{B}_{\mathrm{c}}=3.0$

Figure 5.3. Bed profiles around the bridge abutment of $\mathrm{L}_{\mathrm{a}}=15 \mathrm{~cm}$ with and without collars 


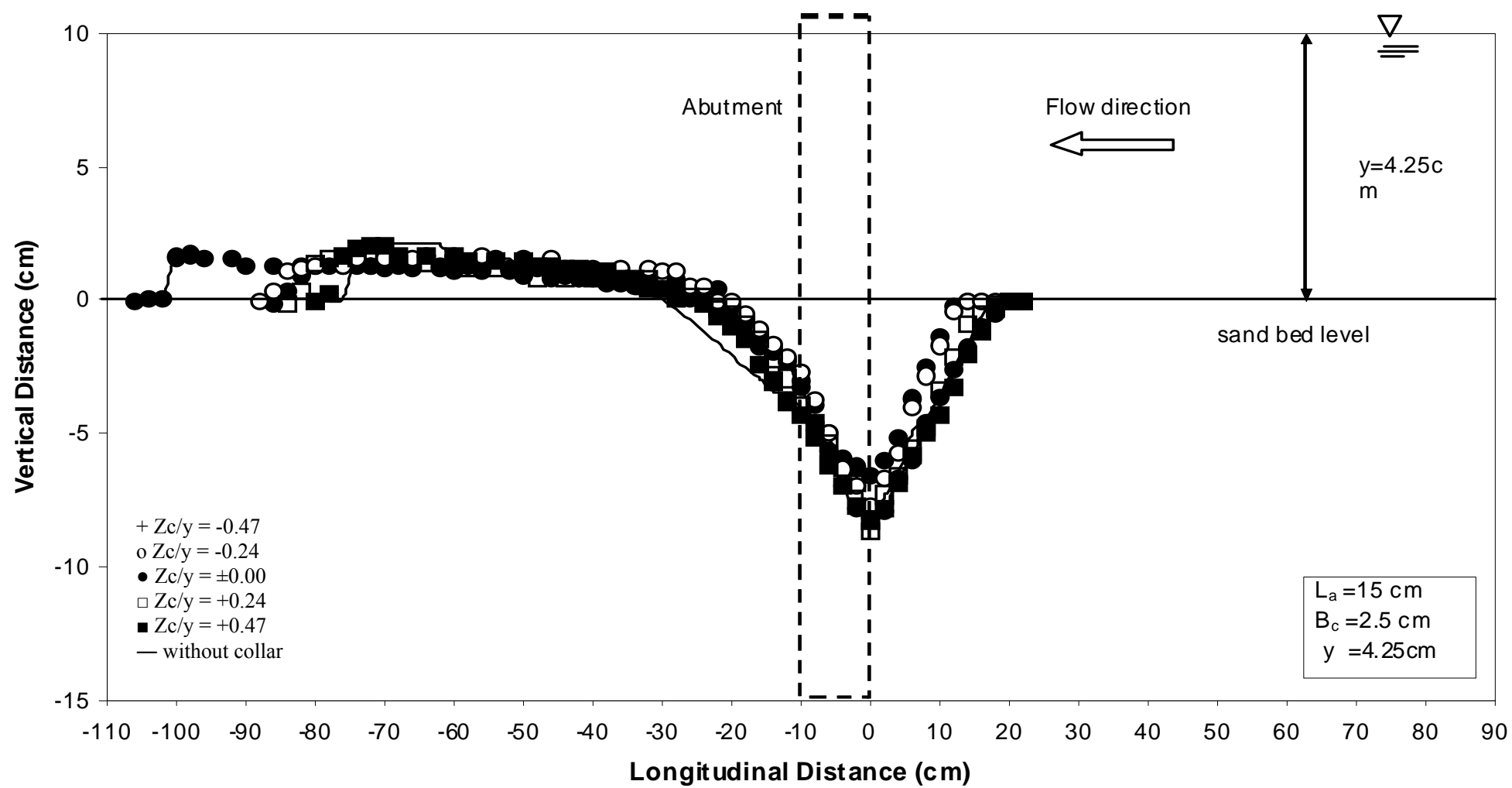

(d) $\mathrm{L}_{\mathrm{a}} / \mathrm{B}_{\mathrm{c}}=6.0$

Figure 5.3. Bed profiles around the bridge abutment of $\mathrm{L}_{\mathrm{a}}=15 \mathrm{~cm}$ with and without collars 
Bed profiles around the abutment of $\mathrm{L}_{\mathrm{a}}=20 \mathrm{~cm}$ without and with collars of different widths, the later located at various elevations are presented in Figures 5.4. For Figure 5.4.(a) the scour does not penetrate below the collars at $Z_{\mathcal{d}} / y=-0.24$ and -0.47 , but for the other elevations, it does. But, this does not yield to the result that the best performance is seen for the collar location of $Z_{c} / y< \pm 0.00$. In fact, it is seen for the collar location at $Z_{c} / y= \pm 0.0$. This is one of the differences between Kayatürk's (2005) study and this study. The other one is that the collar performances are better in this study. In Figure 5.4.(b), the general scour reduction performances of the collar at different elevations are better than those obtained in Kayatürk's (2005) study. In present work, the highest collar efficiency is observed at the collar location of $Z_{d} / y=$ -0.47. Figure 5.4.(c) reveals that the scour penetrates below the collars at all " $\mathrm{Z}_{\mathrm{c}} / \mathrm{y}$ " ratios although the most effective collar elevation is found to be at $Z_{c} / y=-0.47$. When it is compared with the results of Kayatürk (2005), the performance is less than that obtained by Kayatürk (2005). In Figure 5.4.(d), the highest scour reduction percentage is satisfied at an elevation of $Z_{c} / y=-0.47$, as it is in Kayatürk's (2005) study. But, the second best performance belongs to the collar at $Z_{c} / y= \pm 0.00$ in this study. Actually, the difference between the collars at $Z_{c} / y= \pm 0.0$ and at $Z_{c} / y=-0.47$ is less than $2 \%$, which means practically they have almost the same effect on scour reduction. On bealf of these results obtained for each Figure, it can be also concluded that, in general for all cases, the scour is observed at the upstream corner of the abutment, and the sediment deposition occurs at the far downstream of the abutment. Besides, in Figures 5.4.(c) and 5.4.(d), it can be noticed that the scour bed profiles start to get closer to each other, which is a result of the decreasing collar widths. 


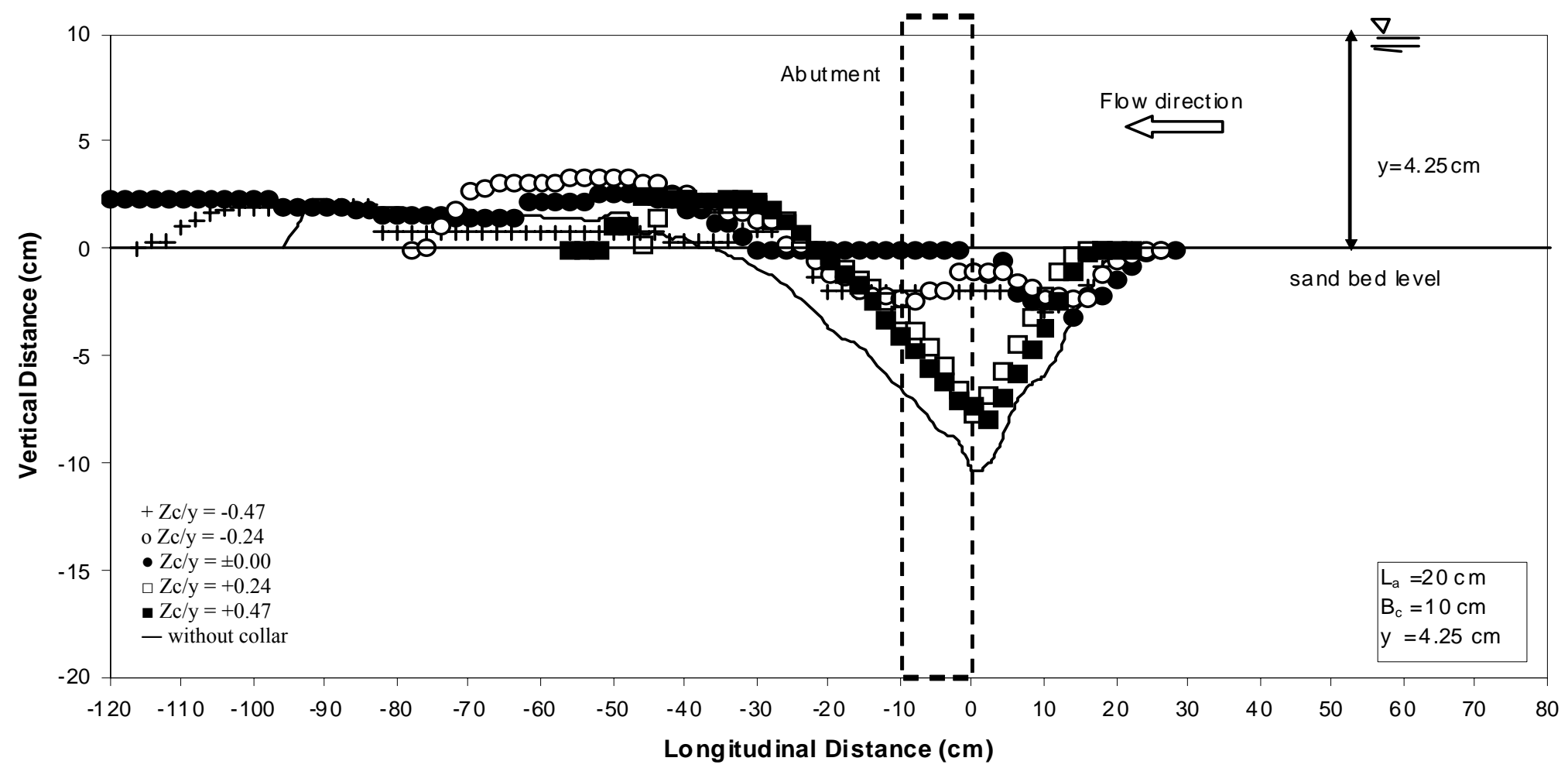

(a) $\mathrm{L}_{\mathrm{a}} / \mathrm{B}_{\mathrm{c}}=2$

Figure 5.4. Bed profiles around the bridge abutment of $\mathrm{L}_{\mathrm{a}}=20 \mathrm{~cm}$ with and without collars 


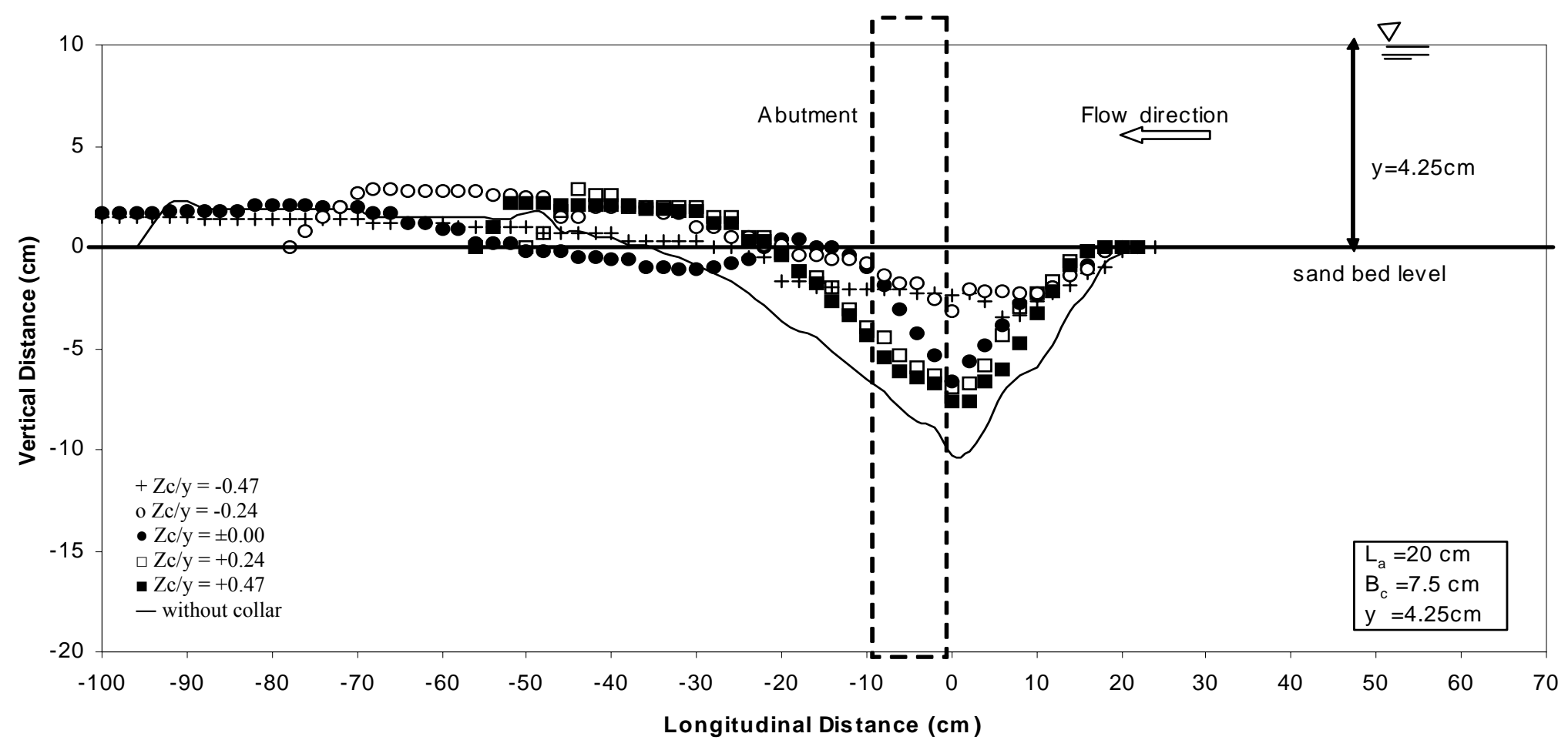

(b) $\mathrm{L}_{\mathrm{a}} / \mathrm{B}_{\mathrm{c}}=2.67$

Figure 5.4. Bed profiles around the bridge abutment of $\mathrm{L}_{\mathrm{a}}=20 \mathrm{~cm}$ with and without collars 


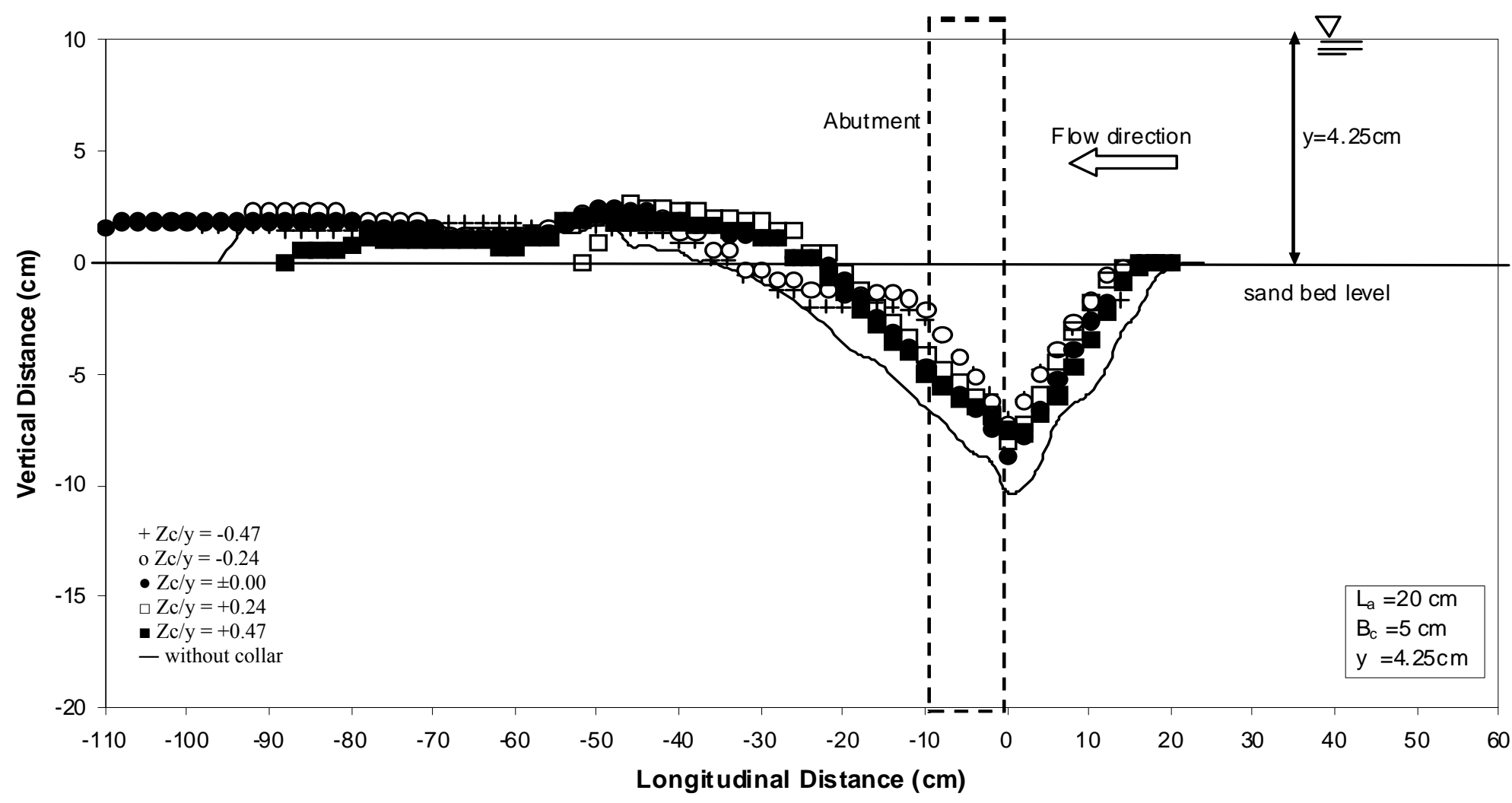

(c) $\mathrm{L}_{\mathrm{a}} / \mathrm{B}_{\mathrm{c}}=4.0$

Figure 5.4. Bed profiles around the bridge abutment of $\mathrm{L}_{\mathrm{a}}=20 \mathrm{~cm}$ with and without collars 


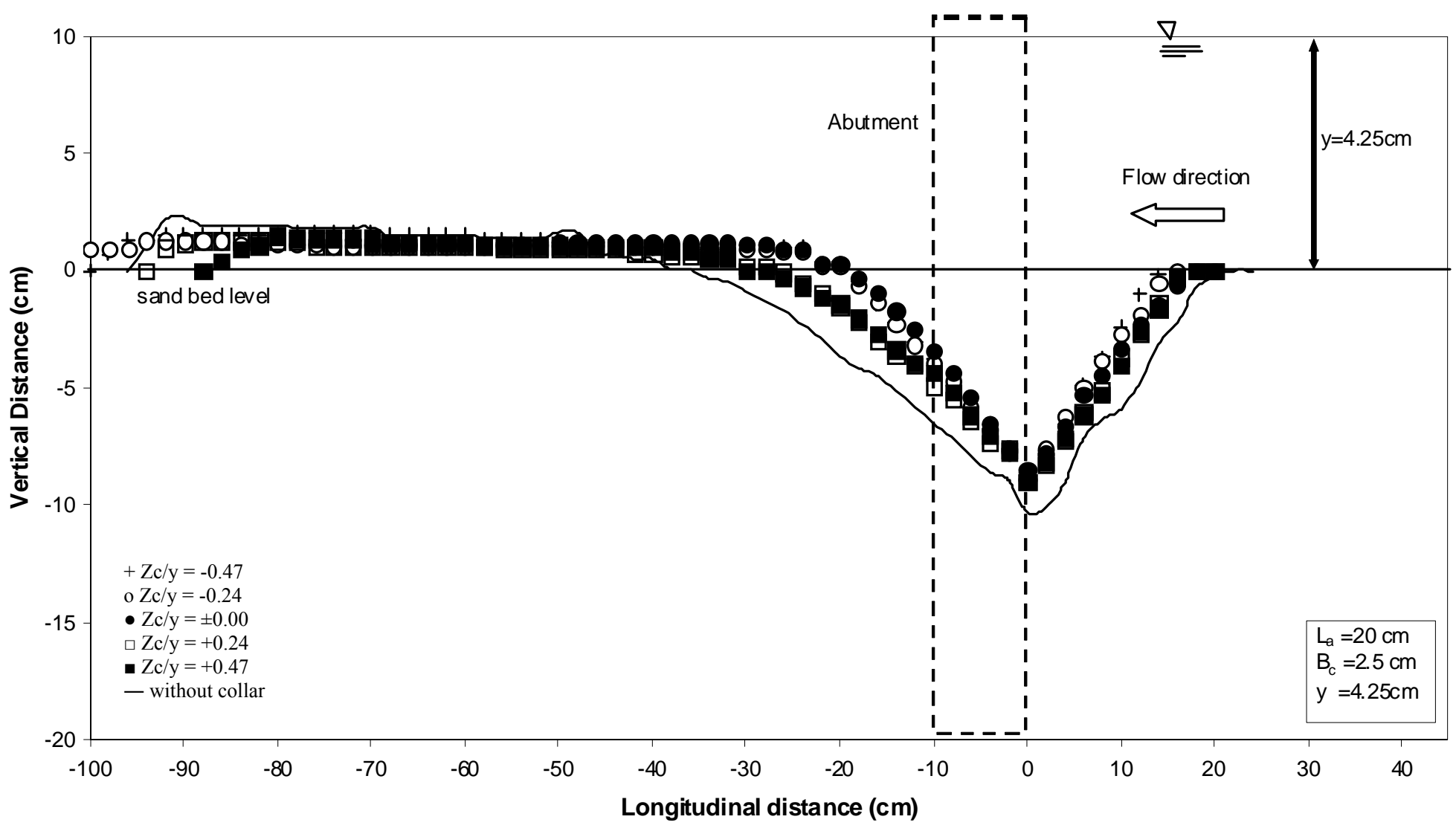

(d) $\mathrm{L}_{\mathrm{a}} / \mathrm{B}_{\mathrm{c}}=8.0$

Figure 5.4. Bed profiles around the bridge abutment of $\mathrm{L}_{\mathrm{a}}=20 \mathrm{~cm}$ with and without collars 
Figure 5.5. shows the bed profiles around the abutment of $\mathrm{L}_{\mathrm{a}}=25 \mathrm{~cm}$ with and without collars. When the bed profiles are investigated, the best collar performance is obtained at an elevation of $Z_{c} / y=-0.47$. From this point of view, this study and the one completed by Kayatürk (2005) coincide with each other. But, there is one difference as well. As can be seen in Figure 5.5.(a), the general scour reduction performance at the elevation of $\mathrm{Z}_{\mathrm{c}} / \mathrm{y}=-0.47$ of this data set is higher than that of Kayatürk's (2005).

Another similarity between the two studies is that as the width of the collars decreases, the gaps between the bed profiles of $Z_{c} / y$ values tested get smaller, and eventually they coincide with the one of no collar case as seen in Figure 5.5.(d). This indicates that the smallest collar width tested, $\mathrm{B}_{\mathrm{c}}=2.5 \mathrm{~cm}$, has almost no influence on the reduction of scour depth around the abutment (Kayatürk, 2005). 


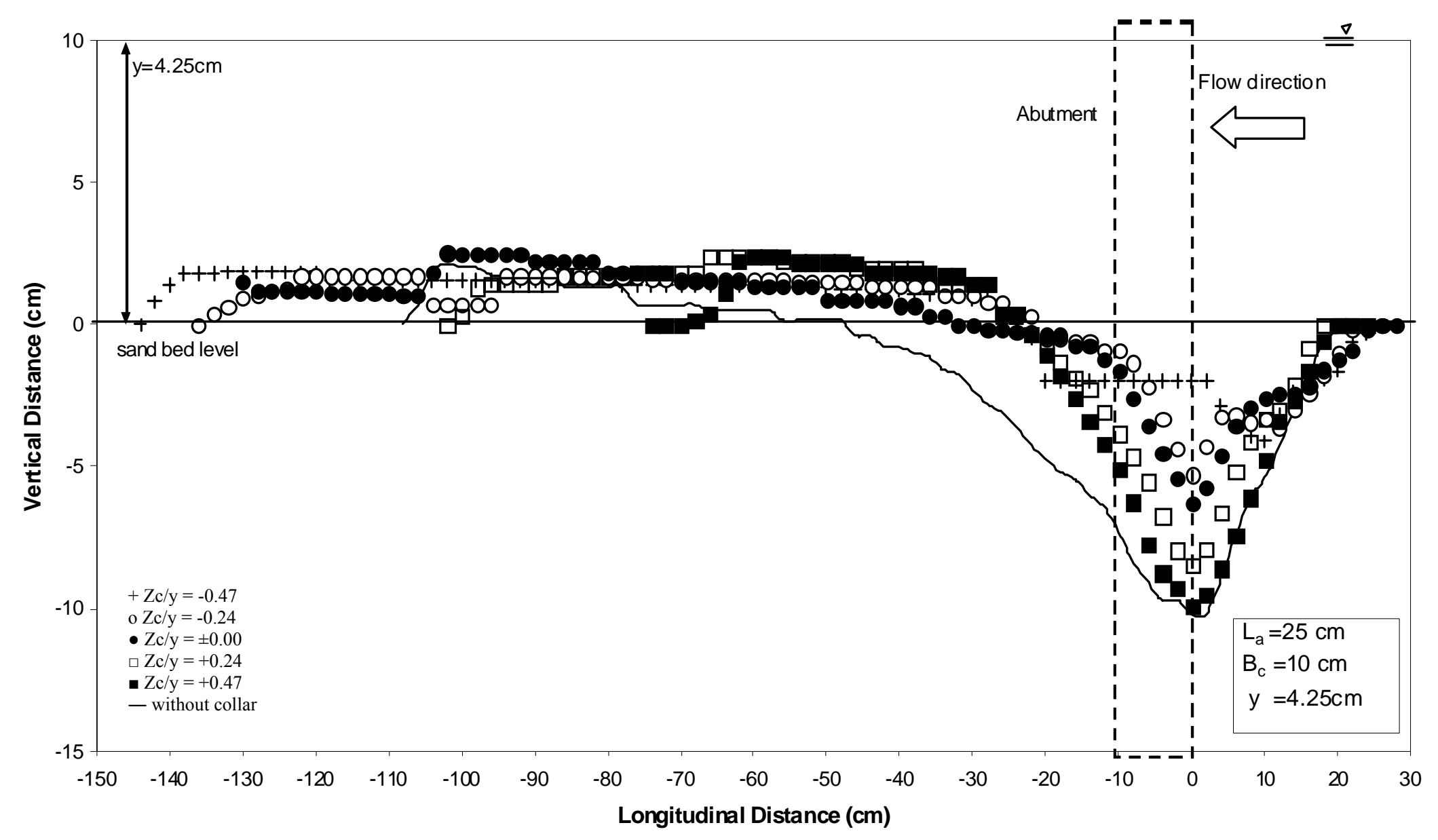

(a) $\mathrm{L}_{\mathrm{a}} / \mathrm{B}_{\mathrm{c}}=2.5$

Figure 5.5. Bed profiles around the bridge abutment of $\mathrm{L}_{\mathrm{a}}=25 \mathrm{~cm}$ with and without collars 


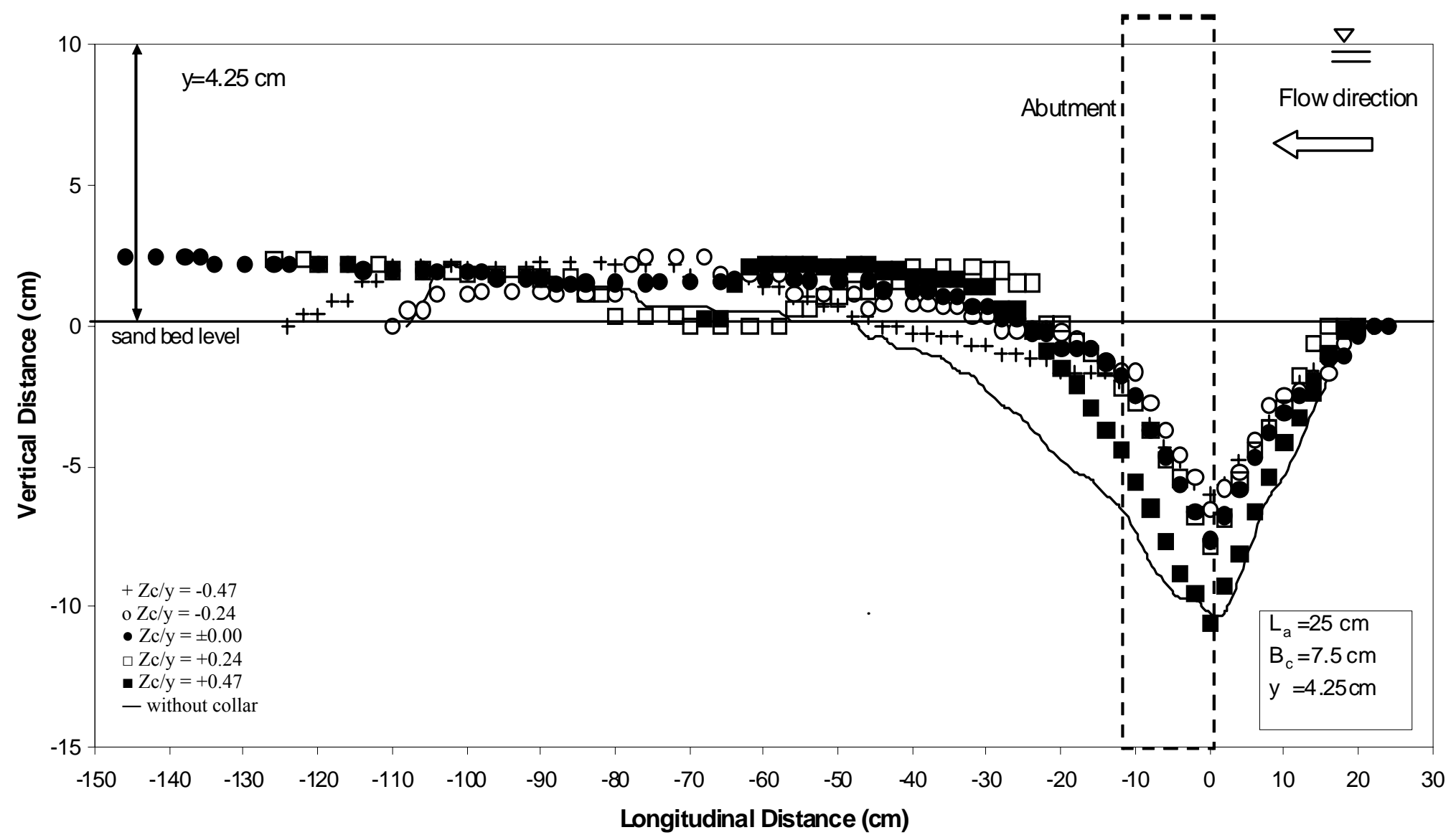

(b) $\mathrm{L}_{\mathrm{a}} / \mathrm{B}_{\mathrm{c}}=3.33$

Figure 5.5. Bed profiles around the bridge abutment of $\mathrm{L}_{\mathrm{a}}=25 \mathrm{~cm}$ with and without collars 


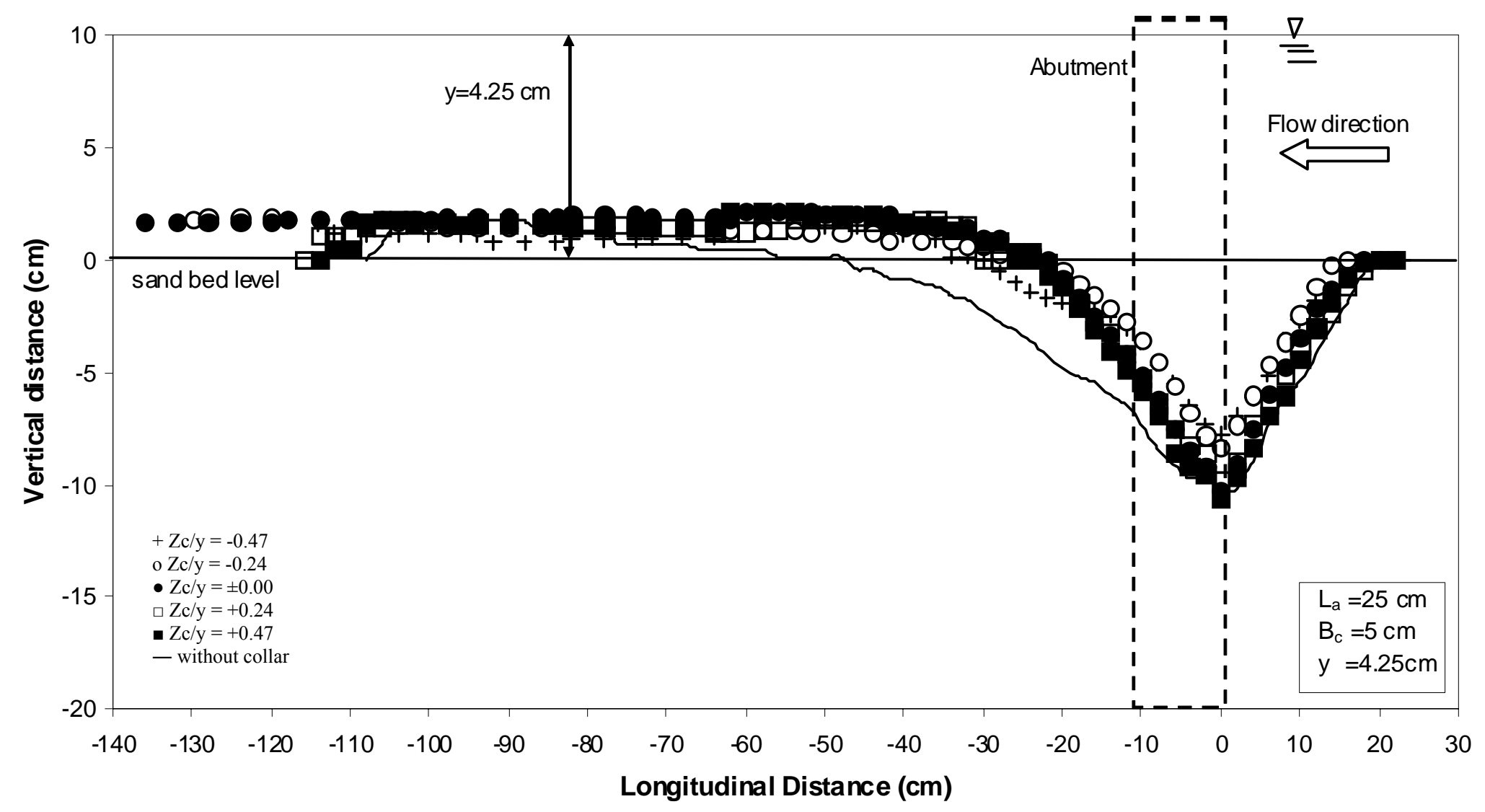

(c) $\mathrm{L}_{\mathrm{a}} / \mathrm{B}_{\mathrm{c}}=5.0$

Figure 5.5. Bed profiles around the bridge abutment of $\mathrm{L}_{\mathrm{a}}=25 \mathrm{~cm}$ with and without collars 


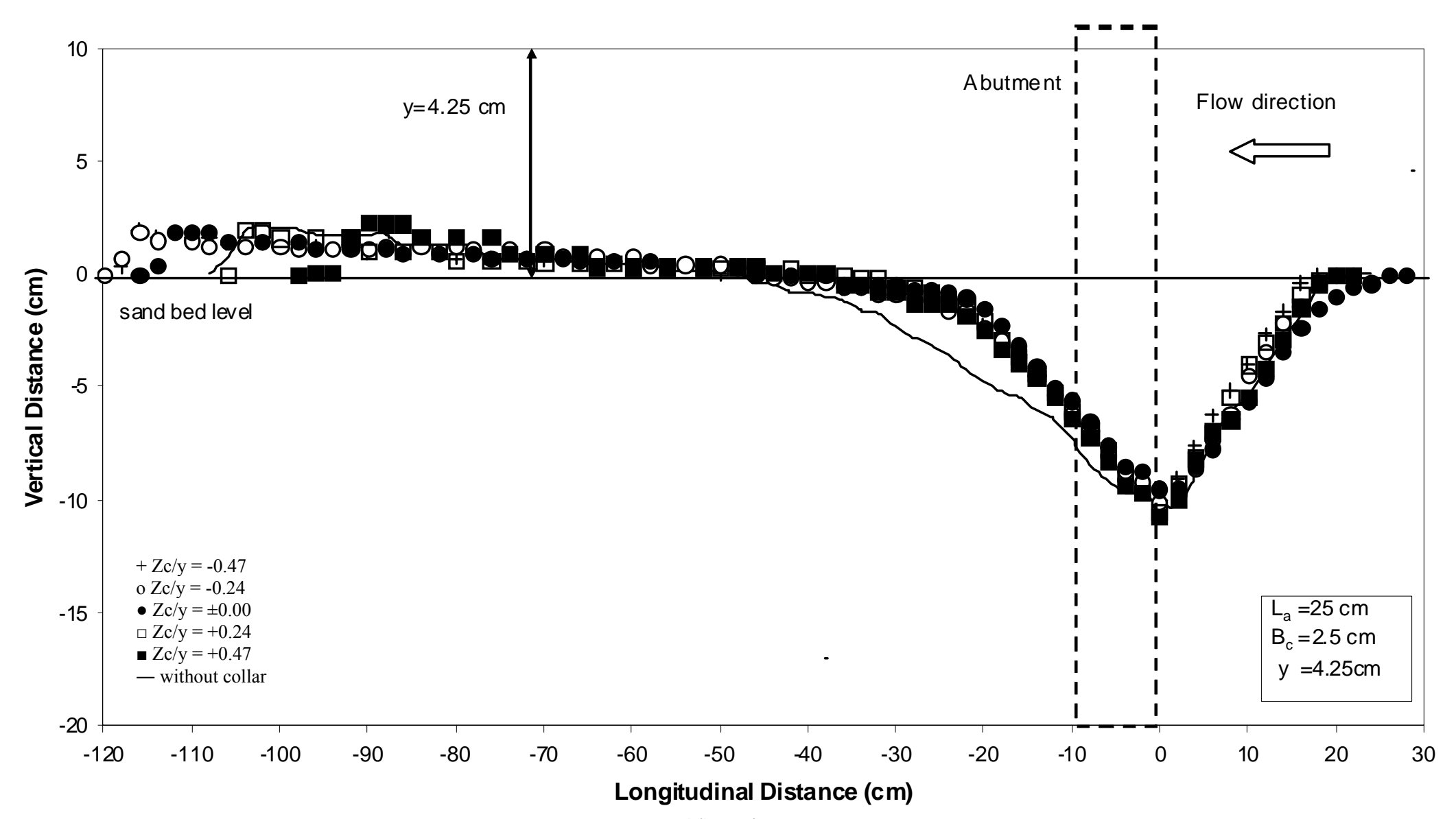

(d) $\mathrm{L}_{\mathrm{a}} / \mathrm{B}_{\mathrm{c}}=10$

Figure 5.5. Bed profiles around the bridge abutment of $\mathrm{L}_{\mathrm{a}}=25 \mathrm{~cm}$ with and without collars 
The bed profiles around the longest abutment tested in the experiments, $L_{a}=35 \mathrm{~cm}$, are shown in Figure 5.6. The maximum scour reduction capabilities are observed at the elevation of $Z_{c} / y=-0.24$ for Figures 5.6.(a) and 5.6.(b). But, they are at $Z_{c} / y=-$ 0.47 elevation in Figures 5.6.(c) and 5.6.(d). In Kayatürk's (2005) study, in comparison, the most efficient collar elevation is $Z_{c} / y=-0.47$ for all collar widths. In addition to these, it is a fact that the scour reduction capabilities of the collars located around the abutments having lengths of $\mathrm{L}_{\mathrm{a}}=25 \mathrm{~cm}$ and $35 \mathrm{~cm}$, are the lowest ones compared with the other abutment lengths. The main reason is that the efficiency of the collars also decreases as their widths decrease (Kayatürk, 2005). It is obvious from the profiles that the increase in $\mathrm{L}_{\mathrm{a}} / \mathrm{B}_{\mathrm{c}}$ ratio leads to the result that the scour profiles converge to each other as if there are no collars anymore. 


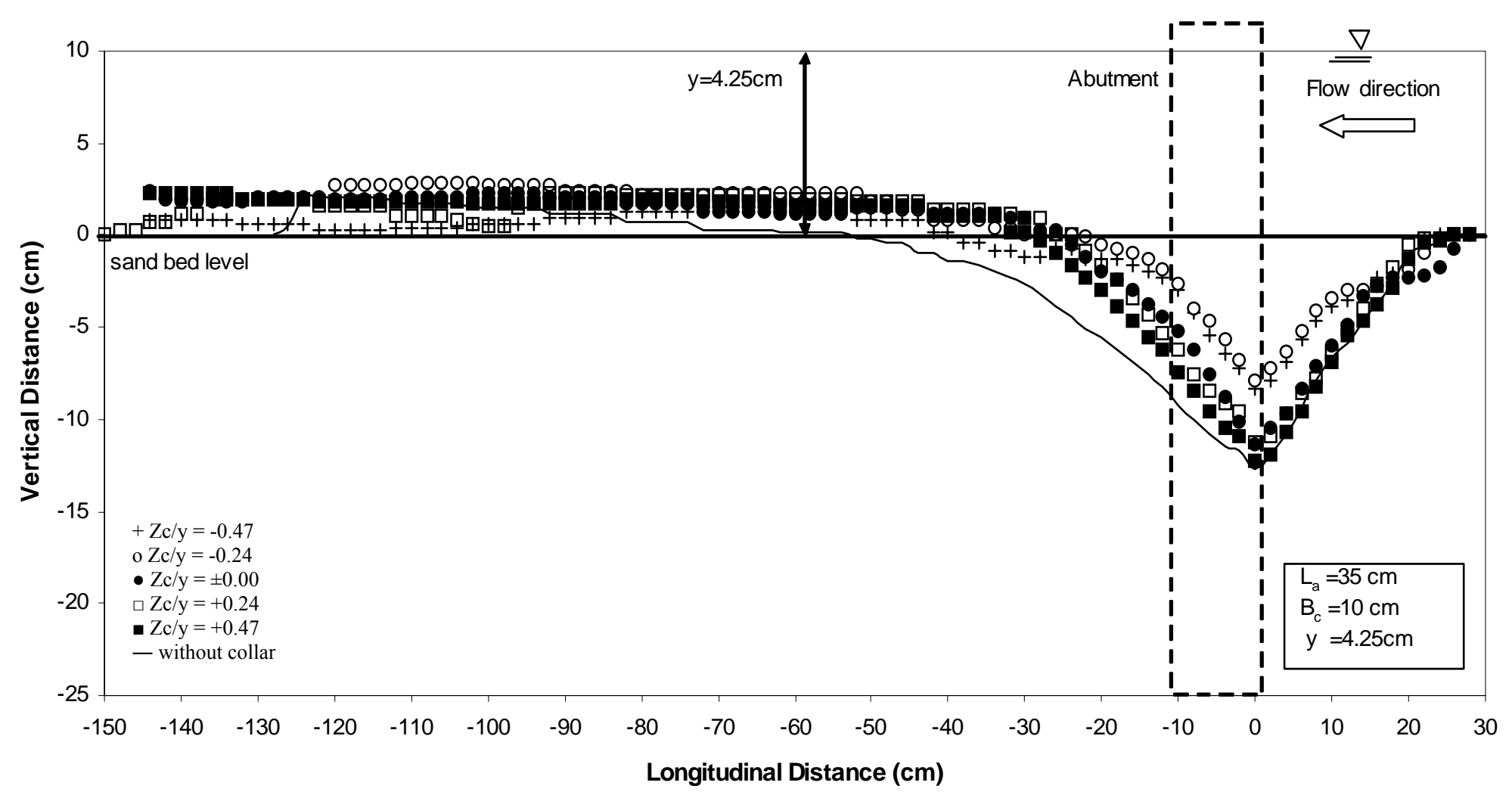

(a) $\mathrm{L}_{\mathrm{a}} / \mathrm{B}_{\mathrm{c}}=3.5$

Figure 5.6. Bed profiles around the bridge abutment of $\mathrm{L}_{\mathrm{a}}=35 \mathrm{~cm}$ with and without collars 


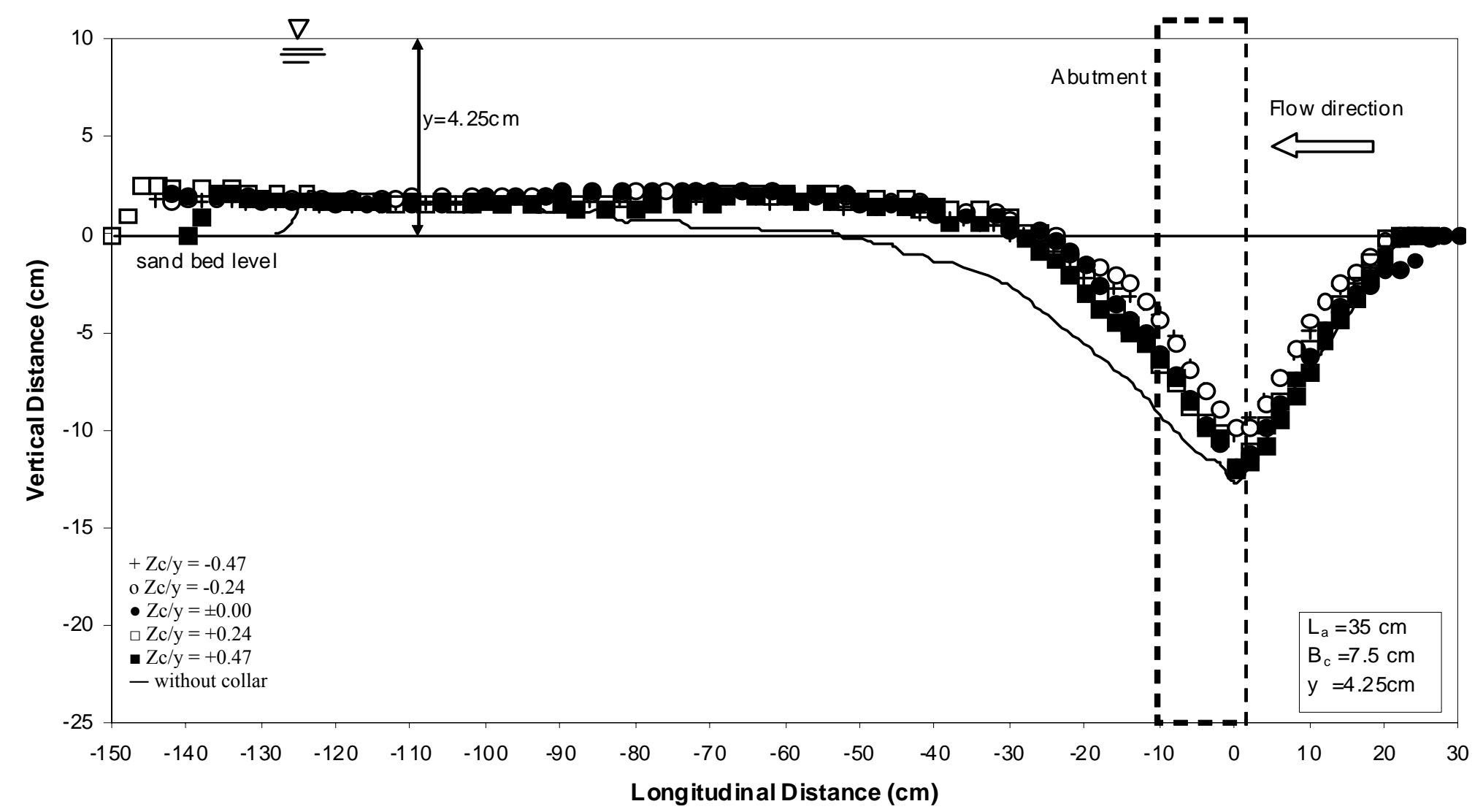

(b) $\mathrm{L}_{\mathrm{a}} / \mathrm{B}_{\mathrm{c}}=4.67$

Figure 5.6. Bed profiles around the bridge abutment of $\mathrm{L}_{\mathrm{a}}=35 \mathrm{~cm}$ with and without collars 


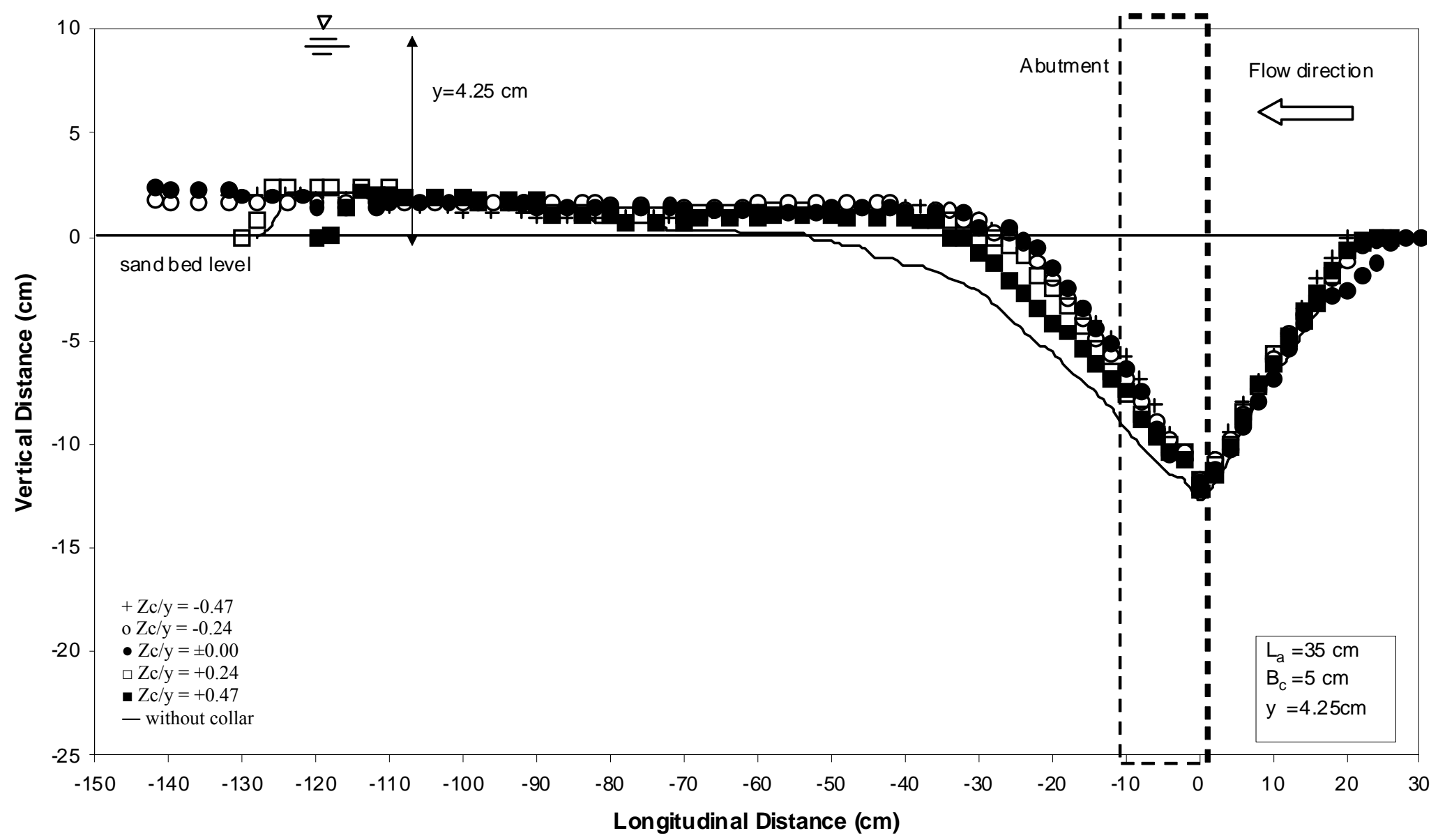

(c) $\mathrm{L}_{\mathrm{a}} / \mathrm{B}_{\mathrm{c}}=7.0$

Figure 5.6. Bed profiles around the bridge abutment of $\mathrm{L}_{\mathrm{a}}=35 \mathrm{~cm}$ with and without collars 


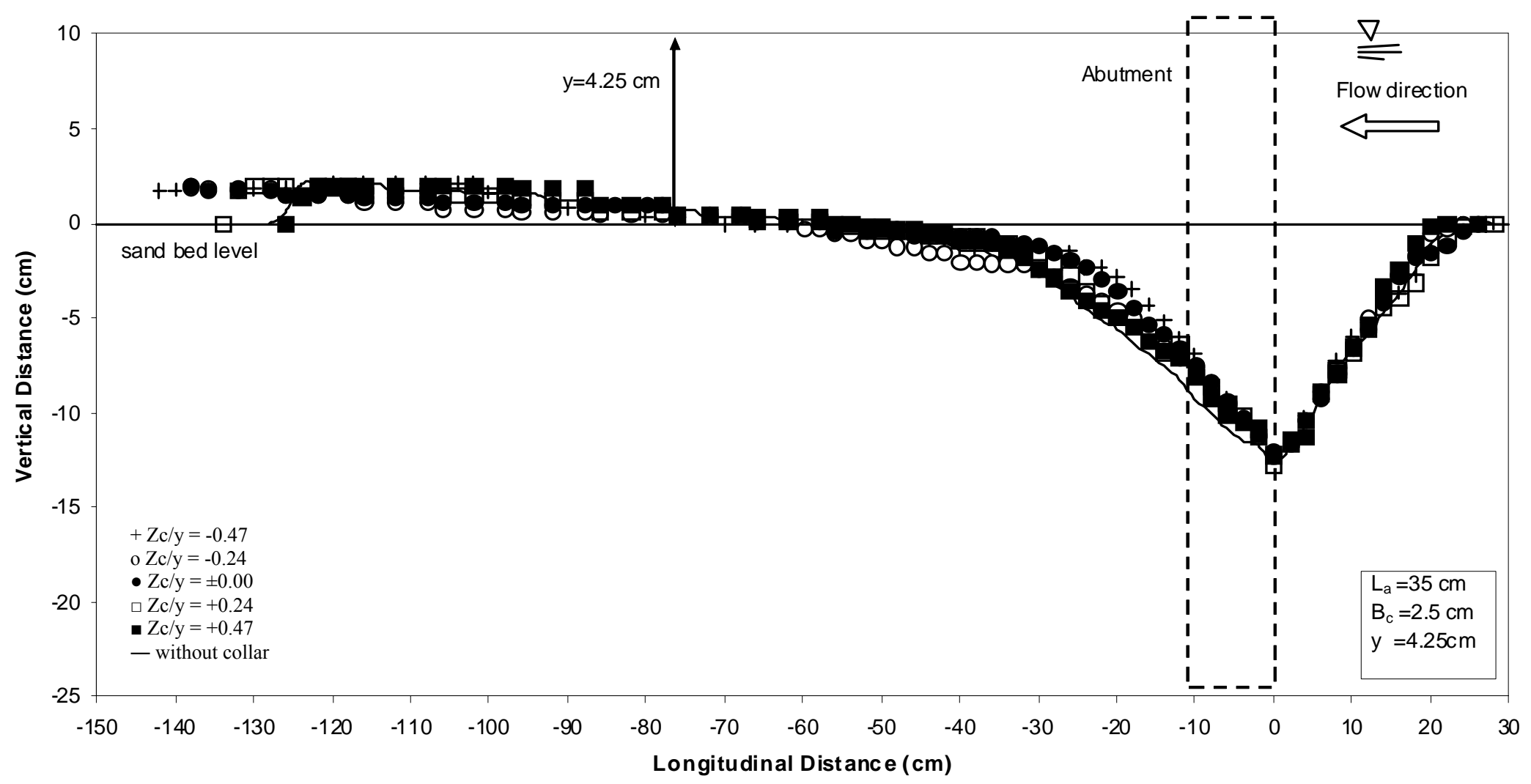

(d) $\mathrm{L}_{\mathrm{a}} / \mathrm{B}_{\mathrm{c}}=14.0$

Figure 5.6. Bed profiles around the bridge abutment of $\mathrm{L}_{\mathrm{a}}=35 \mathrm{~cm}$ with and without collars 


\subsubsection{Maximum Scour Reductions around the Abutments with Collars}

The total number of the experiments conducted; with abutments of lengths: $L_{a}=7.5$ $\mathrm{cm}, 15 \mathrm{~cm}, 20 \mathrm{~cm}, 25 \mathrm{~cm}$ and $35 \mathrm{~cm}$, collars of widths: $\mathrm{B}_{\mathrm{c}}=2.5 \mathrm{~cm}, 5.0 \mathrm{~cm}, 7.5 \mathrm{~cm}$ and $10 \mathrm{~cm}$, and finally collar locations of $Z_{c}=-2.0 \mathrm{~cm},-1.0 \mathrm{~cm}, \pm 0.0 \mathrm{~cm}, 1.0 \mathrm{~cm}$ and $2.0 \mathrm{~cm}$ is 97 . The experiments for the abutment length of $7.5 \mathrm{~cm}$ with the collar widths of $10 \mathrm{~cm}, 7.5 \mathrm{~cm}$, and $5 \mathrm{~cm}$ at the elevation of $Z_{c}=-2.0 \mathrm{~cm}$ have not been performed. The reason is that the propagation of the scour depth in the vertical direction is stoped during the experiments for $Z_{c}=-1.0 \mathrm{~cm}$, meaning that there is no sense or need to locate collars below this limiting level. Bed profiles obtained at the end of these experiments, each conducted for a period of 6-hours, were given in the previous section. Referring to the measurement done by a mirror at the end of the 6 hours, the maximum scour depths around the abutments for each experiment were determined. Table 5.2 lists the experimental data to show the maximum scour depths around the abutments with and without collar conditions. In this table, $\left(\mathrm{d}_{\mathrm{s}}\right)_{\max }$ depicts the maximum scour depth around the abutment which has no collar around it, and $\left(d_{s}\right)_{\text {max,c }}$ depicts the maximum scour depth around the abutment protected by a collar. The last column of the table shows the percent reduction of the maximum scour depth when the collar is used. 
Table 5.2. Experimental data for $Q=0.017 \mathrm{~m}^{3} / \mathrm{s}, \mathrm{y}=4.25 \mathrm{~cm}$ and $\mathrm{B}_{\mathrm{a}}=10 \mathrm{~cm}$

\begin{tabular}{|c|c|c|c|c|c|c|}
\hline Run no & $\begin{array}{c}\mathrm{L}_{\mathrm{a}} \\
(\mathrm{cm})\end{array}$ & $\begin{array}{c}\mathrm{B}_{\mathrm{c}} \\
(\mathrm{cm})\end{array}$ & $\begin{array}{c}\mathrm{Z}_{\mathrm{c}} \\
(\mathrm{cm})\end{array}$ & $\begin{array}{c}\left(\mathrm{d}_{\mathrm{s}}\right)_{\max } \\
(\mathrm{cm})\end{array}$ & $\left(d_{\mathrm{s}}\right)_{\max , \mathrm{c}}$ & $\begin{array}{c}\% \% \\
\text { Reduction } \\
\text { in max. } \\
\text { scour } \\
\text { depth }\end{array}$ \\
\hline R1 & 7.5 & 2.5 & -2 & 6.3 & 3.2 & 49.2 \\
\hline R2 & 7.5 & 2.5 & -1 & 6.3 & 3.1 & 50.8 \\
\hline R3 & 7.5 & 2.5 & \pm 0.0 & 6.3 & 4.8 & 23.8 \\
\hline R4 & 7.5 & 2.5 & 1 & 6.3 & 4.5 & 29.4 \\
\hline R5 & 7.5 & 2.5 & 2 & 6.3 & 5.1 & 19.0 \\
\hline R6 & 7.5 & 5 & -2 & 6.3 & - & - \\
\hline R7 & 7.5 & 5 & -1 & 6.3 & 1.0 & 84.1 \\
\hline R8 & 7.5 & 5 & \pm 0.0 & 6.3 & 1.0 & 84.1 \\
\hline R9 & 7.5 & 5 & 1 & 6.3 & 3.9 & 38.1 \\
\hline R10 & 7.5 & 5 & 2 & 6.3 & 5.3 & 15.9 \\
\hline R11 & 7.5 & 7.5 & -2 & 6.3 & - & - \\
\hline $\mathrm{R} 12$ & 7.5 & 7.5 & -1 & 6.3 & 1.0 & 84.1 \\
\hline $\mathrm{R} 13$ & 7.5 & 7.5 & \pm 0.0 & 6.3 & 0.0 & 100.0 \\
\hline R14 & 7.5 & 7.5 & 1 & 6.3 & 2.9 & 54.0 \\
\hline R15 & 7.5 & 7.5 & 2 & 6.3 & 4.5 & 28.6 \\
\hline R16 & 7.5 & 10 & -2 & 6.3 & - & - \\
\hline R17 & 7.5 & 10 & -1 & 6.3 & 1.0 & 84.1 \\
\hline R18 & 7.5 & 10 & \pm 0.0 & 6.3 & 0.0 & 100.0 \\
\hline R19 & 7.5 & 10 & 1 & 6.3 & 2.0 & 68.3 \\
\hline $\mathrm{R} 20$ & 7.5 & 10 & 2 & 6.3 & 4.1 & 34.9 \\
\hline R21 & 15 & 2.5 & -2 & 8.9 & 7.6 & 14.6 \\
\hline $\mathrm{R} 22$ & 15 & 2.5 & -1 & 8.9 & 8.4 & 5.6 \\
\hline R23 & 15 & 2.5 & \pm 0.0 & 8.9 & 9.5 & -6.7 \\
\hline $\mathrm{R} 24$ & 15 & 2.5 & 1 & 8.9 & 9.0 & -1.1 \\
\hline R25 & 15 & 2.5 & 2 & 8.9 & 9.1 & -2.2 \\
\hline
\end{tabular}


Table 5.2. Experimental data for $\mathrm{Q}=0.017 \mathrm{~m}^{3} / \mathrm{s}, \mathrm{y}=4.25 \mathrm{~cm}$ and $\mathrm{B}_{\mathrm{a}}=10 \mathrm{~cm}$ (continued)

\begin{tabular}{c|c|c|c|c|c|c}
\hline Run no & $\begin{array}{c}\mathrm{L}_{\mathrm{a}} \\
(\mathrm{cm})\end{array}$ & $\begin{array}{c}\mathrm{B}_{\mathrm{c}} \\
(\mathrm{cm})\end{array}$ & $\begin{array}{c}\mathrm{Z}_{\mathrm{c}} \\
(\mathrm{cm})\end{array}$ & $\left(\mathrm{d}_{\mathrm{s}}\right)_{\max }$ & $\left(\mathrm{d}_{\mathrm{s}}\right)_{\max , \mathrm{c}}$ & $\begin{array}{c}\% \\
\text { Reduction } \\
\text { in max. } \\
\text { scour } \\
\text { depth }\end{array}$ \\
\hline $\mathrm{R} 26$ & 15 & 5 & -2 & 8.9 & 6.6 & 25.8 \\
$\mathrm{R} 27$ & 15 & 5 & -1 & 8.9 & 5.6 & $\mathbf{3 7 . 1}$ \\
$\mathrm{R} 28$ & 15 & 5 & \pm 0.0 & 8.9 & 8.0 & 10.1 \\
$\mathrm{R} 29$ & 15 & 5 & 1 & 8.9 & 8.8 & 1.1 \\
$\mathrm{R} 30$ & 15 & 5 & 2 & 8.9 & 8.4 & 5.6 \\
\hline $\mathrm{R} 31$ & 15 & 7.5 & -2 & 8.9 & 2.0 & 77.5 \\
$\mathrm{R} 32$ & 15 & 7.5 & -1 & 8.9 & 2.0 & $\mathbf{7 7 . 5}$ \\
$\mathrm{R} 33$ & 15 & 7.5 & \pm 0.0 & 8.9 & 3.9 & 56.2 \\
$\mathrm{R} 34$ & 15 & 7.5 & 1 & 8.9 & 6.8 & 23.6 \\
$\mathrm{R} 35$ & 15 & 7.5 & 2 & 8.9 & 7.8 & 12.4 \\
\hline $\mathrm{R} 36$ & 15 & 10 & -2 & 8.9 & 2.0 & 77.5 \\
$\mathrm{R} 37$ & 15 & 10 & -1 & 8.9 & 1.0 & 88.8 \\
$\mathrm{R} 38$ & 15 & 10 & \pm 0.0 & 8.9 & 0.0 & $\mathbf{1 0 0 . 0}$ \\
$\mathrm{R} 39$ & 15 & 10 & 1 & 8.9 & 5.2 & 41.6 \\
$\mathrm{R} 40$ & 15 & 10 & 2 & 8.9 & 6.3 & 29.2 \\
\hline $\mathrm{R} 41$ & 20 & 2.5 & -2 & 11.2 & 9.6 & $\mathbf{1 4 . 3}$ \\
$\mathrm{R} 42$ & 20 & 2.5 & -1 & 11.2 & 10.1 & 9.8 \\
$\mathrm{R} 43$ & 20 & 2.5 & \pm 0.0 & 11.2 & 9.8 & 12.5 \\
$\mathrm{R} 44$ & 20 & 2.5 & 1 & 11.2 & 10.3 & 8.0 \\
$\mathrm{R} 45$ & 20 & 2.5 & 2 & 11.2 & 10.3 & 8.0 \\
\hline $\mathrm{R} 46$ & 20 & 5 & -2 & 11.2 & 7.8 & $\mathbf{3 0 . 4}$ \\
$\mathrm{R} 47$ & 20 & 5 & -1 & 11.2 & 8.2 & 26.8 \\
$\mathrm{R} 48$ & 20 & 5 & \pm 0.0 & 11.2 & 9.8 & 12.5 \\
$\mathrm{R} 49$ & 20 & 5 & 1 & 11.2 & 9.3 & 17.0 \\
$\mathrm{R} 50$ & 20 & 5 & 2 & 11.2 & 9.6 & 14.3 \\
\hline & & & & & & \\
\hline
\end{tabular}


Table 5.2. Experimental data for $\mathrm{Q}=0.017 \mathrm{~m}^{3} / \mathrm{s}, \mathrm{y}=4.25 \mathrm{~cm}$ and $\mathrm{B}_{\mathrm{a}}=10 \mathrm{~cm}$ (continued)

\begin{tabular}{c|c|c|c|c|c|c}
\hline Run no & $\begin{array}{c}\mathrm{L}_{\mathrm{a}} \\
(\mathrm{cm})\end{array}$ & $\begin{array}{c}\mathrm{B}_{\mathrm{c}} \\
(\mathrm{cm})\end{array}$ & $\begin{array}{c}\mathrm{Z}_{\mathrm{c}} \\
(\mathrm{cm})\end{array}$ & $\left(\mathrm{d}_{\mathrm{s}}\right)_{\max }$ & $\left(\mathrm{d}_{\mathrm{s}}\right)_{\max , \mathrm{c}}$ & $\begin{array}{c}\% \\
\text { Reduction } \\
\text { in max. } \\
\text { scour } \\
\text { depth }\end{array}$ \\
\hline R51 & 20 & 7.5 & -2 & 11.2 & 3.8 & $\mathbf{6 6 . 1}$ \\
R52 & 20 & 7.5 & -1 & 11.2 & 4.0 & 64.3 \\
R53 & 20 & 7.5 & \pm 0.0 & 11.2 & 7.6 & 32.1 \\
R54 & 20 & 7.5 & 1 & 11.2 & 7.9 & 29.5 \\
R55 & 20 & 7.5 & 2 & 11.2 & 9.2 & 17.9 \\
\hline R56 & 20 & 10 & -2 & 11.2 & 2.0 & 82.1 \\
R57 & 20 & 10 & -1 & 11.2 & 1.0 & 91.1 \\
R58 & 20 & 10 & \pm 0.0 & 11.2 & 1.0 & $\mathbf{9 1 . 1}$ \\
R59 & 20 & 10 & 1 & 11.2 & 8.5 & 24.1 \\
R60 & 20 & 10 & 2 & 11.2 & 9.4 & 16.5 \\
\hline R61 & 25 & 2.5 & -2 & 11.4 & 11.2 & $\mathbf{1 . 8}$ \\
R62 & 25 & 2.5 & -1 & 11.4 & 11.4 & 0.0 \\
R63 & 25 & 2.5 & \pm 0.0 & 11.4 & 11.5 & -0.9 \\
R64 & 25 & 2.5 & 1 & 11.4 & 11.4 & 0.0 \\
R65 & 25 & 2.5 & 2 & 11.4 & 11.5 & -0.9 \\
\hline R66 & 25 & 5 & -2 & 11.4 & 8.8 & $\mathbf{2 2 . 8}$ \\
R67 & 25 & 5 & -1 & 11.4 & 9.3 & 18.4 \\
R68 & 25 & 5 & \pm 0.0 & 11.4 & 10.9 & 4.4 \\
R69 & 25 & 5 & 1 & 11.4 & 10.8 & 5.3 \\
R70 & 25 & 5 & 2 & 11.4 & 11.4 & 0.0 \\
\hline R71 & 25 & 7.5 & -2 & 11.4 & 7.6 & $\mathbf{3 3 . 3}$ \\
R72 & 25 & 7.5 & -1 & 11.4 & 9.4 & 17.5 \\
R73 & 25 & 7.5 & \pm 0.0 & 11.4 & 8.3 & 27.2 \\
R74 & 25 & 7.5 & 1 & 11.4 & 8.1 & 28.9 \\
R75 & 25 & 7.5 & 2 & 11.4 & 11.5 & -0.9 \\
\hline & & & & & & \\
\hline
\end{tabular}


Table 5.2. Experimental data for $\mathrm{Q}=0.017 \mathrm{~m}^{3} / \mathrm{s}, \mathrm{y}=4.25 \mathrm{~cm}$ and $\mathrm{B}_{\mathrm{a}}=10 \mathrm{~cm}$ (continued)

\begin{tabular}{c|c|c|c|c|c|c}
\hline Run no & $\begin{array}{c}\mathrm{L}_{\mathrm{a}} \\
(\mathrm{cm})\end{array}$ & $\begin{array}{c}\mathrm{B}_{\mathrm{c}} \\
(\mathrm{cm})\end{array}$ & $\begin{array}{c}\mathrm{Z}_{\mathrm{c}} \\
(\mathrm{cm})\end{array}$ & $\left(\mathrm{d}_{\mathrm{s}}\right)_{\max }$ & $\left(\mathrm{d}_{\mathrm{s}}\right)_{\max , \mathrm{c}}$ & $\begin{array}{c}\% \\
\text { Reduction } \\
\text { in max. } \\
\text { scour } \\
\text { depth }\end{array}$ \\
\hline R76 & 25 & 10 & -2 & 11.4 & 2.0 & $\mathbf{8 2 . 5}$ \\
R77 & 25 & 10 & -1 & 11.4 & 6.3 & 44.7 \\
R78 & 25 & 10 & \pm 0.0 & 11.4 & 7.3 & 36.0 \\
R79 & 25 & 10 & 1 & 11.4 & 9.7 & 14.9 \\
R80 & 25 & 10 & 2 & 11.4 & 11.2 & 1.8 \\
\hline R81 & 35 & 2.5 & -2 & 13.2 & 12.9 & 2.3 \\
R82 & 35 & 2.5 & -1 & 13.2 & 12.9 & 2.3 \\
R83 & 35 & 2.5 & \pm 0.0 & 13.2 & 13.2 & 0.0 \\
R84 & 35 & 2.5 & 1 & 13.2 & 13.2 & 0.0 \\
R85 & 35 & 2.5 & 2 & 13.2 & 13.2 & 0.0 \\
\hline R86 & 35 & 5 & -2 & 13.2 & 12.4 & $\mathbf{6 . 1}$ \\
R87 & 35 & 5 & -1 & 13.2 & 12.5 & 5.3 \\
R88 & 35 & 5 & \pm 0.0 & 13.2 & 13.0 & 1.5 \\
R89 & 35 & 5 & 1 & 13.2 & 12.9 & 2.0 \\
R90 & 35 & 5 & 2 & 13.2 & 12.8 & 3.0 \\
\hline R91 & 35 & 7.5 & -2 & 13.2 & 11.0 & 16.7 \\
R92 & 35 & 7.5 & -1 & 13.2 & 10.9 & $\mathbf{1 7 . 4}$ \\
R93 & 35 & 7.5 & \pm 0.0 & 13.2 & 12.6 & 4.5 \\
R94 & 35 & 7.5 & 1 & 13.2 & 12.5 & 5.3 \\
R95 & 35 & 7.5 & 2 & 13.2 & 12.7 & 3.8 \\
\hline R96 & 35 & 10 & -2 & 13.2 & 9.4 & 28.8 \\
R97 & 35 & 10 & -1 & 13.2 & 8.6 & $\mathbf{3 4 . 8}$ \\
R98 & 35 & 10 & \pm 0.0 & 13.2 & 12.1 & 8.3 \\
R99 & 35 & 10 & 1 & 13.2 & 12.1 & 8.3 \\
R100 & 35 & 10 & 2 & 13.2 & 13.1 & 0.8 \\
\hline & & & & & &
\end{tabular}


In Figure 5.7 the overall effect of abutment length, collar width and the location of the collar on the reduction of maximum scour depth can be seen according to the results of this study. Figure 5.8 is provided to show the same graph for the Kayatürk's results (2005). Each line given in the figures corresponds to a constant $\mathrm{L}_{\mathrm{a}} / \mathrm{B}_{\mathrm{c}}$ value. $\mathrm{L}_{\mathrm{a}} / \mathrm{B}_{\mathrm{c}}$ values are stated on the figures. According to the plot of Kayatürk (2005), at small values of $L_{a} / B_{c}$ which is less than about 2.0, maximum reductions in scour depths are mainly obtained when the collars are located at the bed level, $\mathrm{Z}_{\mathrm{c}} / \mathrm{y}= \pm 0.0$. For greater values of $\mathrm{L}_{\mathrm{a}} / \mathrm{B}_{\mathrm{c}}$, maximum reduction in scour depths are mostly observed when the collars have the value of $Z_{c} / y=-0.50$. This figure also clearly shows that scour reduction capacity of a collar increases as the width of the collar increases, and decreases with increasing abutment length. Collars are generally more effective in reducing the scour depth around the abutment when they are located below the sand bed, $-0.50<\mathrm{Z}_{\mathrm{c}} / \mathrm{y}<-0.25$, compared to the cases of above the sand bed, $0.0<Z_{c} / y<0.50$, for the value of $L_{a} / B_{c}>2.0$. Trend lines of data points in Figure 5.8 also imply that at $Z_{\mathcal{c}} / y$ values less than -0.50 , higher reductions in the maximum scour depths around the abutments can be obtained than those given in the figure for $Z_{c} / y=-0.50$. For design purposes when the optimum value of $Z_{d} / y$ is required, the one close to the bed level but having adequate scour reduction capacity should be selected (Kayatürk, 2005). When the Figure 5.7 is taken into account, it is obvious that the trends and results are similar. The behaviour is the same with the Kayatürk's (2005) results in the beginning. At small values of $L_{a} / B_{c}$, which is less than and equal to 2.0, maximum reductions in scour depths are mainly obtained when the collars are located at the bed level, $\mathrm{Z}_{\mathrm{c}} / \mathrm{y}= \pm 0.0$. For the range of $\mathrm{L}_{\mathrm{a}} / \mathrm{B}_{\mathrm{c}}$ between $(2$, 5), the maximum reduction in the scour depths is observed for $Z_{\mathcal{c}} / y$ values inbetween $[-0.24,-0.47]$. But, it has a fluctuating behaviour. For the $\mathrm{L}_{\mathrm{a}} / \mathrm{B}_{\mathrm{c}}$ values greater than 
and equal to 5 , the optimum $Z_{c} / y$ occurs at $Z_{d} / y=-0.47$, which is similar to the results of Kayatürk (2005). One additional observation can be summarized as the increase in the collar width increases the scour reduction performance of the collar, whereas the increase in the abutment length decreases this efficiency. This holds true for both studies. The Figures 5.7 and 5.8 are given in the next pages. 


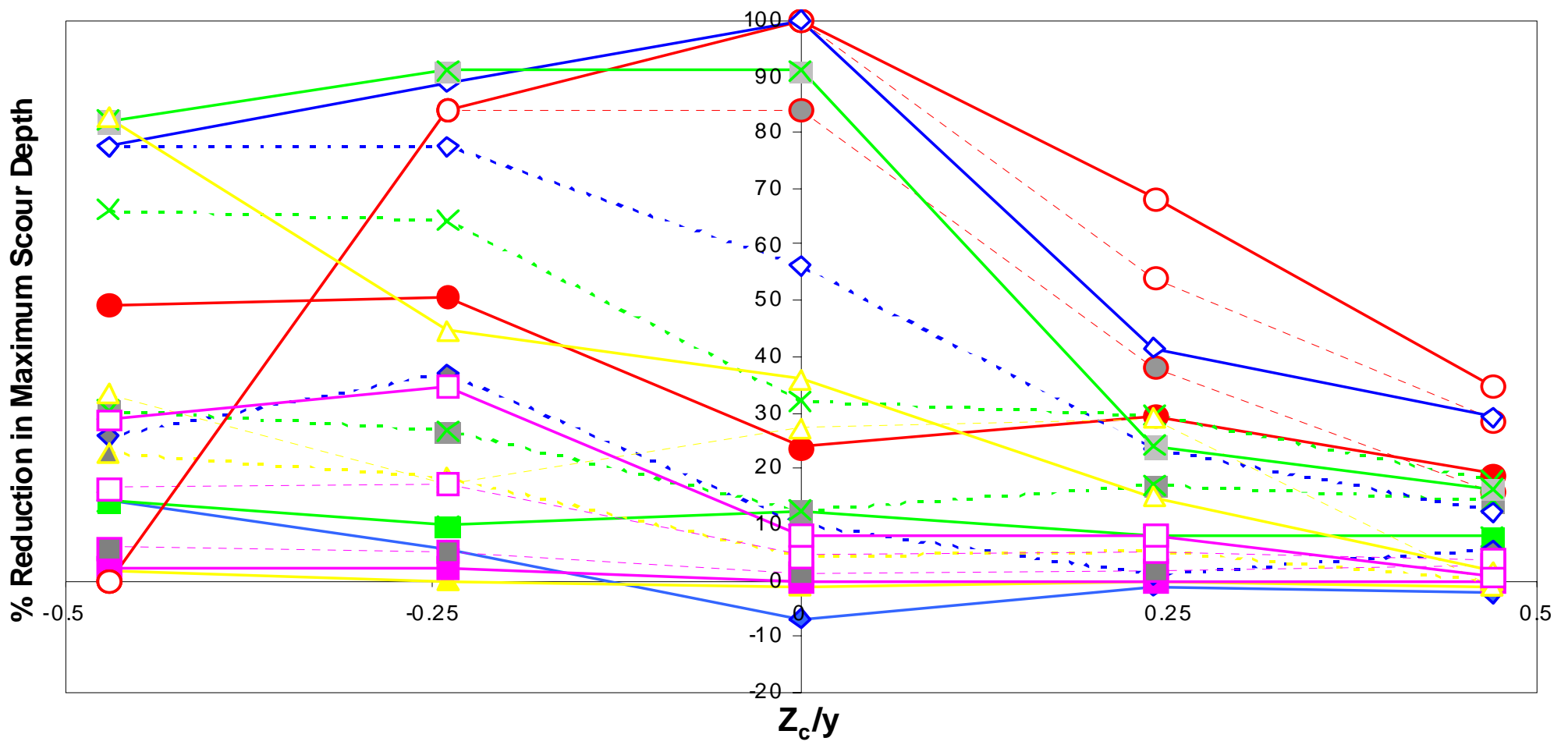

$\mathrm{L}_{\mathrm{a}}=7.5 \mathrm{~cm}, \mathrm{~L}_{\mathrm{a}} / \mathrm{B}_{\mathrm{c}} \quad \mathrm{L}_{\mathrm{a}}=15 \mathrm{~cm}, \mathrm{~L}_{\mathrm{a}} / \mathrm{B}_{\mathrm{c}} \quad \mathrm{L}_{\mathrm{a}}=20 \mathrm{~cm}, \mathrm{~L}_{\mathrm{a}} / \mathrm{B}_{\mathrm{c}} \quad \mathrm{L}_{\mathrm{a}}=25 \mathrm{~cm}, \mathrm{~L}_{\mathrm{a}} / \mathrm{B}_{\mathrm{c}} \quad \mathrm{L}_{\mathrm{a}}=35 \mathrm{~cm}, \mathrm{~L}_{\mathrm{a}} / \mathrm{B}_{\mathrm{c}}$

\begin{tabular}{|c|c|c|c|c|}
\hline-3.0 & $\approx-6.0$ & -8.0 & -10.0 & $\longrightarrow-14.0$ \\
\hline$--0-1.5$ & $\cdots \infty \cdot-3.0$ & $=--4.0$ & $=\Delta-5.0$ & $--\square--7.0$ \\
\hline$--0-1.0$ & $-\diamond \cdots-2.0$ & $--x=-2.7$ & $-\quad 3.3$ & $--\square^{--4.7}$ \\
\hline$-0-0.8$ & $\checkmark-1.5$ & $-x-2.0$ & $\Delta-2.5$ & $-\square-3.5$ \\
\hline
\end{tabular}

Figure 5.7. Effect of collar size and elevation on the maximum scour depth around the abutments of various lengths $\left(\mathrm{Q}=0.017 \mathrm{~m}^{3} / \mathrm{s}, \mathrm{y}=4.25 \mathrm{~cm}, \mathrm{~d}_{50}=0.90 \mathrm{~mm}\right)$ 


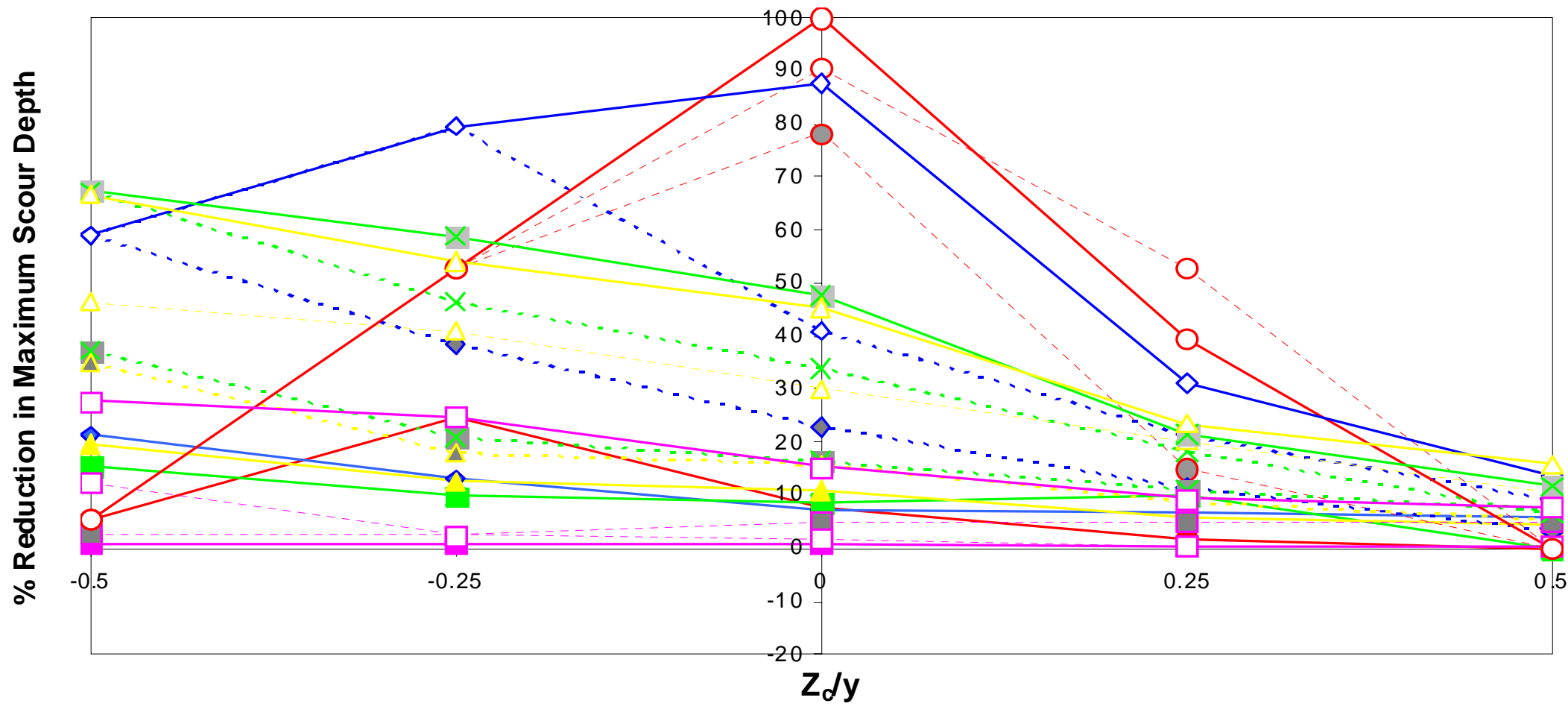

$\mathrm{L}_{\mathrm{a}}=7.5 \mathrm{~cm}, \mathrm{~L}_{\mathrm{a}} / \mathrm{B}_{\mathrm{c}} \quad \mathrm{L}_{\mathrm{a}}=15 \mathrm{~cm}, \mathrm{~L}_{\mathrm{d}} / \mathrm{B}_{\mathrm{c}} \mathrm{L}_{\mathrm{a}}=20 \mathrm{~cm}, \mathrm{~L}_{\mathrm{a}} / \mathrm{B}_{\mathrm{c}} \quad \mathrm{L}_{\mathrm{a}}=25 \mathrm{~cm}, \mathrm{~L}_{\mathrm{a}} / \mathrm{B}_{\mathrm{c}} \quad \mathrm{L}_{\mathrm{a}}=35 \mathrm{~cm}, \mathrm{~L}_{\mathrm{a}} / \mathrm{B}_{\mathrm{c}}$

\begin{tabular}{|c|c|c|c|c|}
\hline-3.0 & $\approx 6.0$ & $-7-8.0$ & 10.0 & -14.0 \\
\hline$--0--1.5$ & $--\diamond--3.0$ & ---4.0 & -5.0 & $--\square--7.0$ \\
\hline$--0--1.0$ & $\because \diamond \cdot-2.0$ & $=-x=-2.7$ & 3.0 & $--\square--4.7$ \\
\hline-0.8 & $\sim-1.5$ & $\longrightarrow x-2.0$ & $\Delta$ & $\square \square-3.5$ \\
\hline
\end{tabular}

Figure 5.8. Effect of collar size and elevation on the maximum scour depth around the abutments of various lengths $\left(\mathrm{Q}=0.050 \mathrm{~m}^{3} / \mathrm{s}, \mathrm{y}=10 \mathrm{~cm}, \mathrm{~d}_{50}=1.48 \mathrm{~mm}\right)($ Kayatürk, 2005) 
From Table 5.2 given previously, the locations of the collar having the best scour reduction efficiency for each abutment lengths and collar widths are chosen and presented in Table 5.3 along with the corresponding values of $\left\lfloor\left(d_{s}\right)_{\max , c} / y\right\rfloor_{\text {opt }}$ and $\left[Z_{c} / y\right]_{o p t}$. In this table, $\theta$ depicts ratio of the total area of the abutment and collar to the abutment area on horizantal plane. That is:

$\theta=\frac{L_{c} B_{t}}{L_{a} B_{a}}=\frac{A_{\text {total }}}{A_{\text {abutment }}}$

$\theta$, simply shows how big the collar is when compared to the area of the abutment (Kayatürk, 2005). For comparison, the results obtained in this study and in Kayatürk's study (2005) are presented together for convenience. 
Table 5.3. Optimum design parameters of an abutment-collar arrangement

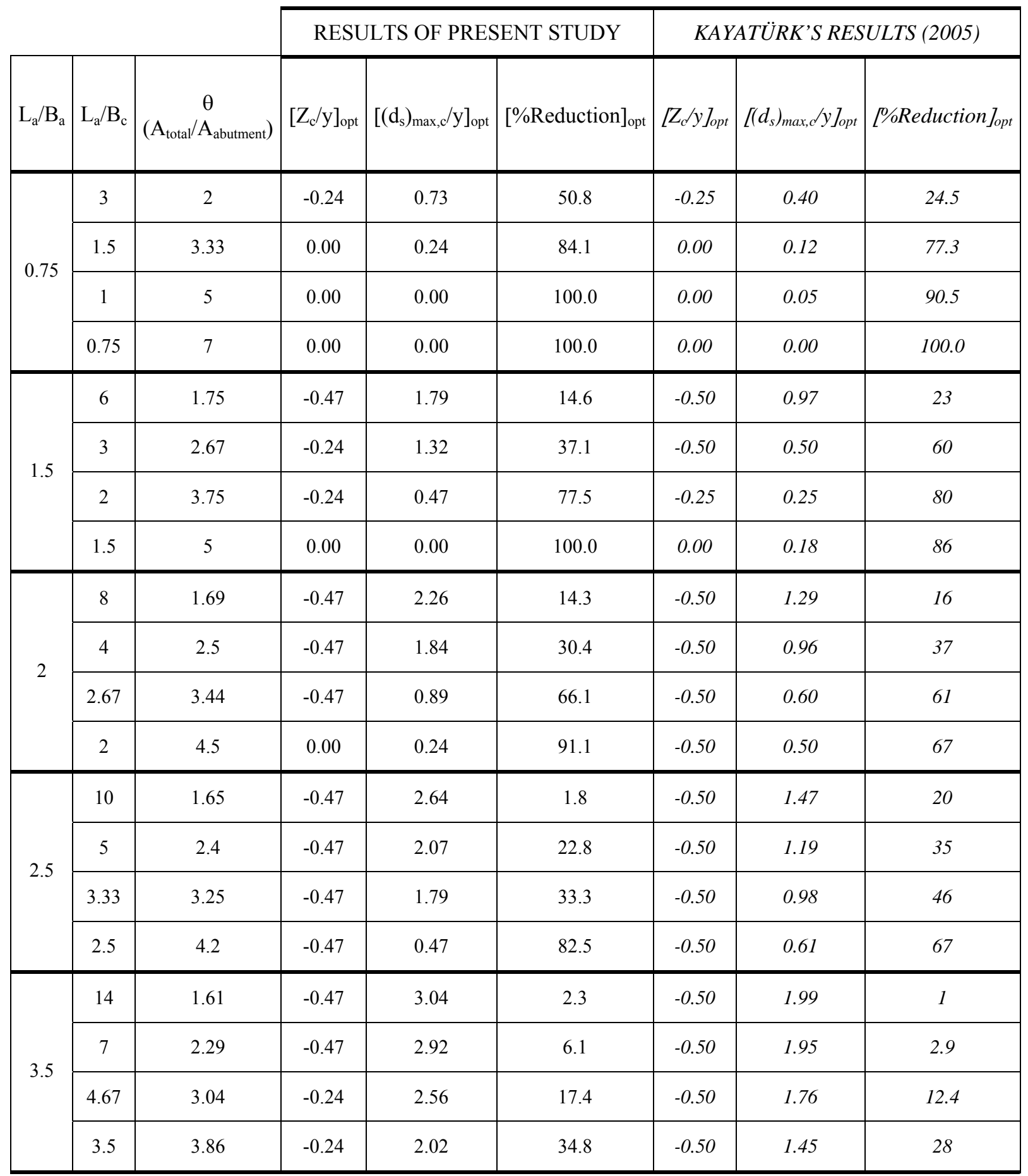


Variation of $\left[\left(\mathrm{d}_{\mathrm{s}}\right)_{\max , \mathrm{c}} / \mathrm{y}\right]_{\text {opt }}$ versus $\theta$ values are shown in Figure 5.9 with $\mathrm{L}_{\mathrm{a}} / \mathrm{B}_{\mathrm{a}}$ as a third parameter. The same plot is presented for the Kayatürk's study (2005) in Figure 5.10 for comparison. On data points corresponding $\left(\mathrm{Z}_{\mathrm{c}} / \mathrm{y}\right)_{\mathrm{opt}}$ values are also given. $\left[\left(d_{s}\right)_{\max , c} / y\right]_{\text {opt }}$ values show a decreasing trend with increasing $\theta$ values for a given value of $L_{a} / B_{a}$. For a given abutment and collar size, the optimum location of the collar and the corresponding maximum scour depths can be computed easily from these Figures for the two different sediment sizes. For instance, in both Figures 5.9 and 5.10, if $\theta$ value is selected as 7 for an abutment of $L_{a} / B_{a}=0.75$, expected scour depth is determined as zero for both sediment sizes of $1.48 \mathrm{~mm}$ and $0.90 \mathrm{~mm}$. But, the situation changes for values of $\theta$ less than about 4 . For an abutment of $L_{a} / B_{a}=2.0$ having a $\theta$ value of 3.44 , the expected scour depth is found to be $(0.89 . y)$ for the sediment size of $0.90 \mathrm{~mm}$ in Figure 5.9, whereas it is $(0.60 . \mathrm{y})$ for the sediment size of $1.48 \mathrm{~mm}$ in Figure 5.10. From the comparison of these two figures, it can be concluded that $\left[\left(\mathrm{d}_{\mathrm{s}}\right)_{\max , \mathrm{c}} / \mathrm{y}\right]_{\text {opt }}$ ratios of the present study is generally greater than the ratios obtained in Kayatürk's one (2005). 


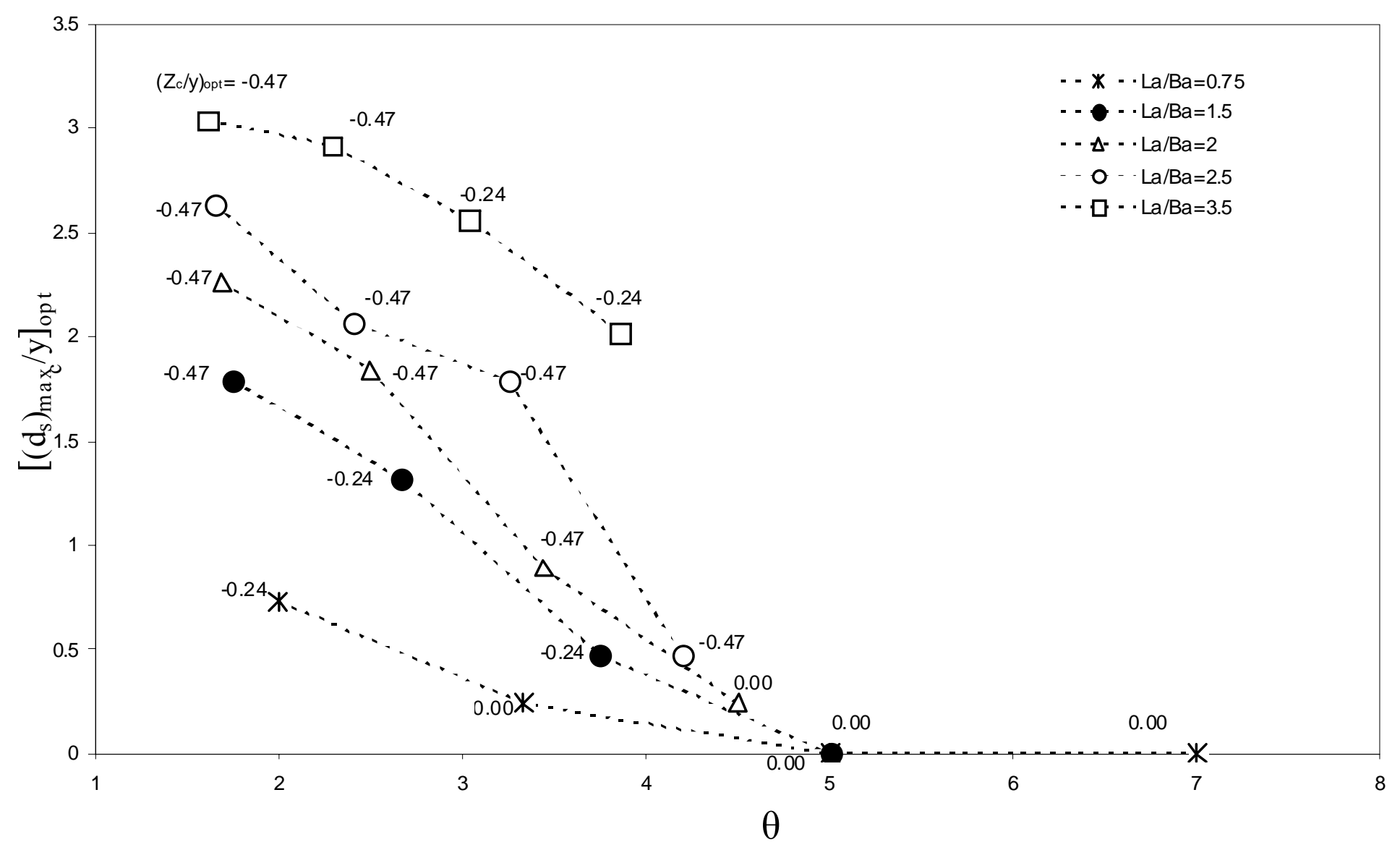

Figure 5.9. Variation of $\left\lfloor\left(d_{s}\right)_{\max , c} / y\right\rfloor_{\text {opt }}$ with $\theta\left(\mathrm{Q}=0.017 \mathrm{~m}^{3} / \mathrm{s}, \mathrm{y}=4.25 \mathrm{~cm}, \mathrm{~F}_{\mathrm{r}}=0.41, \mathrm{U} * / \mathrm{U}_{* \mathrm{c}}=0.90, \mathrm{~d}_{50}=0.90 \mathrm{~mm}\right)$ 


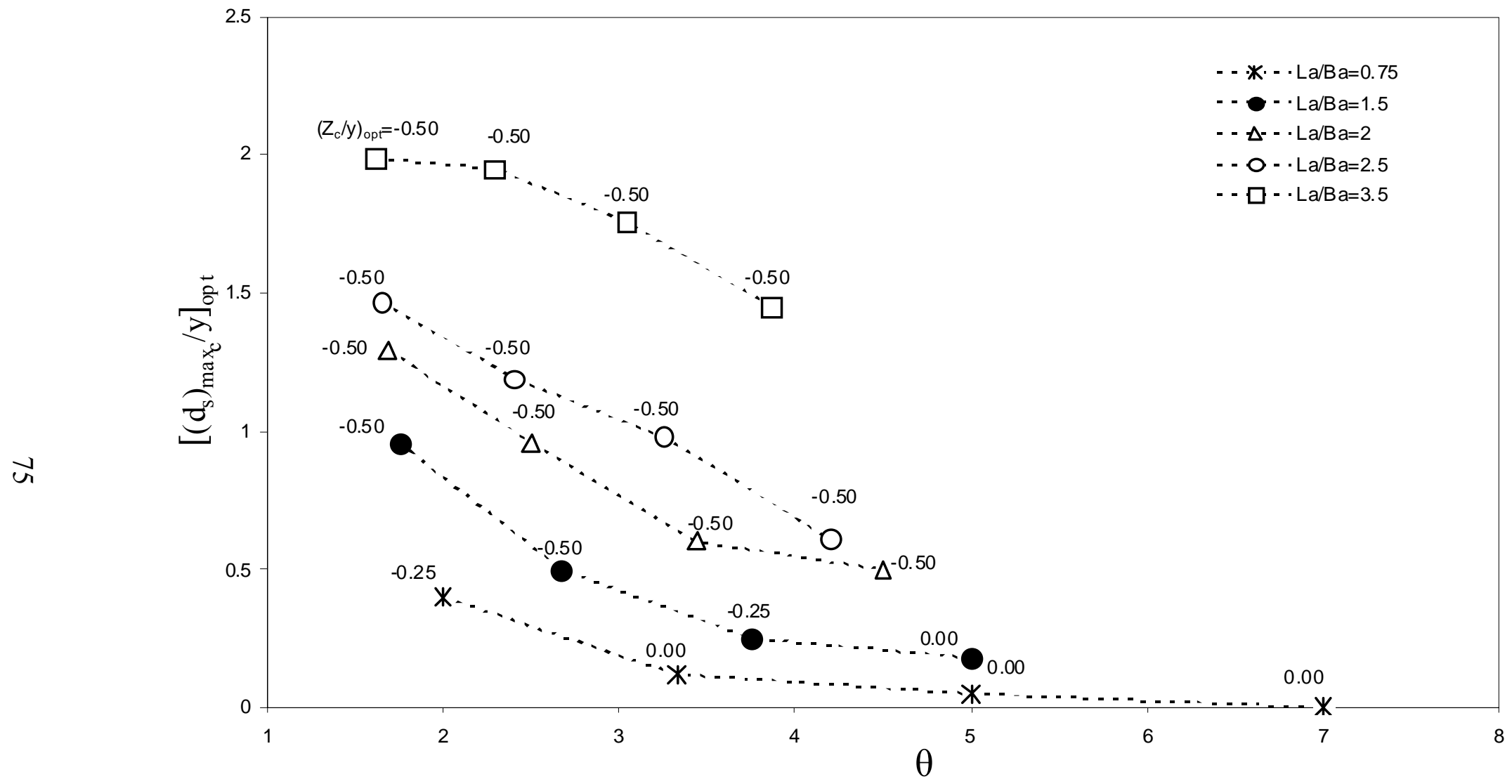

Figure 5.10. Variation of $\left[\left(d_{s}\right)_{\max , c} / y\right\rfloor_{\text {opt }}$ with $\theta\left(\mathrm{Q}=0.050 \mathrm{~m}^{3} / \mathrm{s}, \mathrm{y}=10 \mathrm{~cm}, \mathrm{~F}_{\mathrm{r}}=0.34, \mathrm{U} * / \mathrm{U}_{*}=0.90, \mathrm{~d}_{50}=1.48 \mathrm{~mm}\right)$ (Kayatürk, 2005) 
An alternative figure to Figure 5.9 is Figure 5.11 in which the parameter on the horizantal axis is $\theta^{0.5}\left(L_{a} / B_{c}\right)^{0.5}$ instead of $\theta$. In this Figure, as seen, the data points of the present study and that belongs to Kayatürk (2005) can be considered as collected around a straight line instead of grouping as a function of $\mathrm{L}_{\mathrm{a}} / \mathrm{B}_{\mathrm{a}}$. Referring to this Figure one can estimate the $\left[\left(\mathrm{d}_{\mathrm{s}}\right)_{\max , \mathrm{c}} \mathrm{y}\right]_{\text {opt }}$ value of an abutment of known $\mathrm{L}_{\mathrm{a}}$, $\mathrm{B}_{\mathrm{c}}$ and $\theta$ within the range of parameters used in both studies.

To determine the optimum locations of the collars for known values of $\mathrm{L}_{a} / \mathrm{B}_{\mathrm{c}}$, the data of $\left[Z_{c} / y\right]_{\text {opt }}$ given in Table 5.3 for both studies are plotted versus $L_{a} / B_{c}$ in Figure 5.12. From this Figure the following classification for $\mathrm{L}_{\mathrm{a}} / \mathrm{B}_{\mathrm{c}}$ and $\left[\mathrm{Z}_{\mathrm{c}} / \mathrm{y}\right]_{\text {opt }}$ can be proposed for the present study:

$$
\begin{array}{ll}
{\left[\mathrm{Z}_{\mathrm{c}} / \mathrm{y}\right]_{\text {opt }}=0} & \text { for } \mathrm{L}_{\mathrm{a}} / \mathrm{B}_{\mathrm{c}} \leq 2.0 \\
-0.47 \leq\left[\mathrm{Z}_{\mathrm{c}} / \mathrm{y}\right]_{\mathrm{opt}} \leq-0.24 & \text { for } 2.0<\mathrm{L}_{\mathrm{a}} / \mathrm{B}_{\mathrm{c}}<5.0 \\
{\left[\mathrm{Z}_{\mathrm{c}} / \mathrm{y}\right]_{\text {opt }}=-0.47} & \text { for } 5.0 \leq \mathrm{L}_{\mathrm{a}} / \mathrm{B}_{\mathrm{c}} \leq 14.0
\end{array}
$$

And for the Kayatürk's one (2005):

$$
\begin{array}{ll}
{\left[\mathrm{Z}_{\mathrm{c}} / \mathrm{y}\right]_{\mathrm{opt}}=0} & \text { for } \mathrm{L}_{\mathrm{a}} / \mathrm{B}_{\mathrm{c}}<2.0 \\
-0.50 \leq\left[\mathrm{Z}_{\mathrm{c}} / \mathrm{y}\right]_{\mathrm{opt}} \leq-0.25 & \text { for } 2.0 \leq \mathrm{L}_{\mathrm{a}} / \mathrm{B}_{\mathrm{c}} \leq 3.0 \\
{\left[\mathrm{Z}_{\mathrm{c}} / \mathrm{y}\right]_{\mathrm{opt}}=-0.50} & \text { for } 3.0<\mathrm{L}_{\mathrm{a}} / \mathrm{B}_{\mathrm{c}} \leq 14
\end{array}
$$

The above relations are valid within the range of $\mathrm{L}_{\mathrm{a}} / \mathrm{B}_{\mathrm{c}}$ between 0.75 and 14 . 


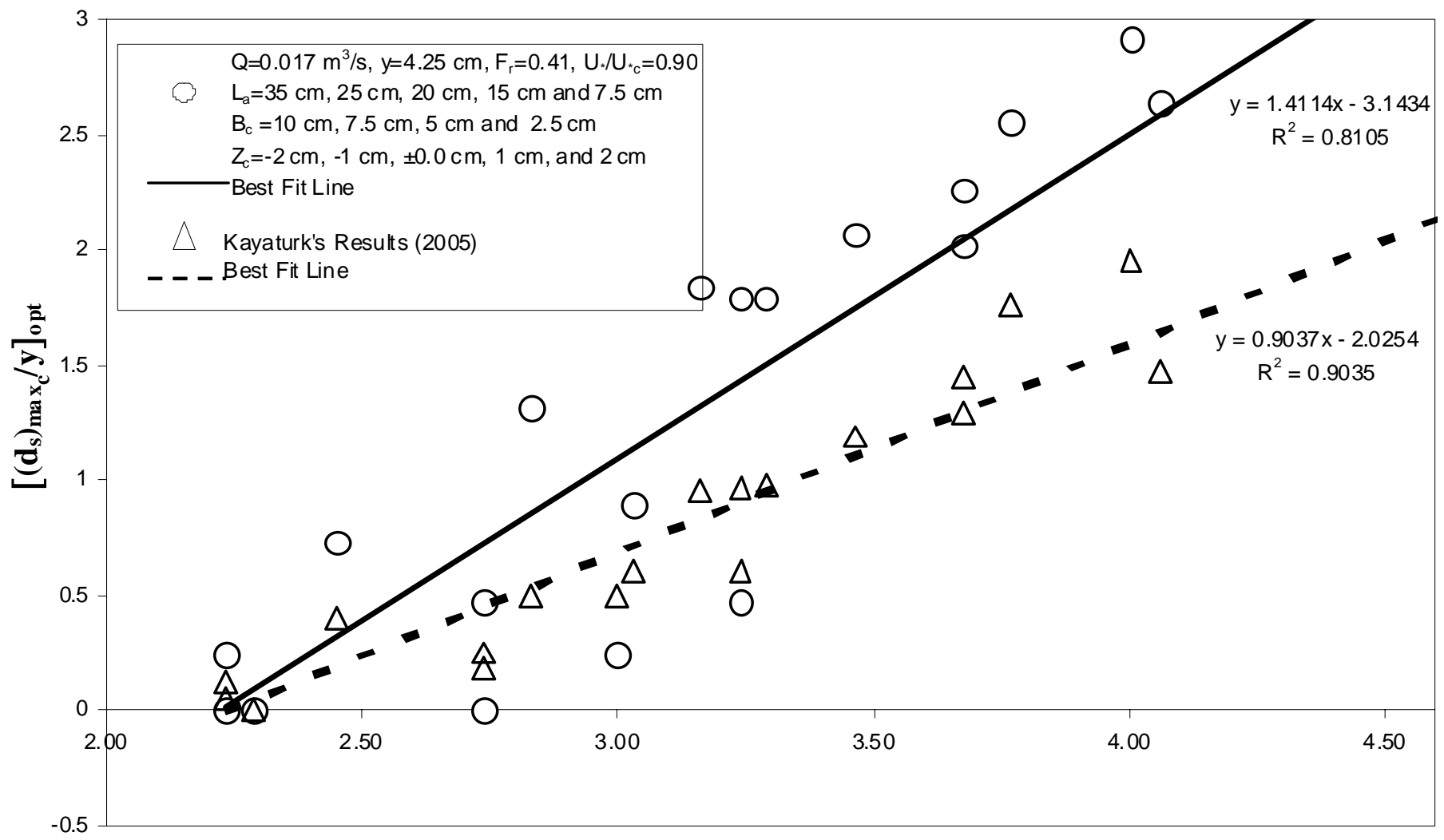

$$
\sqrt{\theta\left(L_{a} / B_{c}\right)}
$$

Figure 5.11. Variation of $\left\lfloor\left(d_{s}\right)_{\max , c} / y\right\rfloor_{o p t}$ with $\sqrt{\theta\left(L_{a} / B_{c}\right)}$ 


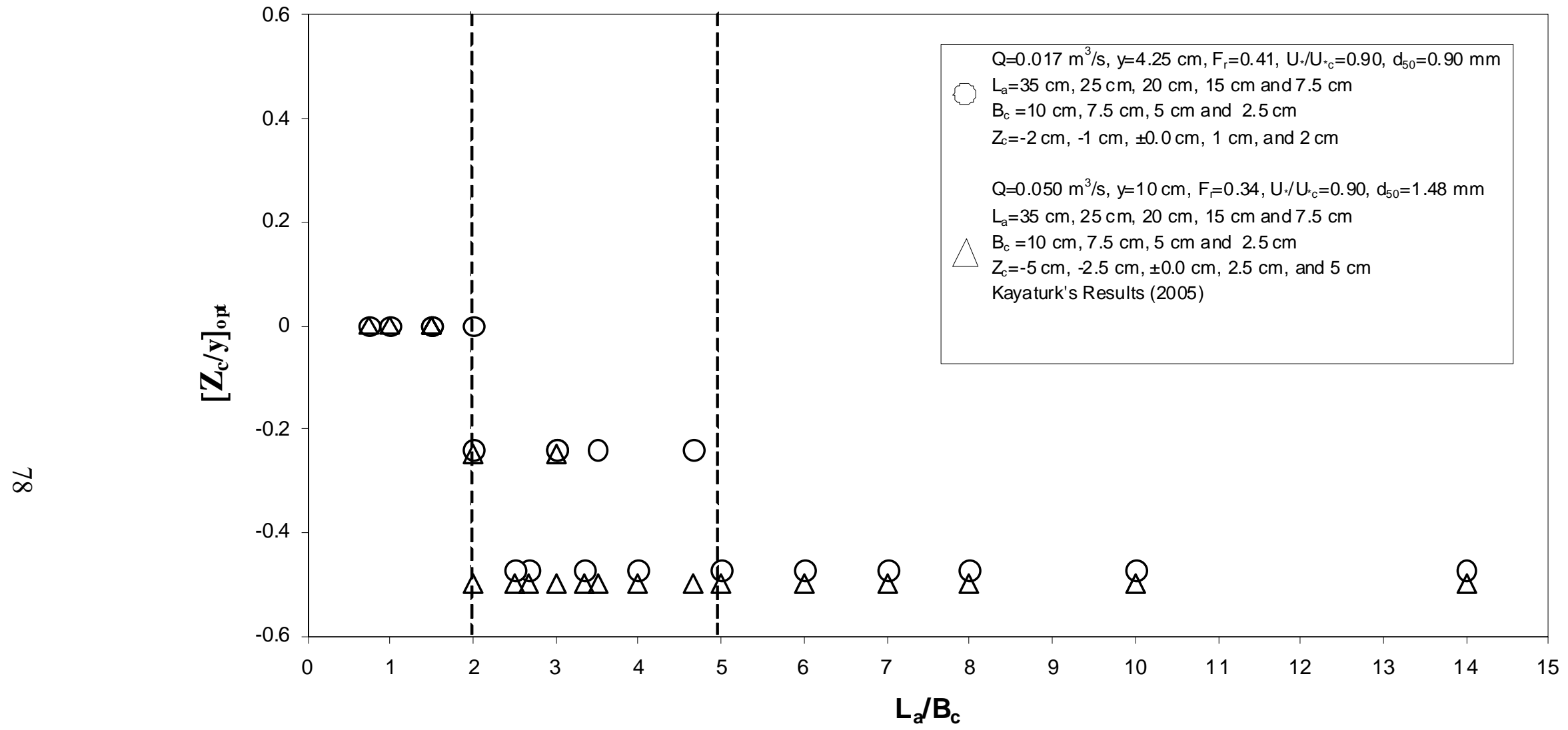

Figure 5.12. Variation of $\left[\mathrm{Z}_{\mathrm{c}} / \mathrm{y}\right]_{\text {opt }}$ with $\mathrm{L}_{\mathrm{a}} / \mathrm{B}_{\mathrm{c}}$ 
Figure 5.13 shows the variation of $[\% \text { Reduction }]_{\text {opt }}$ with $L_{a} / B_{c}$ (Table 5.3) for the data of both studies. In the figure it is seen that the best fit lines drawn for all data sets almost coincide to each other. This means that after determining the optimum location of the collar from Figure 5.12 for a given $\mathrm{L}_{\mathrm{a}} / \mathrm{B}_{\mathrm{c}}$, one can also estimate the corresponding [\%Reduction $]_{\mathrm{opt}}$ from Figure 5.13. Consequently, the scour reduction percentages for both sediment sizes are very close to each other. Referring to this figure it can be concluded that to have at least $20 \%$ reduction in the maximum scour depth around an abutment, the $\mathrm{L}_{\mathrm{a}} / \mathrm{B}_{\mathrm{c}}$ value of the abutment must be less than 6 , while this value would be less than about 2 to have at least $60 \%$ reduction for the Kayatürk's data set (2005). The results for the present data set are almost the same. 


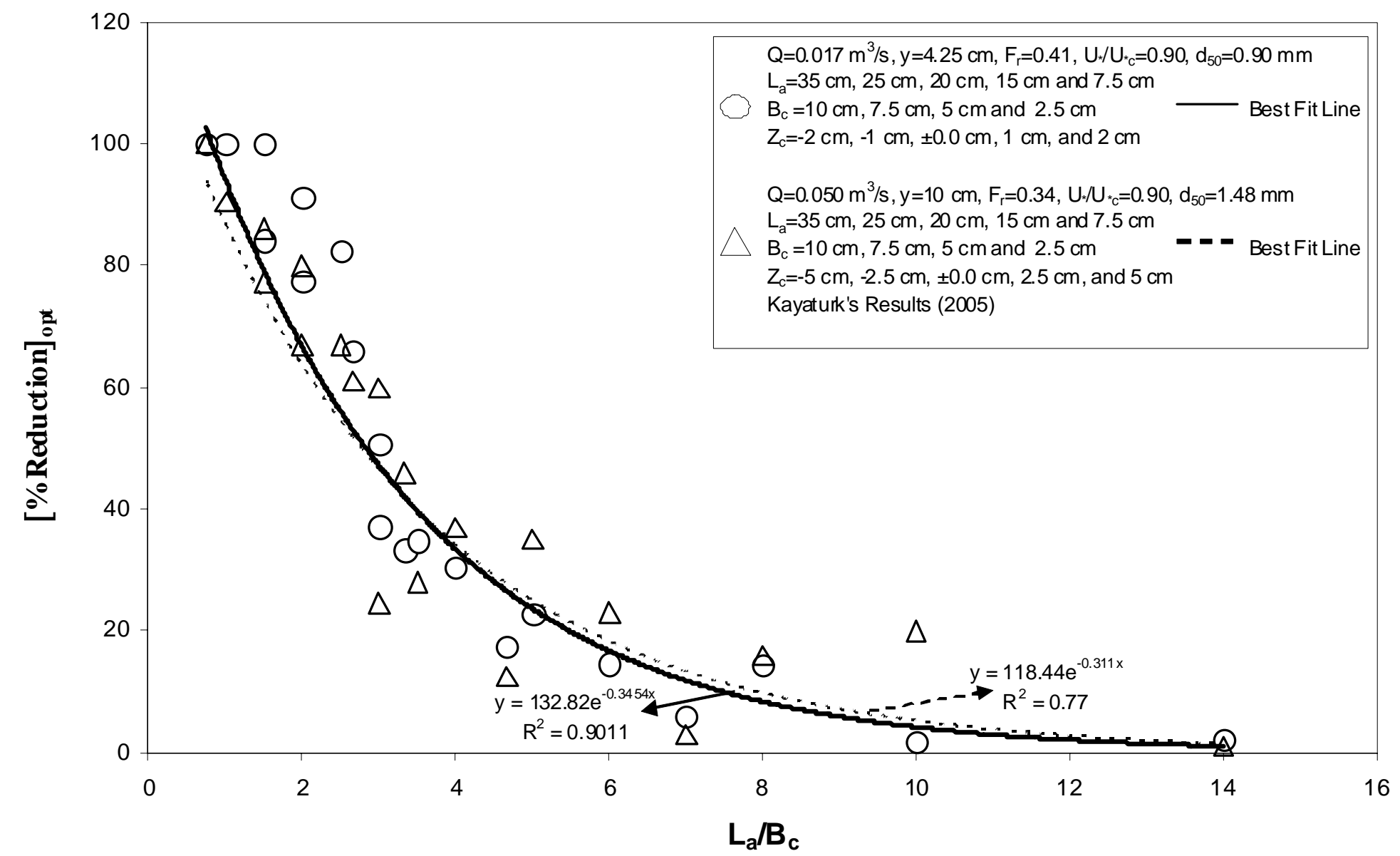

Figure 5.13. Variation of [\%Reduction $]_{\text {opt }}$ with $\mathrm{L}_{\mathrm{a}} / \mathrm{B}_{\mathrm{c}}$ 


\subsection{CONCLUSIONS}

A collar prevents the sediment particles at the bottom of an abutment from erosion by down flow. Efficiency of a collar for preventing scour is a function of its size and its vertical location on the abutment. As the size of the collar increases the scour depth decreases. But, increasing abutment lengths reduce the performance of a collar.

In Kayatürk's study (2005), if $\mathrm{L}_{\mathrm{a}} / \mathrm{y}>1$, the efficiency of the collar increases with decreasing $\mathrm{L}_{\mathrm{a}} / \mathrm{B}_{\mathrm{c}}$. Also, the elevation of the collar shifts in the downward direction from the bed level for increasing $L_{a} / B_{c}$, as long as the clear water flow conditions are satisfied, regardless of the flow depth, that is $\mathrm{U}_{*} / \mathrm{U}_{*_{\mathrm{c}}}=0.90$. If $\mathrm{L}_{\mathrm{a}} / \mathrm{y}<1$, the collar, which is placed at the bed level $\left(Z_{\mathcal{C}} / y= \pm 0.00\right)$, gives higher performance than those having other $Z_{\mathrm{c}} / y$ values. In this study, all of the experiments satisfy the condition of $\mathrm{L}_{\mathrm{a}} / \mathrm{y}>1$ for all the abutment lengths, which were used. Accordingly, the result derived by Kayatürk (2005) is also satisfied by the results of this study, that is, the efficiency of the collar increases with decreasing $L_{a} / B_{c}$ and the elevation of the collar shifts in the downward direction from the bed level for increasing $L_{a} / B_{c}$, as long as the clear water flow conditions are satisfied, regardless of the flow depth, that is $\mathrm{U} * / \mathrm{U}_{*_{\mathrm{c}}}=0.90$. In other words, according to the general trends, the experiments conducted with a grain size diameter of $0.90 \mathrm{~mm}$ provide almost the same results of the expriments conducted with a grain size diameter of $1.48 \mathrm{~mm}$ by Kayatürk (2005). In both studies the optimum location of the collar on the abutment, $\left(Z_{\mathrm{c}} / \mathrm{y}\right)_{\mathrm{opt}}$, which will yield the maximum reduction in the scour is almost the same for a given $L_{a} / B_{c}$ within the ranges tested. 


\section{REFERENCES}

- Barbhuiya, A. K., and Dey, S., (2004). Local Scour at Abutments: A Review. Sadhana. Vol. 29, Part 5, 449-476.

- Borghei, S. M., and Nazari, A., (2004). Experimental Investigation of $\underline{\text { Sediment Pattern in River Confluence. }} 6^{\text {th }}$ International Civil Engineering Conference, Isfahan Technical Unversity, Isfahan, Iran, pp: 247-255.

- Breusers, H. N. C., and Raudkivi, A. J., (1991). Scouring. A.A. Balkema, Rotterdam, Brookfield.

- Breusers, H. N. C., Nicollet, G., and Shen, H. W., (1977). Local Scour Around Cylindrical Piers. J.of Hydr. Research, Vol. 15, No. 3, 211-252.

- Chabert, J. and Engeldinger, P., (1956). Etude des affouillements autour des piles de points (Study of scour at bridge piers). Bureau Central d.Etudes les Equipment d.Outre-Mer, Laboratoire National d.Hydraulique, France.

- Chiew, Y. M., (1992). Scour Protection at Bridge Piers. J. of Hydr. Engrg, Vol. 118, No. 9, 1260-1269. 
- Dargahi, B., (1990). Controlling Mechanism of Local scouring. J. of Hydr. Engrg, Vol. 116, No. 10, 1197-1214.

- Ettema, R., Nakato, T., and Muste, M., (2003). An Overview of Scour Types and Scour-Estimation Difficulties Faced at Bridge Abutments. Proceedings of the 2003 Mid-Continent Transportation Research Symposium, Ames, Iowa.

- Federal Highway Adminisration, New Jersey (2005). Handbook of Scour Countermeasures Designs. Report No. 49777-11-04, U. S.

- Federal Highway Adminisration, (2004). Enhanced Abutment Scour Studies for Compound Channels. U.S. Department of Transportation, Publication No. FHWA RD 99-156, U. S.

- Federal Highway Adminisration, (2001). Bridge Scour and Stream Instability Countermeasures. National Highway Institute, Publication No. FHWA NHI 01-003, HEC No. 23, U. S.

- Federal Highway Adminisration, (2001). Evaluating Scour At Bridges. National Highway Institute, Publication No. FHWA NHI 01-001, HEC No. 18 , U. S.

- Federal Highway Adminisration, (1973). Hydraulics of Bridge Waterways. 
- Gill, M. A., (1972). Erosion of Sand Beds Around Spur-Dikes. J. of the Hydr. Division Proceedings of the American Society of Civil Engineers, Vol. 98, No. $9,1587-1602$.

- Gill, M. A., (1970). Bed Erosion Around Obstructions In Rivers. Ph.D thesis, The University of London (Imperial College of Science and Technology).

- Kandasamy, J. K., and Melville, B. W., (1998). Maximum Local Scour Depth at Bridge Piers and Abutments. J. of Hydr. Eng., Vol. 36, No. 2, 183-198.

- Kapoor, B. S., and Keana, C. M., (1994). Experimental Overview to Mechanism of Scour Around A Round Nosed Pier and Effect of Delta Wing

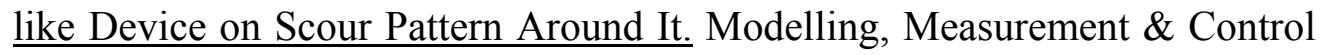
C: Energetics, Chemistry, Earth, Environmental \& Biomedical Problems, v46, Issue number: n3, 1994, p 25-44, AMSE Press, Tassin-la-Demi-Lune, Fr.

- Kayatürk, Ş.Y., (2005). Scour and Scour Protection at Bridge Abutments. Thesis presented to Middle East Technical University, Ankara, Turkey, in partial fulfillment of the requirements for the degree of Doctor of Philosophy.

- Kumar, V., Raju, K. G. R., and Vittal, N., (1997). Reduction of Local Scour Around Bridge Piers Using Slots and Collars. J. of Hydr. Eng., Vol. 125, No. $12,1302-1305$. 
- Laursen, E.M., (1952). Observation on the Nature of Scour. Proceedings, 5th Hydraulics Conference, Iowa.

- Li, H., Kuhnle, R. A., and Barkdoll, B. D. (2006). Countermeasures Against

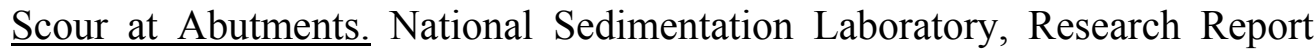
No. 49., U.S.

- Liu, M. K., Chang, F. M., Skinner, M. M., (1961). Effect of Bridge Construction on Scour and Backwater. Report No. CER60-HKL22, Department of Civil Engineering, Colorado State University, Fort Collins, Colorado.

- Mashahir, M. B. and Zarrati, A. R., (2002). Effect of Collar on Time Development of Scouring around Rectangular Bridge Piers. The $5^{\text {th }}$ International Conference on Hydro Science and Engineering, Warsaw, Poland.

- Melville, B. W., (1992). Local Scour at Bridge Abutments. J. of Hydr. Eng., Vol. 118, No. 4, 615-631.

- Oliveto, G., and Hager, W. H., (2002). Temporal Evolution of Clear-Water Pier and Abutments Scour. J. of Hydr. Eng., Vol. 128, No. 9, 811-820. 
- Shirhole, A. M., and Holt, R. C., (1991). Planning for a Comprehensive Bridge Safety Program. Transportation Research Record 1290, Transportation Research Board, National Research Council, Washington, D.C., 1, 39-50.

- Singh, C. P., Setia, B. and Verma, D. V. S., (2001). Collar-Sleeve Combination as a Scour Protection Device Around a Circular Pier. XXIX IAHR Congress Proceedings, Beijing, China, Vol. 2, 202-210.

- Sümer, B., Roulund, A., Fredsoe, J., and Michelsen, J., (2002). 3-D Numerical Modeling of Flow and Scour around a Pile. First International Conference on Scour of Foundations, ICSF-1, College Station, Texas, 17-20 Nov, Vol. 2, pp. 795-809.

- Tey, C. B., (1984). Local Scour at Bridge Abutments. Report No. 329, University of Auckland, School of T. Engineering, Department of Civil Engineering Private Bag, Auckland, New Zealand.

- Wardhana, K., and Hadipriono, F. C., (2003). Analysis of Recent Bridge Failures in the United States. J.of Performance of Constructed Facilities, ASCE.

- Zarrati, A. R., Gholami, H. and Mashahir, M. B., (2004). Application of Collar to Control Scouring Around Rectangular Bridge Piers. J. Hydr. Research, Vol. 42, No. 1, 97-103. 
APPENDIX

Table A.1 - Cross-sections (profiles) of the scour hole for $L_{a}=7.5 \mathrm{~cm}$

\begin{tabular}{|c|c|c|c|c|c|c|c|c|c|c|c|}
\hline \multicolumn{12}{|c|}{ Scour Depth for $\mathrm{L}_{\mathrm{a}}=7.5 \mathrm{~cm}(\mathrm{~cm})$} \\
\hline \multirow{3}{*}{$\begin{array}{c}X \\
(\mathrm{~cm})\end{array}$} & \multirow{3}{*}{ WithoutCollar } & \multicolumn{5}{|c|}{$\mathrm{B}_{\mathrm{c}}=10 \mathrm{~cm}$} & \multirow{2}{*}{\multicolumn{5}{|c|}{$\mathrm{B}_{\mathrm{c}}=7.5 \mathrm{~cm}$}} \\
\hline & & \multicolumn{5}{|c|}{$\mathrm{Z}_{\mathrm{c}}(\mathrm{cm})$} & & & & & \\
\hline & & -2 & -1 & 0 & 1 & 2 & -2 & -1 & 0 & 1 & 2 \\
\hline \multicolumn{12}{|l|}{-84} \\
\hline \multicolumn{12}{|l|}{-82} \\
\hline \multicolumn{12}{|l|}{-80} \\
\hline \multicolumn{12}{|l|}{-78} \\
\hline-76 & & \multirow{48}{*}{ 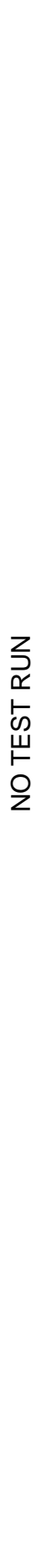 } & & & & & \multirow{48}{*}{ 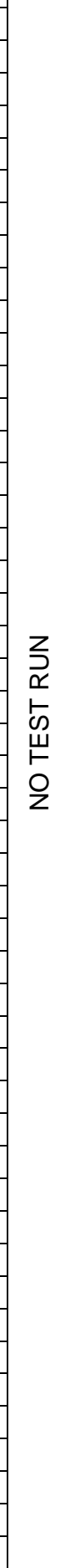 } & & 0 & 0 & \\
\hline-74 & & & & & & & & & 0 & 0.55 & \\
\hline-72 & & & 0 & & & & & & 0 & 0.55 & \\
\hline-70 & & & 0 & & & & & & 0 & 0.1 & \\
\hline-68 & & & 0 & & & & & -0.2 & 0 & 0.1 & \\
\hline-66 & & & 0.7 & & & & & 0.35 & 0 & 0.1 & \\
\hline-64 & & & 1.3 & & & & & 1.6 & 0 & 0.1 & \\
\hline-62 & & & 1.8 & & & & & 2 & 0 & 0.1 & \\
\hline-60 & & & 2.25 & & & & & 2 & 0 & -0.1 & \\
\hline-58 & & & 2.5 & & & & & 2.1 & 0 & -0.1 & \\
\hline-56 & & & 2.5 & & & & & 2.1 & 0 & -0.1 & \\
\hline-54 & & & 2.5 & & & & & 2.1 & 0 & -0.1 & \\
\hline-52 & 0 & & 2.5 & & & & & 2.2 & 0 & -0.1 & \\
\hline-50 & 0.55 & & 2.5 & & & & & 2.2 & 0 & -0.1 & \\
\hline-48 & 1.65 & & 2.5 & & & & & 2.2 & 0 & -0.1 & \\
\hline-46 & 1.65 & & 2.5 & & & & & 2.2 & 0 & -0.1 & \\
\hline-44 & 1.65 & & 2.4 & & & & & 2.2 & 0 & -0.1 & \\
\hline-42 & 1.45 & & 2.4 & & & & & 2 & 0 & -0.1 & \\
\hline-40 & 1.45 & & 1.9 & & & & & 2 & 0 & -0.1 & \\
\hline-38 & 1.3 & & 1.9 & & & & & 1.75 & 0 & -0.1 & -0.15 \\
\hline-36 & 1.3 & & 1.6 & 0 & & 0 & & 1.75 & 0 & -0.1 & -0.15 \\
\hline-34 & 0.65 & & 1.3 & 0 & & 0.4 & & 1.25 & 0 & -0.1 & 0.95 \\
\hline-32 & 0.65 & & 0.5 & 0 & & 0.4 & & 1.25 & 0 & 0.15 & 1.55 \\
\hline-30 & 0.1 & & 0.2 & 0 & 0 & 1.4 & & 1.15 & 0 & 0.15 & 1.3 \\
\hline-28 & 0.1 & & -0.35 & 0 & -0.1 & 1.05 & & 1.15 & 0 & 0.15 & 1.3 \\
\hline-26 & -0.35 & & -1.1 & 0 & -0.1 & 1.05 & & 0.3 & 0 & 0.15 & 0.9 \\
\hline-24 & -0.75 & & -1.5 & 0 & -0.1 & 0.55 & & 0.3 & 0 & -0.3 & 0.9 \\
\hline-22 & -0.95 & & -1.75 & 0 & -0.1 & 0.55 & & -0.35 & 0 & $\begin{array}{l}-0.3 \\
\end{array}$ & 0.3 \\
\hline-20 & -1.25 & & -1 & 0 & -0.1 & 0.1 & & -0.85 & 0 & 0.9 & 0.3 \\
\hline-18 & -1.35 & & -1 & 0 & 0.7 & 0.1 & & -1 & 0 & 0.9 & -0.1 \\
\hline-16 & -1.5 & & -1 & 0 & 0.6 & -0.15 & & -1.2 & 0 & 0.6 & -0.45 \\
\hline-14 & -1.15 & & -1 & 0 & 0.6 & -0.15 & & -1 & 0 & 0.6 & -0.45 \\
\hline-12 & -0.8 & & -1 & 0 & 0.3 & -0.25 & & -1 & 0 & 0.2 & -0.65 \\
\hline-10 & -1.3 & & -1 & 0 & 0.3 & -0.55 & & -1 & 0 & 0.2 & -0.85 \\
\hline $\begin{array}{l}-8 \\
\end{array}$ & $\begin{array}{l}-1.9 \\
\end{array}$ & & -1 & 0 & -0.2 & $\begin{array}{l}-1.2 \\
\end{array}$ & & -1 & 0 & $\begin{array}{l}-0.3 \\
\end{array}$ & -1.55 \\
\hline-6 & -2.6 & & -1 & 0 & -0.8 & -1.85 & & -1 & 0 & \begin{tabular}{l|l}
-0.8 \\
\end{tabular} & -1.95 \\
\hline-4 & $\begin{array}{l}-3.4 \\
\end{array}$ & & -1 & 0 & -1.3 & -2.5 & & -1 & 0 & $\begin{array}{l}-1.4 \\
\end{array}$ & -2.6 \\
\hline-2 & -3.95 & & -1 & 0 & -1.7 & -2.9 & & -1 & 0 & -2.05 & -3.2 \\
\hline 0 & -5.6 & & -1 & 0 & -2.2 & -3.5 & & -1 & 0 & -3 & -3.8 \\
\hline 2 & -4.8 & & -1 & 0 & -1.65 & -3 & & -1 & 0 & -2.25 & -3.25 \\
\hline 4 & -3.55 & & -1 & 0 & -0.7 & -2.2 & & -1 & -0.85 & -1.05 & -2.4 \\
\hline 6 & -2.95 & & 0 & 0 & -0.2 & -1.4 & & $\begin{array}{l}-0.4 \\
\end{array}$ & -1.35 & -0.75 & $\begin{array}{l}-1.7 \\
\end{array}$ \\
\hline 8 & -1.75 & & 0 & -0.2 & 0 & -0.5 & & -0.65 & -1 & -0.5 & -0.65 \\
\hline 10 & -0.5 & & 0 & -0.8 & 0 & 0 & & 0 & 0 & 0 & -0.15 \\
\hline 12 & -0.2 & & & -0.2 & 0 & 0 & & 0 & 0 & 0 & 0 \\
\hline 14 & 0 & & & 0 & 0 & 0 & & 0 & 0 & 0 & 0 \\
\hline 16 & 0 & & & 0 & 0 & & & & & 0 & \\
\hline 18 & & & & & 0 & & & & & & \\
\hline
\end{tabular}


Table A.1 - Cross-sections (profiles) of the scour hole for $L_{a}=7.5 \mathrm{~cm}$ (continued)

\begin{tabular}{|c|c|c|c|c|c|c|c|c|c|c|c|}
\hline \multicolumn{12}{|c|}{ Scour Depth for $\mathrm{L}_{\mathrm{a}}=7.5 \mathrm{~cm}(\mathrm{~cm})$} \\
\hline \multirow{3}{*}{$\begin{array}{c}X \\
(\mathrm{~cm})\end{array}$} & \multirow{3}{*}{ WithoutCollar } & \multicolumn{5}{|c|}{$\mathrm{B}_{\mathrm{c}}=5 \mathrm{~cm}$} & \multicolumn{5}{|c|}{$\mathrm{B}_{\mathrm{c}}=2.5 \mathrm{~cm}$} \\
\hline & & \multicolumn{10}{|c|}{$Z_{c}(\mathrm{~cm})$} \\
\hline & & -2 & -1 & 0 & 1 & 2 & -2 & -1 & 0 & 1 & 2 \\
\hline \multicolumn{12}{|l|}{-84} \\
\hline \multicolumn{12}{|l|}{-82} \\
\hline \multicolumn{12}{|l|}{-80} \\
\hline \multicolumn{12}{|l|}{-78} \\
\hline \multicolumn{12}{|l|}{-76} \\
\hline \multicolumn{12}{|l|}{-74} \\
\hline \multicolumn{12}{|l|}{-72} \\
\hline \multicolumn{12}{|l|}{-70} \\
\hline \multicolumn{12}{|l|}{-68} \\
\hline-66 & & & & & & & & & & & \\
\hline-64 & & & & & & & & & & & \\
\hline-62 & & & & & & & & & & -0.1 & \\
\hline-60 & & & -0.2 & -0.2 & & & & & & -0.1 & \\
\hline-58 & & & 1.2 & 0.3 & -0.2 & & & & -0.1 & -0.1 & \\
\hline-56 & & & 1.65 & 1.05 & 1 & & & & 0.15 & -0.1 & \\
\hline-54 & & & 1.65 & 1.6 & 0.95 & & & -0.1 & 0.15 & -0.1 & 0 \\
\hline-52 & 0 & & 1.65 & 1.5 & 0.95 & & & -0.1 & 0.45 & -0.1 & 0 \\
\hline-50 & 0.55 & & 1.65 & 1.5 & 0.3 & & -0.3 & -0.1 & 0.45 & -0.1 & 0 \\
\hline-48 & 1.65 & & 1.65 & 1.25 & 0.3 & & 0 & -0.1 & 0.65 & -0.1 & 0.3 \\
\hline-46 & 1.65 & & 1.65 & 1.25 & -0.6 & & 0 & -0.1 & 0.65 & -0.1 & 0.3 \\
\hline-44 & 1.65 & & 1.4 & 1 & -0.6 & & 0 & 0.7 & 0.7 & 0.1 & 0.35 \\
\hline-42 & 1.45 & & 1.4 & 1 & -1.2 & & 1.1 & 0.9 & 0.7 & 0.1 & 0.85 \\
\hline-40 & 1.45 & & 1.05 & 0.75 & -1.2 & & 1.3 & 0.7 & 0.9 & 0.1 & 1.2 \\
\hline-38 & 1.3 & $z$ & 1.05 & 0.75 & -1.5 & & 1.3 & 0.7 & 0.9 & 0.1 & 1.2 \\
\hline-36 & 1.3 & $\vec{\partial}$ & 0.95 & 0.2 & -1.5 & & 1.3 & 0.7 & 1 & 0.1 & 1.2 \\
\hline-34 & 0.65 & 5 & 0.95 & 0.2 & -0.75 & -0.2 & 1.15 & 0.7 & 1 & 0.4 & 1.2 \\
\hline-32 & 0.65 & w & 0.45 & -0.1 & -0.75 & 1 & 1.15 & 0.7 & 1 & 0.4 & 1.05 \\
\hline-30 & 0.1 & 0 & 0.45 & -0.3 & -0.15 & 1.6 & 0.8 & 0.6 & 1 & 0.4 & 1.05 \\
\hline-28 & 0.1 & $z$ & 0.1 & -0.6 & -0.15 & 1.75 & 0.8 & 0.6 & 1.2 & 0.4 & 0.65 \\
\hline-26 & -0.35 & & 0.1 & -0.6 & 0.2 & 1.35 & 0.1 & 0.15 & -0.05 & 0.4 & 0.65 \\
\hline-24 & -0.75 & & -0.3 & -0.7 & 0.2 & 1.35 & 0.1 & 0.15 & -0.3 & 0.1 & -0.15 \\
\hline-22 & -0.95 & & -0.55 & -0.4 & 0.3 & 0.65 & -0.5 & -0.85 & -0.55 & 0.1 & -0.15 \\
\hline-20 & -1.25 & & -0.75 & -0.1 & 0.3 & 0.65 & -1 & -0.85 & -0.75 & 0.1 & -0.6 \\
\hline-18 & -1.35 & & -0.95 & 0.1 & 0.3 & 0.25 & -1.4 & -1.35 & -0.85 & 0.1 & -0.6 \\
\hline-16 & -1.5 & & -0.75 & 0.2 & 0.3 & -0.05 & -1.8 & -1.5 & -0.8 & 0.1 & -0.6 \\
\hline-14 & -1.15 & & -1 & 0.2 & 0.15 & $\begin{array}{l}-0.4 \\
\end{array}$ & -1.9 & -1 & -0.35 & 0.1 & -0.5 \\
\hline-12 & -0.8 & & -1 & -0.2 & 0 & -0.55 & -2 & -1.3 & -0.35 & 0.1 & -0.6 \\
\hline-10 & -1.3 & & -1 & -0.2 & -0.9 & -1.1 & -2 & -1.3 & -0.75 & -0.4 & -1 \\
\hline-8 & -1.9 & & -1 & -0.7 & -1.65 & -1.6 & -2 & -1.3 & -1.25 & -1 & -1.6 \\
\hline-6 & -2.6 & & -1 & -0.7 & -2 & -2.1 & -2 & -1.3 & -1.95 & -1.65 & -2.3 \\
\hline-4 & $\begin{array}{l}-3.4 \\
\end{array}$ & & -1 & -0.7 & -2.35 & -2.55 & -2 & -1.9 & -2.75 & -2.45 & -2.9 \\
\hline-2 & -3.95 & & -1 & -0.8 & -2.85 & -3.4 & -2 & -2.4 & -4 & -3.4 & -3.75 \\
\hline 0 & -5.6 & & -1 & -0.65 & -3.5 & -4.5 & -2.7 & -2.6 & -4.4 & -4.35 & -4.85 \\
\hline 2 & $\begin{array}{l}-4.8 \\
\end{array}$ & & -1 & -1 & -2.35 & -3.5 & -3.55 & -2.5 & -3.4 & -3.5 & -4.4 \\
\hline 4 & -3.55 & & -1.4 & -0.65 & -1.5 & -2.55 & -2.7 & -2.25 & -2.35 & -2.25 & -3.3 \\
\hline 6 & -2.95 & & -1.2 & -1 & -0.6 & -1.75 & -1.8 & -1.85 & -1.7 & -0.8 & -2.15 \\
\hline 8 & -1.75 & & -0.95 & -1.2 & -0.4 & -0.25 & -0.55 & $\begin{array}{l}-0.6 \\
\end{array}$ & -0.95 & 0 & -1.05 \\
\hline 10 & -0.5 & & 0 & -1.2 & 0 & 0 & -0.15 & -0.4 & -0.2 & 0 & -0.2 \\
\hline 12 & -0.2 & & 0 & -0.4 & 0 & 0 & 0 & 0 & 0 & 0 & 0 \\
\hline 14 & 0 & & 0 & 0 & 0 & 0 & 0 & 0 & 0 & & 0 \\
\hline 16 & 0 & & 0 & 0 & 0 & & & 0 & & & \\
\hline 18 & & & & 0 & & & & & & & \\
\hline
\end{tabular}


Table A.2 - Cross-sections (profiles) of the scour hole for $\mathrm{L}_{\mathrm{a}}=15 \mathrm{~cm}$

\begin{tabular}{|c|c|c|c|c|c|c|c|c|c|c|c|}
\hline \multicolumn{12}{|c|}{ Scour Depth for $\mathrm{L}_{\mathrm{a}}=15 \mathrm{~cm}(\mathrm{~cm})$} \\
\hline \multirow{3}{*}{$\begin{array}{c}X \\
(\mathrm{~cm})\end{array}$} & \multirow{3}{*}{ WithoutCollar } & \multicolumn{5}{|c|}{$\mathrm{B}_{\mathrm{c}}=10 \mathrm{~cm}$} & \multicolumn{5}{|c|}{$\mathrm{B}_{\mathrm{c}}=7.5 \mathrm{~cm}$} \\
\hline & & \multicolumn{10}{|c|}{$\mathrm{Z}_{\mathrm{c}}(\mathrm{cm})$} \\
\hline & & -2 & -1 & 0 & 1 & 2 & -2 & -1 & 0 & 1 & 2 \\
\hline \multicolumn{12}{|l|}{-114} \\
\hline \multicolumn{12}{|l|}{-112} \\
\hline \multicolumn{12}{|l|}{-110} \\
\hline \multicolumn{12}{|l|}{-108} \\
\hline \multicolumn{12}{|l|}{-106} \\
\hline \multirow{2}{*}{\multicolumn{12}{|c|}{-104}} \\
\hline \multirow{2}{*}{\multicolumn{12}{|c|}{$\frac{-102}{-100}$}} \\
\hline & & & & & & & & & & & \\
\hline-98 & & & & & & & & & & & \\
\hline-96 & & & & & & & & & & & \\
\hline-94 & & & & & & & & & & & \\
\hline-92 & & & & & & & & & & & \\
\hline-90 & & 0 & & & & & & & & & \\
\hline-88 & & 0.3 & & & & & & & 0 & & \\
\hline-86 & & 0.8 & & & & & & & 0.1 & & \\
\hline-84 & & 1.5 & & & & & & & 0.1 & & \\
\hline-82 & & 1.7 & & & & & & & 0.1 & & \\
\hline-80 & 0 & 1.85 & & & & & & & 0.1 & & \\
\hline-78 & 0 & 2.2 & & & & & & 0 & 0.2 & & \\
\hline-76 & 0 & 2.2 & 0 & 0 & & & & 1.4 & 0.25 & & \\
\hline-74 & 1.7 & 2.2 & 0.3 & 1.25 & & & & 1.4 & 0.25 & & \\
\hline-72 & 2.1 & 2.2 & 0.3 & 2.4 & & & & 1.6 & 0.55 & & \\
\hline-70 & 2.1 & 2.2 & 1.5 & 3.1 & & & & 1.7 & 1.6 & & \\
\hline-68 & 2.1 & 2.2 & 2.25 & 3.1 & & & 0 & 1.7 & 1.7 & & \\
\hline-66 & 2.1 & 2.2 & 2.4 & 2.95 & & & 0.1 & 1.7 & 1.7 & & \\
\hline-64 & 2.1 & 2.2 & 2.4 & 2.95 & & & 1.4 & 1.7 & 1.7 & & \\
\hline-62 & 2.1 & 2.2 & 2.4 & 2.95 & & & 2.05 & 1.7 & 1.7 & & \\
\hline-60 & 1.55 & 1.9 & 2.75 & 2.95 & & & 2 & 1.45 & 1.7 & & \\
\hline-58 & 1.55 & 1.9 & 2.75 & 2.95 & & & 1.8 & 1.45 & 1.65 & & \\
\hline-56 & 1.55 & 1.9 & 2.75 & 2.95 & & & 1.8 & 1.45 & 1.65 & & \\
\hline-54 & 1.55 & 1.9 & 2.75 & 2.9 & & & 1.8 & 1.45 & 1.2 & & \\
\hline-52 & 1.55 & 1.9 & 2.75 & 2.9 & & & 1.6 & 1.45 & 1.2 & & \\
\hline-50 & 1.25 & 1.75 & 2.6 & 2.9 & & & 1.6 & 1.35 & 1.2 & & \\
\hline-48 & 1.25 & 1.75 & 2.6 & 2.9 & & & 1.6 & 1.35 & 1.2 & & \\
\hline-46 & 1.25 & 1.75 & 2.6 & 2.95 & & & 1.6 & 1.25 & 1.15 & & 0 \\
\hline-44 & 1.25 & 1.75 & 2.6 & 2.95 & & 0 & 1.6 & 1.25 & 1.15 & & 0 \\
\hline-42 & 1.1 & 1.75 & 2.6 & 2.9 & & 0 & 1.2 & 0.85 & 0.75 & & 0 \\
\hline-40 & 1.1 & 1.15 & 2.25 & 2.9 & & 0 & 1.2 & 0.85 & 0.75 & 0 & 0 \\
\hline-38 & 0.85 & 1.15 & 2.25 & 2.8 & & 1.25 & 1.2 & 0.7 & 0.45 & 0.2 & 2.4 \\
\hline-36 & 0.85 & 1.15 & 2.25 & 2.8 & & 2.35 & 1.2 & 0.7 & 0.45 & 0.2 & 1.9 \\
\hline-34 & $\begin{array}{l}0.3 \\
\end{array}$ & 1.15 & 2.25 & 2.65 & & 2.35 & 1.2 & 0.4 & 0 & 1.35 & 1.75 \\
\hline-32 & 0.3 & 1 & 2.25 & 2.65 & & 2.05 & 1 & 0.4 & 0 & 2 & 1.75 \\
\hline-30 & 0.05 & 1 & 2.1 & 2.4 & 0 & 2.05 & 1 & 0.15 & -0.3 & 2.1 & 1.6 \\
\hline-28 & $\begin{array}{l}-0.3 \\
\end{array}$ & 0.4 & 2.1 & 2.4 & 0.3 & 1.6 & 1.05 & 0.15 & $\begin{array}{l}-0.4 \\
\end{array}$ & 1.85 & 1.6 \\
\hline-26 & -0.75 & 0.4 & 1.8 & 1.7 & 0.75 & 1.6 & 1.05 & 0.15 & -0.55 & 1.85 & 1.1 \\
\hline-24 & -1.15 & -0.15 & 1.05 & 1.7 & 0.95 & 0.85 & 1.3 & 0.15 & -0.8 & 1.05 & 1.1 \\
\hline-22 & -1.6 & -0.4 & 0 & 1.5 & 0.85 & 0.85 & 1.3 & 0.15 & -0.4 & 1.05 & 0.3 \\
\hline-20 & -2 & -2 & 0 & 1.5 & 0.85 & 0.2 & 0.7 & -1 & -0.2 & 0.15 & 0.3 \\
\hline-18 & -2.55 & -2 & 0 & 1.7 & 1 & 0.2 & 0.7 & -1.2 & 0 & 0.15 & -0.3 \\
\hline-16 & $\begin{array}{l}-2.9 \\
\end{array}$ & -2 & 0 & 1.7 & 1 & -0.25 & 0.3 & -1.2 & 0 & -0.3 & -1 \\
\hline-14 & $\begin{array}{l}-3.4 \\
\end{array}$ & -2 & 0 & 0 & 0.3 & -0.55 & 0.3 & -1.2 & 0 & -0.65 & -1.6 \\
\hline-12 & -3.55 & -2 & 0 & 0 & 0.3 & -1 & -1.6 & -1.2 & 0 & -1.05 & -2.45 \\
\hline-10 & -4 & -2 & 0 & 0 & -0.1 & $\begin{array}{l}-1.8 \\
\end{array}$ & -2.2 & -1.2 & 0 & -1.6 & -2.9 \\
\hline-8 & -4.5 & -2 & -0.2 & 0 & -1.15 & -2.35 & -2 & -1.2 & -0.45 & -2.15 & -3.8 \\
\hline-6 & -5.2 & -2 & -0.5 & 0 & -2 & -2.85 & -2 & -1.2 & -1.35 & -2.75 & -4.3 \\
\hline-4 & -6 & -2 & -1 & 0 & -2.45 & -3.75 & -2 & -1.2 & -2.3 & -3.7 & -5.1 \\
\hline-2 & -6.6 & -2 & -1 & 0 & -3.55 & -4.35 & -2 & -1.2 & -3.15 & -4.9 & -5.9 \\
\hline
\end{tabular}




\begin{tabular}{|c|c|c|c|c|c|c|c|c|c|c|c|}
\hline 0 & -8.3 & -2 & -1 & 0 & -4.3 & -5.5 & -2 & -1.2 & -3.3 & -5.9 & -6.7 \\
\hline 2 & -7.4 & -2 & -1 & 0 & -4.05 & -4.7 & -2 & -1.6 & -2.35 & -5.1 & -6.2 \\
\hline 4 & -6.55 & -2 & -1 & -0.4 & -3.4 & -3.75 & -2 & -2 & -1.6 & -4.3 & -5.4 \\
\hline 6 & -5 & -2 & -1 & -0.85 & -3.05 & -2.65 & -2 & -2.35 & -1.9 & -3.15 & -4 \\
\hline 8 & -4.4 & -2 & -1 & -1.2 & -2 & -2.05 & -2.2 & -2.1 & -2 & -1.4 & -2.75 \\
\hline 10 & -4 & -2 & -1.75 & -1.4 & -0.75 & -0.85 & -2.2 & -2 & -2.15 & -0.6 & -1.65 \\
\hline 12 & -2.8 & -1.4 & -1.55 & -1.65 & -0.2 & -0.1 & -2.4 & -1.75 & -1.9 & -0.2 & -0.6 \\
\hline 14 & -1.75 & -0.4 & -0.5 & -1.45 & 0 & 0 & -1.35 & -1.25 & -0.15 & 0 & 0 \\
\hline 16 & -0.6 & 0 & -0.15 & -1.4 & 0 & 0 & -0.3 & -0.4 & -0.3 & 0 & 0 \\
\hline 18 & 0 & 0 & 0 & -0.4 & & & 0 & 0 & 0 & & 0 \\
\hline 20 & 0 & & 0 & -0.2 & & & & 0 & & & \\
\hline 22 & 0 & & & 0 & & & & & & & \\
\hline 24 & & & & 0 & & & & & & & \\
\hline
\end{tabular}


Table A. 2 - Cross-sections (profiles) of the scour hole for $\mathrm{L}_{\mathrm{a}}=15 \mathrm{~cm}$ (continued)

\begin{tabular}{|c|c|c|c|c|c|c|c|c|c|c|c|}
\hline \multicolumn{12}{|c|}{ Scour Depth for $\mathrm{L}_{a}=15 \mathrm{~cm}(\mathrm{~cm})$} \\
\hline \multirow{3}{*}{$\begin{array}{c}X \\
(\mathrm{~cm})\end{array}$} & \multirow{3}{*}{ WithoutCollar } & \multicolumn{5}{|c|}{$\mathrm{B}_{\mathrm{c}}=5 \mathrm{~cm}$} & \multicolumn{5}{|c|}{$B_{c}=2.5 \mathrm{~cm}$} \\
\hline & & \multicolumn{10}{|c|}{$\mathrm{Z}_{\mathrm{c}}(\mathrm{cm})$} \\
\hline & & -2 & -1 & 0 & 1 & 2 & -2 & -1 & 0 & 1 & 2 \\
\hline-114 & & & & & & & & & & & \\
\hline-112 & & 0 & & & & & & & & & \\
\hline-110 & & 1.1 & & 0 & & & & & & & \\
\hline-108 & & 1.7 & & 0.25 & & & & & & & \\
\hline-106 & & 1.8 & & 0.25 & & & & & 0 & & \\
\hline-104 & & 1.8 & & 0.6 & & & & & 0.1 & & \\
\hline-102 & & 1.8 & & 0.6 & & & & & 0.1 & & \\
\hline-100 & & 1.8 & & 1 & & & & & 1.65 & & \\
\hline-98 & & 1.8 & & 1 & & & & & 1.75 & & \\
\hline-96 & & 1.8 & & 1.4 & & & & & 1.6 & & \\
\hline-94 & & 2 & & 1.4 & & & & & 1.6 & & \\
\hline-92 & & 2 & & 1.8 & & & & & 1.6 & & \\
\hline-90 & & 2 & 0 & 1.8 & & & & & 1.35 & & \\
\hline-88 & & 2 & 0.1 & 2.05 & & & & 0 & 1.35 & & \\
\hline-86 & & 2 & 0.1 & 2.05 & & 0 & -0.1 & 0.35 & 1.35 & & \\
\hline-84 & & 1.6 & 0.5 & 2.05 & 0.6 & 0.4 & 0.35 & 1.15 & 1.35 & -0.1 & \\
\hline-82 & & 1.6 & 0.9 & 2.05 & 0.6 & 0.4 & 1 & 1.25 & 1.35 & 0.4 & \\
\hline-80 & 0 & 1.6 & 1.1 & 2.05 & 0.6 & 0.4 & 1.35 & 1.35 & 1.35 & 1.4 & 0 \\
\hline-78 & 0 & 1.6 & 1.25 & 2 & 0.6 & 0.4 & 1.35 & 1.35 & 1.35 & 1.6 & 0.3 \\
\hline-76 & 0 & 1.6 & 1.5 & 2 & 0.6 & 0.4 & 1.35 & 1.35 & 1.35 & 1.6 & 1.7 \\
\hline-74 & 1.7 & 1.35 & 1.9 & 2 & 0.6 & 0.4 & 1.35 & 1.6 & 1.35 & 1.6 & 2 \\
\hline-72 & 2.1 & 1.35 & 1.9 & 2 & 0.6 & 0.4 & 1.35 & 1.6 & 1.3 & 1.6 & 2.1 \\
\hline-70 & 2.1 & 1.35 & 1.9 & 2 & 0.6 & 0.4 & 1.35 & 1.6 & 1.25 & 1.6 & 2.1 \\
\hline-68 & 2.1 & 1.35 & 1.9 & 2 & 0.6 & 0.4 & 1.35 & 1.6 & 1.25 & 1.4 & 1.7 \\
\hline-66 & 2.1 & 1.35 & 1.9 & 2 & 0.6 & 0.4 & 1.3 & 1.6 & 1.25 & 1.4 & 1.7 \\
\hline-64 & 2.1 & 1.35 & 1.85 & 2 & 0.45 & 0.4 & 1.3 & 1.7 & 1.25 & 1.4 & 1.7 \\
\hline-62 & 2.1 & 1.2 & 1.85 & 1.65 & 0.8 & 0.4 & 1.3 & 1.7 & 1.25 & 1.4 & 1.7 \\
\hline-60 & 1.55 & 1.2 & 1.85 & 1.65 & 0.8 & 0.4 & 1.3 & 1.7 & 1.1 & 1.4 & 1.7 \\
\hline-58 & 1.55 & 1 & 1.85 & 1.8 & 2.1 & 0.4 & 1.3 & 1.7 & 1.1 & 1.2 & 1.5 \\
\hline-56 & 1.55 & 1 & 1.85 & 1.8 & 2.1 & 0.4 & 1.2 & 1.7 & 1.1 & 1.2 & 1.5 \\
\hline-54 & 1.55 & 0.75 & 1.8 & 2 & 2.15 & 0.2 & 1.2 & 1.6 & 1.1 & 1.2 & 1.5 \\
\hline-52 & 1.55 & 0.7 & 1.8 & 2 & 2.15 & 0.55 & 1.2 & 1.6 & 1.1 & 1.2 & 1.5 \\
\hline-50 & 1.25 & 0.5 & 1.5 & 1.6 & 2 & 1.8 & 1.2 & 1.6 & 0.95 & 1.2 & 1.5 \\
\hline-48 & 1.25 & 0.5 & 1.5 & 1.6 & 2 & 2 & 1.2 & 1.6 & 0.95 & 0.85 & 1.35 \\
\hline-46 & 1.25 & 0.25 & 1 & 1.55 & 2 & 2 & 0.85 & 1.6 & 0.95 & 0.85 & 1.35 \\
\hline-44 & 1.25 & 0.25 & 1 & 1.55 & 2 & 1.9 & 0.85 & 1.25 & 0.95 & 0.85 & 1.2 \\
\hline-42 & 1.1 & 0.25 & 0.35 & 1.2 & 1.9 & 1.9 & 0.85 & 1.25 & 0.85 & 0.85 & 1.2 \\
\hline-40 & 1.1 & -0.2 & 0.35 & 1.2 & 1.9 & 1.75 & 0.85 & 1.25 & 0.85 & 0.85 & 1.15 \\
\hline-38 & 0.85 & -0.2 & \begin{tabular}{|c|}
-0.3 \\
\end{tabular} & 0.95 & 1.6 & 1.75 & 0.85 & 1.25 & 0.7 & 0.85 & 1.15 \\
\hline-36 & 0.85 & -0.7 & -0.65 & 0.95 & 1.6 & 1.75 & 0.8 & 1.25 & 0.7 & 0.85 & 0.85 \\
\hline-34 & 0.3 & -0.7 & -1 & 0.95 & 1.25 & 1.45 & 0.8 & 1.25 & 0.6 & 0.8 & 0.85 \\
\hline-32 & 0.3 & -1.5 & -1.1 & 0.95 & 1.25 & 1.45 & 0.8 & 1.25 & 0.6 & 0.8 & 0.45 \\
\hline-30 & 0.05 & -1.5 & -1.4 & 0.85 & 0.9 & 1.45 & 0.8 & 1.1 & 0.6 & 0.5 & 0.45 \\
\hline-28 & $\begin{array}{l}-0.3 \\
\end{array}$ & -2.25 & -1.6 & 0.85 & 0.9 & 1.15 & 0.8 & 1.1 & 0.6 & 0.5 & 0.1 \\
\hline-26 & -0.75 & -2.25 & -1.7 & 0.45 & 0.9 & 1.15 & 0.5 & 0.6 & 0.15 & 0.2 & -0.1 \\
\hline-24 & -1.15 & -2.5 & -1.85 & 0.45 & 0.1 & 0.45 & 0.5 & 0.6 & -0.15 & 0.2 & -0.1 \\
\hline-22 & -1.6 & -2.5 & -2 & 0 & 0.1 & 0.45 & 0.5 & 0 & -0.15 & -0.3 & -0.6 \\
\hline-20 & -2 & 0 & -1.9 & 0 & -0.5 & -0.1 & -0.1 & 0 & -0.6 & -0.5 & $\begin{array}{l}-0.9 \\
\end{array}$ \\
\hline-18 & -2.55 & -2.35 & -1.75 & -0.45 & -1.4 & -0.75 & -0.75 & -0.45 & -1.05 & -0.85 & -1.45 \\
\hline-16 & -2.9 & -2.35 & -1.3 & -0.9 & -1.9 & -1.45 & -1.35 & -1.05 & -1.7 & -1.4 & -2.35 \\
\hline-14 & $\begin{array}{l}-3.4 \\
\end{array}$ & -2.5 & -1.3 & -1.35 & -2.5 & -2.25 & -1.75 & $\begin{array}{l}-1.6 \\
\end{array}$ & -1.9 & -2.15 & -3 \\
\hline-12 & -3.55 & -2.4 & -1.3 & -1.85 & -3.35 & -2.8 & -2.15 & -2.1 & -2.3 & -2.9 & -3.75 \\
\hline-10 & -4 & -2.15 & -2 & -2.5 & -4.25 & $\begin{array}{l}-3.7 \\
\end{array}$ & -3 & -2.65 & -3.2 & $\begin{array}{l}-3.9 \\
\end{array}$ & -4.3 \\
\hline-8 & -4.5 & -2.45 & -2.8 & -3.7 & -4.9 & -4.5 & $\begin{array}{l}-3.9 \\
\end{array}$ & -3.7 & -4.55 & -4.55 & -5.1 \\
\hline-6 & -5.2 & -3 & -3.4 & -4.55 & -6.2 & -5.1 & -4.95 & -4.9 & -5.65 & -5.3 & -6.1 \\
\hline-4 & -6 & $\begin{array}{l}-3.8 \\
\end{array}$ & -4.5 & -5.35 & -6.35 & -5.85 & -5.9 & -6.3 & -6.95 & $\begin{array}{l}-6.2 \\
\end{array}$ & $\begin{array}{l}-6.9 \\
\end{array}$ \\
\hline-2 & -6.6 & -4.35 & -5.25 & -6 & -6.35 & $\begin{array}{l}-6.8 \\
\end{array}$ & -6.2 & -6.9 & -7.75 & -6.85 & -7.65 \\
\hline
\end{tabular}




\begin{tabular}{|c|c|c|c|c|c|c|c|c|c|c|c|}
\hline 0 & -8.3 & -5 & -5.85 & -6.8 & -7.3 & -7.4 & -6.5 & -7.7 & -8.1 & -8.6 & -8.2 \\
\hline 2 & -7.4 & -4.6 & -4.9 & -6.15 & -6.8 & -6.95 & -6 & -6.6 & -7.9 & -7.25 & -7.8 \\
\hline 4 & -6.55 & -4.15 & -3.3 & -5.1 & -5.75 & -5.95 & -5.1 & -5.7 & -6.65 & -6.5 & -6.85 \\
\hline 6 & -5 & -3.35 & -2.8 & -4.1 & -4.6 & -5.1 & -3.65 & -4 & -5.95 & -5.55 & -5.8 \\
\hline 8 & -4.4 & -2.65 & -2.2 & -3.15 & -3.1 & -3.9 & -2.45 & -2.8 & -4.55 & -4.75 & -4.9 \\
\hline 10 & -4 & -2.15 & -1.35 & -2.15 & -1.8 & -2.7 & -1.3 & -1.65 & -3.6 & -3.3 & -4.3 \\
\hline 12 & -2.8 & -1 & -0.3 & -1.75 & -0.8 & -1.5 & -0.2 & -0.4 & -2.55 & -2.1 & -3.25 \\
\hline 14 & -1.75 & -0.4 & 0 & -1.75 & -0.2 & -0.45 & 0 & 0 & -1.75 & -0.85 & -2 \\
\hline 16 & -0.6 & 0 & 0 & -0.5 & 0 & 0 & 0 & 0 & -0.95 & -0.5 & -1.1 \\
\hline 18 & 0 & 0 & & 0 & 0 & 0 & & 0 & -0.45 & -0.1 & -0.25 \\
\hline 20 & 0 & & & 0 & & 0 & & & 0 & 0 & 0 \\
\hline 22 & 0 & & & 0 & & & & & 0 & 0 & 0 \\
\hline 24 & & & & & & & & & & & \\
\hline
\end{tabular}


Table A.3 - Cross-sections (profiles) of the scour hole for $\mathrm{L}_{\mathrm{a}}=20 \mathrm{~cm}$

\begin{tabular}{|c|c|c|c|c|c|c|c|c|c|c|c|}
\hline \multicolumn{12}{|c|}{ Scour Depth for $\mathrm{L}_{\mathrm{a}}=20 \mathrm{~cm}(\mathrm{~cm})$} \\
\hline \multirow{3}{*}{$\begin{array}{c}\mathrm{X} \\
(\mathrm{cm})\end{array}$} & \multirow{3}{*}{ WithoutCollar } & \multicolumn{5}{|c|}{$\mathrm{B}_{\mathrm{c}}=10 \mathrm{~cm}$} & \multirow{2}{*}{\multicolumn{5}{|c|}{$\mathrm{B}_{\mathrm{c}}=7.5 \mathrm{~cm}$}} \\
\hline & & & & & & & & & & & \\
\hline & & -2 & -1 & 0 & 1 & 2 & -2 & -1 & 0 & 1 & 2 \\
\hline-124 & & & & 26 & & & & & & & \\
\hline-122 & & & & 2.4 & & & & & & & \\
\hline-120 & & & & 2.4 & & & & & & & \\
\hline-118 & & & & 2.4 & & & & & & & \\
\hline-116 & & 0 & & 2.4 & & & & & & & \\
\hline-114 & & 0.35 & & 2.4 & & & & & & & \\
\hline-112 & & 0.35 & & 2.4 & & & & & & & \\
\hline-110 & & 1 & & 2.4 & & & & & & & \\
\hline-108 & & 1.35 & & 2.4 & & & & & & & \\
\hline-106 & & 1.65 & & 2.4 & & & & & & & \\
\hline-104 & & 1.85 & & 2.4 & & & & & & & \\
\hline-102 & & 1.9 & & 2.4 & & & & & 2.25 & & \\
\hline-100 & & 1.9 & & 2.4 & & & 1.5 & & 1.7 & & \\
\hline-98 & & 1.9 & & 2.4 & & & 1.5 & & 1.7 & & \\
\hline-96 & 0 & 1.9 & & 2 & & & 1.5 & & 1.7 & & \\
\hline-94 & 1.05 & 2 & & 2 & & & 1.5 & & 1.7 & & \\
\hline-92 & 2.2 & 2 & & 2 & & & 1.5 & & 1.8 & & \\
\hline-90 & 2.3 & 2 & & 2 & & & 1.5 & & 1.8 & & \\
\hline-88 & 1.9 & 2 & & 2 & & & 1.4 & & 1.8 & & \\
\hline-86 & 1.9 & 2 & & 1.85 & & & 1.4 & & 1.8 & & \\
\hline-84 & 1.9 & 2 & & 1.85 & & & 1.4 & & 1.8 & & \\
\hline-82 & 1.9 & 0.8 & & 1.6 & & & 1.4 & & 2.1 & & \\
\hline-80 & 1.9 & 0.8 & & 1.6 & & & 1.4 & & 2.1 & & \\
\hline-78 & 1.85 & 0.8 & 0 & 1.6 & & & 1.4 & 0 & 2.1 & & \\
\hline-76 & 1.85 & 0.8 & 0.1 & 1.6 & & & 1.4 & 0.8 & 2.1 & & \\
\hline-74 & 1.85 & 0.8 & 1.1 & 1.6 & & & 1.4 & 1.5 & 1.95 & & \\
\hline-72 & 1.85 & 0.8 & 1.9 & 1.45 & & & 1.4 & 1.95 & 1.95 & & \\
\hline-70 & 1.85 & 0.8 & 2.75 & 1.45 & & & 1.4 & 2.7 & 1.95 & & \\
\hline-68 & 1.5 & 0.8 & 2.85 & 1.45 & & & 1.2 & 2.85 & 1.7 & & \\
\hline-66 & 1.5 & 0.8 & 3.1 & 1.45 & & & 1.2 & 2.85 & 1.7 & & \\
\hline-64 & 1.5 & 0.8 & 3.1 & 1.45 & & & 1.2 & 2.75 & 1.15 & & \\
\hline-62 & 1.5 & 0.8 & 3.1 & 2.2 & & & 1.2 & 2.75 & 1.15 & & \\
\hline-60 & 1.5 & 0.8 & 3.1 & 2.2 & & & 1.2 & 2.75 & 0.85 & & \\
\hline-58 & 1.45 & 0.8 & 3.1 & 2.2 & & & 1 & 2.75 & 0.85 & & \\
\hline-56 & 1.45 & 0.8 & 3.3 & 2.2 & & 0 & 1 & 2.75 & 0.2 & & 0 \\
\hline-54 & 1.35 & 0.8 & 3.3 & 2.2 & & 0 & 1 & 2.55 & 0.2 & & 1 \\
\hline-52 & 1.35 & 0.75 & 3.3 & 2.6 & & 0 & 1 & 2.55 & 0.2 & & 2.2 \\
\hline-50 & 1.65 & 0.75 & 3.3 & 2.6 & & 1.15 & 1 & 2.45 & -0.15 & 0 & 2.2 \\
\hline-48 & 1.65 & 0.75 & 3.3 & 2.6 & & 1.15 & 0.65 & 2.45 & -0.15 & 0.7 & 2.2 \\
\hline-46 & 0.75 & 0.75 & 3.1 & 2.6 & 0.2 & 2.5 & 0.65 & 1.5 & -0.15 & 1.75 & 2.1 \\
\hline-44 & 0.75 & 0.75 & 3.1 & 2.4 & 1.5 & 2.5 & 0.65 & 1.5 & -0.5 & 2.85 & 2.1 \\
\hline-42 & 0.5 & 0.35 & 2.55 & 2.4 & 2.45 & 2.4 & 0.65 & 2 & -0.5 & 2.6 & 2.1 \\
\hline-40 & 0.5 & 0.35 & 2.55 & 1.85 & 2.4 & 2.4 & 0.65 & 2 & $\begin{array}{l}-0.6 \\
\end{array}$ & 2.6 & 2.1 \\
\hline-38 & 0.05 & 0.35 & 2.25 & 1.85 & 2.1 & 2.3 & 0.25 & 2 & -0.6 & 2 & 2.1 \\
\hline-36 & 0.05 & 0.35 & 2.25 & 1.25 & 2.1 & 2.3 & 0.25 & 2 & -0.95 & 2 & 1.9 \\
\hline-34 & -0.3 & 0.35 & 1.75 & 1.25 & 2.1 & 2.4 & 0.25 & 1.65 & -0.95 & 2 & 1.9 \\
\hline-32 & -0.5 & 0.85 & 1.75 & 0.6 & 2.1 & 2.4 & 0.25 & 1.65 & $\begin{array}{l}-1.1 \\
\end{array}$ & 2 & 1.75 \\
\hline-30 & -0.9 & 0.85 & 1.4 & 0 & 2.1 & 2.2 & 0.25 & 1 & -1.1 & 2 & 1.75 \\
\hline $\begin{array}{l}-28 \\
\end{array}$ & -1.25 & 0.85 & 1.4 & 0 & 1.4 & 1.8 & 0 & 1 & -1 & 1.5 & 1.15 \\
\hline-26 & $\begin{array}{l}-1.7 \\
\end{array}$ & 0.2 & 0.2 & 0 & $\begin{array}{l}1.4 \\
\end{array}$ & 1.3 & 0 & 0.45 & -0.8 & 1.5 & 1.15 \\
\hline-24 & -2.3 & 0.2 & 0.2 & 0 & 0.05 & 0.8 & -0.5 & 0.45 & -0.6 & 0.45 & 0.3 \\
\hline-22 & -2.85 & $\begin{array}{l}-1.3 \\
\end{array}$ & -0.5 & 0 & 0.05 & 0 & -0.5 & 0.1 & 0 & 0.45 & 0.3 \\
\hline-20 & -3.65 & -2 & -1.15 & 0 & -0.3 & -0.5 & -1.7 & 0.1 & 0.4 & -0.25 & -0.4 \\
\hline-18 & -4.15 & -2 & -1.3 & 0 & -0.85 & -1.1 & -1.7 & -0.35 & 0.4 & -1.2 & -1.2 \\
\hline-16 & -4.45 & -2 & -1.95 & 0 & -1.35 & -1.6 & -2 & -0.35 & 0 & -1.5 & -1.75 \\
\hline-14 & -5.1 & -2 & -2.1 & 0 & -1.8 & -2.4 & -2 & -0.6 & 0 & -2 & -2.7 \\
\hline
\end{tabular}




\begin{tabular}{|c|c|c|c|c|c|c|c|c|c|c|c|}
\hline-12 & -5.8 & -2 & -2.1 & 0 & -2.35 & -3.3 & -2.1 & -0.6 & -0.35 & -3.1 & -3.35 \\
\hline-10 & -6.5 & -2 & -2.25 & 0 & -3.05 & -4 & -2.1 & -0.8 & -0.95 & -4 & -4.35 \\
\hline-8 & -7.1 & -2 & -2.35 & 0 & -3.8 & -4.7 & -2.1 & -1.35 & -1.9 & -4.5 & -5.4 \\
\hline-6 & -7.9 & -2 & -1.95 & 0 & -4.55 & -5.5 & -2.1 & -1.8 & -3.1 & -5.3 & -6.1 \\
\hline-4 & -8.6 & -2 & -1.95 & 0 & -5.45 & -6.15 & -2.3 & -1.8 & -4.3 & -5.9 & -6.4 \\
\hline-2 & -8.9 & -2 & -1 & 0 & -6.5 & -7 & -2.3 & -2.6 & -5.35 & -6.3 & -6.7 \\
\hline 0 & -10.3 & -2 & -1 & -1 & -7.6 & -7.3 & -2.4 & -3.2 & -6.6 & -6.9 & -7.6 \\
\hline 2 & -10.1 & -2 & -1 & -1.1 & -6.8 & -7.9 & -2.3 & -2.1 & -5.6 & -6.7 & -7.6 \\
\hline 4 & -9.05 & -2 & -1 & -0.5 & -5.65 & -6.9 & -2.65 & -2.15 & -4.85 & -5.8 & -6.65 \\
\hline 6 & -7.2 & -2 & -1.45 & -2 & -4.35 & -5.8 & -3.5 & -2.15 & -3.85 & -4.4 & -6 \\
\hline 8 & -6.35 & -2.35 & -1.8 & -2.4 & -3.1 & -4.65 & -3.35 & -2.25 & -2.8 & -3 & -4.75 \\
\hline 10 & -5.9 & -2.9 & -2.2 & -2.45 & -2.1 & -3.6 & -2.65 & -2.3 & -2.4 & -2.3 & -3.3 \\
\hline 12 & -4.85 & -2.65 & -2.15 & -2.4 & -1.05 & -2.4 & -2.3 & -1.95 & -1.95 & -1.7 & -2.2 \\
\hline 14 & -3.15 & -2.35 & -2.3 & -3.1 & -0.25 & -1.05 & -1.85 & -1.4 & -1.4 & -0.7 & -0.85 \\
\hline 16 & -2.2 & -1.75 & -2.25 & -2.15 & 0 & -0.2 & -1.3 & -1.05 & -0.9 & -0.2 & -0.2 \\
\hline 18 & -0.8 & -0.85 & -1.2 & -2.15 & 0 & 0 & -1 & -0.2 & -0.2 & 0 & 0 \\
\hline 20 & -0.25 & -0.25 & -0.5 & -1.4 & & 0 & -0.15 & 0 & 0 & 0 & 0 \\
\hline 22 & 0 & 0 & -0.25 & -0.75 & & 0 & 0 & 0 & 0 & & 0 \\
\hline 24 & 0 & 0 & 0 & -0.2 & & & 0 & & & & \\
\hline 26 & & & 0 & 0 & & & & & & & \\
\hline 28 & & & & 0 & & & & & & & \\
\hline 30 & & & & & & & & & & \\
\hline
\end{tabular}


Table A.3 - Cross-sections (profiles) of the scour hole for $\mathrm{L}_{\mathrm{a}}=20 \mathrm{~cm}$ (continued)

\begin{tabular}{|c|c|c|c|c|c|c|c|c|c|c|c|}
\hline \multicolumn{12}{|c|}{ Scour Depth for $\mathrm{L}_{\mathrm{a}}=20 \mathrm{~cm}(\mathrm{~cm})$} \\
\hline \multirow{3}{*}{$\begin{array}{c}X \\
(\mathrm{~cm})\end{array}$} & \multirow{3}{*}{ WithoutCollar } & \multicolumn{5}{|c|}{$\mathrm{B}_{\mathrm{c}}=5 \mathrm{~cm}$} & \multirow{2}{*}{\multicolumn{5}{|c|}{$\mathrm{B}_{\mathrm{c}}=2.5 \mathrm{~cm}$}} \\
\hline & & \multicolumn{6}{|c|}{$Z_{c}(\mathrm{~cm})$} & & & & \\
\hline & & -2 & -1 & 0 & 1 & 2 & -2 & -1 & 0 & 1 & 2 \\
\hline-124 & & & & & & & & & & & \\
\hline-122 & & & & & & & & & & & \\
\hline-120 & & & & & & & & & & & \\
\hline-118 & & & & & & & & & & & \\
\hline-116 & & & & & & & & & & & \\
\hline-114 & & & & & & & & & & & \\
\hline-112 & & & & & & & & & & & \\
\hline-110 & & & & 1.6 & & & & & & & \\
\hline-108 & & & & 1.85 & & & & & & & \\
\hline-106 & & & & 1.85 & & & & & & & \\
\hline-104 & & & & 1.85 & & & & & & & \\
\hline-102 & & & & 1.85 & & & & & & & \\
\hline-100 & & 1.85 & & 1.85 & & & 0 & 0.9 & & & \\
\hline-98 & & 1.6 & & 1.85 & & & 0.7 & 0.9 & & & \\
\hline-96 & 0 & 1.6 & & 1.85 & & & 1.35 & 0.9 & & & \\
\hline-94 & 1.05 & 1.6 & & 1.85 & & & 1.35 & 1.3 & & 0 & \\
\hline-92 & 2.2 & 1.6 & 2.3 & 1.85 & & & 1.5 & 1.3 & & 1 & \\
\hline-90 & 2.3 & 1.6 & 2.3 & 1.85 & & & 1.5 & 1.3 & & 1.2 & \\
\hline-88 & 1.9 & 1.4 & 2.3 & 1.85 & & 0 & 1.5 & 1.3 & & 1.3 & 0 \\
\hline-86 & 1.9 & 1.4 & 2.3 & 1.85 & & 0.55 & 1.5 & 1.3 & & 1.3 & 0.4 \\
\hline-84 & 1.9 & 1.4 & 2.3 & 1.85 & & 0.55 & 1.5 & 1.15 & & 1.3 & 0.9 \\
\hline-82 & 1.9 & 1.4 & 2.3 & 1.85 & & 0.55 & 1.5 & 1.15 & & 1.3 & 1.1 \\
\hline-80 & 1.9 & 1.4 & 1.9 & 1.85 & & 0.8 & 1.5 & 1.15 & & 1.3 & 1.5 \\
\hline-78 & 1.85 & 1.4 & 1.9 & 1.55 & & 1.2 & 1.6 & 1.15 & & 1.3 & 1.4 \\
\hline-76 & 1.85 & 1.4 & 1.9 & 1.55 & & 1.05 & 1.6 & 1.15 & & 1.05 & 1.4 \\
\hline-74 & 1.85 & 1.4 & 1.9 & 1.55 & & 1.05 & 1.6 & 1.1 & & 1.05 & 1.4 \\
\hline-72 & 1.85 & 1.4 & 1.9 & 1.55 & & 1.05 & 1.6 & 1.1 & 1.35 & 1.05 & 1.4 \\
\hline-70 & 1.85 & 1.4 & 1.25 & 1.55 & & 1.05 & 1.6 & 1.1 & 1.15 & 1.05 & 1.4 \\
\hline-68 & 1.5 & 1.75 & 1.25 & 1.1 & & 1.05 & 1.5 & 1.1 & 1.15 & 1.05 & 1.25 \\
\hline-66 & 1.5 & 1.75 & 1.25 & 1.1 & & 1 & 1.5 & 1.1 & 1.15 & 1.05 & 1.25 \\
\hline-64 & 1.5 & 1.75 & 1.25 & 1.1 & & 1 & 1.5 & 1.1 & 1.15 & 1.05 & 1.25 \\
\hline-62 & 1.5 & 1.75 & 1.25 & 1.25 & & 0.7 & 1.5 & 1.1 & 1.15 & 1.05 & 1.25 \\
\hline-60 & 1.5 & 1.75 & 1.25 & 1.25 & & 0.7 & 1.5 & 1.1 & 1.15 & 1.05 & 1.25 \\
\hline-58 & 1.45 & 1.6 & 1.25 & 1.4 & & 1.15 & 1.35 & 1.1 & 1.15 & 1.05 & 1.1 \\
\hline-56 & 1.45 & 1.6 & 1.55 & 1.4 & & 1.15 & 1.35 & 1.1 & 1.15 & 0.95 & 1.1 \\
\hline-54 & 1.35 & 1.6 & 1.9 & 1.7 & & 1.9 & 1.35 & 1.1 & 1.15 & 0.95 & 1.1 \\
\hline-52 & 1.35 & 1.6 & 2.2 & 2.15 & 0 & 1.9 & 1.35 & 1.1 & 1.15 & 0.95 & 1.1 \\
\hline-50 & 1.65 & 1.6 & 2.25 & 2.45 & 0.9 & 2.15 & 1.35 & 1.1 & 1.25 & 0.95 & 1.1 \\
\hline-48 & 1.65 & 1.45 & 2.25 & 2.45 & 2.25 & 1.85 & 1 & 1.1 & 1.25 & 0.95 & 1.05 \\
\hline-46 & 0.75 & 1.45 & 2.25 & 2.3 & 2.7 & 1.85 & 1 & 1.1 & 1.25 & 0.95 & 1.05 \\
\hline-44 & 0.75 & 1.35 & 2 & 2.3 & 2.5 & 1.85 & 1 & 1.1 & 1.25 & 0.95 & 1.05 \\
\hline-42 & 0.5 & 1.35 & 2 & 1.9 & 2.5 & 1.85 & 1 & 1.1 & 1.25 & 0.75 & 1.05 \\
\hline-40 & 0.5 & 0.9 & 1.4 & 1.9 & 2.35 & 1.85 & 1 & 1.1 & 1.2 & 0.75 & 1.05 \\
\hline-38 & 0.05 & 0.9 & 1.4 & 1.7 & 2.35 & 1.65 & 1 & 1.1 & 1.2 & 0.65 & 0.8 \\
\hline-36 & 0.05 & 0.1 & 0.6 & 1.7 & 2.05 & 1.65 & 1 & 1.1 & 1.2 & 0.65 & 0.8 \\
\hline-34 & $\begin{array}{l}-0.3 \\
\end{array}$ & $\begin{array}{l}0.1 \\
\end{array}$ & 0.6 & 1.3 & 2.05 & 1.5 & 1 & 1 & 1.2 & 0.6 & 0.5 \\
\hline-32 & -0.5 & -0.6 & $\begin{array}{l}-0.3 \\
\end{array}$ & 1.3 & 1.85 & 1.5 & 1 & 1 & 1.2 & 0.6 & 0.5 \\
\hline-30 & -0.9 & -0.6 & -0.3 & 1.1 & 1.85 & 1.15 & 1.05 & 0.9 & 1.15 & 0.2 & 0.05 \\
\hline-28 & -1.25 & -1.3 & -0.75 & 1.1 & 1.5 & 1.15 & 1.05 & 0.9 & 1.15 & $\begin{array}{l}0.2 \\
\end{array}$ & 0.05 \\
\hline-26 & $\begin{array}{l}-1.7 \\
\end{array}$ & -1.3 & -0.75 & 0.2 & 1.5 & 0.25 & 1 & 0.85 & 0.9 & -0.05 & -0.3 \\
\hline-24 & -2.3 & -2 & -1.2 & 0.2 & 0.45 & 0.25 & 1 & 0.85 & 0.9 & -0.55 & -0.65 \\
\hline-22 & -2.85 & -2 & -1.2 & -0.15 & 0.45 & -0.6 & 0.35 & 0.25 & 0.3 & -0.9 & -1.1 \\
\hline-20 & -3.65 & -2 & -1.4 & -0.75 & -0.4 & -1.35 & 0.35 & 0.25 & 0.3 & -1.5 & -1.4 \\
\hline-18 & -4.15 & -2 & -1.4 & -1.6 & -1.25 & -2.05 & -0.5 & -0.6 & -0.3 & -2.2 & -2 \\
\hline-16 & -4.45 & -1.8 & -1.35 & -2.4 & -2 & -2.8 & $\begin{array}{l}-1.4 \\
\end{array}$ & -1.3 & -0.9 & -3 & -2.7 \\
\hline-14 & -5.1 & -2 & -1.35 & -3.1 & -2.65 & -3.5 & -2.25 & \begin{tabular}{|l|}
-2.3 \\
\end{tabular} & -1.7 & $\begin{array}{l}-3.6 \\
\end{array}$ & -3.35 \\
\hline
\end{tabular}




\begin{tabular}{|c|c|c|c|c|c|c|c|c|c|c|c|}
\hline-12 & -5.8 & -2.1 & -1.6 & -3.8 & -3.35 & -3.95 & -3 & -3.15 & -2.45 & -4 & -3.95 \\
\hline-10 & -6.5 & -2.55 & -2.1 & -4.7 & -4.1 & -5 & -3.8 & -3.9 & -3.4 & -4.9 & -4.35 \\
\hline-8 & -7.1 & -3.3 & -3.2 & -5.4 & -4.75 & -5.5 & -4.95 & -4.7 & -4.3 & -5.5 & -5.2 \\
\hline-6 & -7.9 & -4.2 & -4.2 & -5.9 & -5.3 & -6.15 & -5.8 & -5.75 & -5.4 & -6.35 & -6.15 \\
\hline-4 & -8.6 & -5 & -5.1 & -6.55 & -6 & -6.45 & -6.5 & -6.75 & -6.5 & -7.35 & -7.05 \\
\hline-2 & -8.9 & -5.9 & -6.2 & -7.4 & -6.8 & -6.85 & -7.6 & -7.7 & -7.6 & -7.6 & -7.7 \\
\hline 0 & -10.3 & -7 & -7.2 & -8.7 & -8 & -7.5 & -8.65 & -8.9 & -8.5 & -9 & -9 \\
\hline 2 & -10.1 & -6.15 & -6.2 & -7.8 & -7.25 & -7.6 & -7.7 & -7.6 & -7.8 & -8.25 & -8.1 \\
\hline 4 & -9.05 & -4.85 & -5 & -6.6 & -5.95 & -6.8 & -6.5 & -6.2 & -6.6 & -7.2 & -7.1 \\
\hline 6 & -7.2 & -3.85 & -3.85 & -5.2 & -4.4 & -5.95 & -4.9 & -4.95 & -5.3 & -6 & -6.15 \\
\hline 8 & -6.35 & -3 & -2.65 & -3.85 & -3.05 & -4.7 & -3.7 & -3.8 & -4.4 & -5.1 & -5.3 \\
\hline 10 & -5.9 & -2.1 & -1.7 & -2.6 & -1.8 & -3.4 & -2.4 & -2.7 & -3.3 & -3.65 & -4 \\
\hline 12 & -4.85 & -2 & -0.55 & -1.75 & -0.75 & -2.2 & -1 & -1.85 & -2.25 & -2.7 & -2.55 \\
\hline 14 & -3.15 & -1.7 & -0.2 & -0.85 & -0.2 & -0.8 & -0.2 & -0.5 & -1.5 & -1.4 & -1.6 \\
\hline 16 & -2.2 & -0.2 & 0 & 0 & 0 & -0.2 & 0 & 0 & -0.6 & -0.3 & -0.2 \\
\hline 18 & -0.8 & 0 & 0 & 0 & 0 & 0 & 0 & 0 & 0 & 0 & 0 \\
\hline 20 & -0.25 & 0 & & 0 & & 0 & & 0 & 0 & 0 & 0 \\
\hline 22 & 0 & & & & & & & & & & \\
\hline 24 & 0 & & & & & & & & & & \\
\hline 26 & & & & & & & & & & & \\
\hline 28 & & & & & & & & & & & \\
\hline 30 & & & & & & & & & & \\
\hline
\end{tabular}


Table A.4 - Cross-sections (profiles) of the scour hole for $\mathrm{L}_{\mathrm{a}}=25 \mathrm{~cm}$

\begin{tabular}{|c|c|c|c|c|c|c|c|c|c|c|c|}
\hline \multicolumn{12}{|c|}{ Scour Depth for $\mathrm{L}_{\mathrm{a}}=25 \mathrm{~cm}(\mathrm{~cm})$} \\
\hline \multirow{3}{*}{$\begin{array}{c}X \\
(\mathrm{~cm})\end{array}$} & \multirow{3}{*}{ WithoutCollar } & \multicolumn{5}{|c|}{$\mathrm{B}_{\mathrm{c}}=10 \mathrm{~cm}$} & \multicolumn{5}{|c|}{$\mathrm{B}_{\mathrm{c}}=7.5 \mathrm{~cm}$} \\
\hline & & & & & & & & & & & \\
\hline & & -2 & -1 & 0 & 1 & 2 & -2 & -1 & 0 & 1 & 2 \\
\hline-146 & & & & & & & & & 2.45 & & \\
\hline-144 & & 0 & & & & & & & 2.45 & & \\
\hline-142 & & 0.8 & & & & & & & 2.45 & & \\
\hline-140 & & 1.4 & & & & & & & 2.45 & & \\
\hline-138 & & 1.8 & & & & & & & 2.45 & & \\
\hline-136 & & 1.8 & 0 & & & & & & 2.45 & & \\
\hline-134 & & 1.8 & 0.4 & & & & & & 2.25 & & \\
\hline-132 & & 1.85 & 0.6 & & & & & & 2.25 & & \\
\hline-130 & & 1.85 & 0.95 & 1.5 & & & & & 2.25 & & \\
\hline-128 & & 1.85 & 1 & 1.15 & & & & & 2.25 & & \\
\hline-126 & & 1.85 & 1.2 & 1.15 & & & & & 2.25 & 2.4 & \\
\hline-124 & & 1.85 & 1.25 & 1.15 & & & 0 & & 2.2 & 2.4 & \\
\hline-122 & & 1.85 & 1.7 & 1.15 & & & 0.4 & & 2.2 & 2.4 & \\
\hline-120 & & 1.85 & 1.7 & 1.15 & & & 0.4 & & 2.2 & 2.25 & \\
\hline-118 & & 1.55 & 1.7 & 1.1 & & & 0.9 & & 2.2 & 2.25 & \\
\hline-116 & & 1.55 & 1.7 & 1.1 & & & 0.9 & & 2.2 & 2.25 & \\
\hline-114 & & 1.55 & 1.7 & 1.1 & & & 1.6 & & 2 & 2.25 & \\
\hline-112 & & 1.55 & 1.7 & 1.1 & & & 1.6 & & 2 & 2.25 & \\
\hline-110 & & 1.55 & 1.7 & 1.1 & & & 2.15 & 0 & 2 & 2 & \\
\hline-108 & 0 & 1.55 & 1.7 & 1.05 & & & 2.15 & 0.6 & 2 & 2 & \\
\hline-106 & 0.7 & 1.55 & 1.7 & 1.05 & & & 2.15 & 0.6 & 2 & 2 & \\
\hline-104 & 1.85 & 1.55 & 0.7 & 1.8 & & & 2.15 & 1.15 & 1.95 & 2 & \\
\hline-102 & 2.15 & 1.55 & 0.7 & 2.5 & 0 & & 2.15 & 1.15 & 1.95 & 2 & \\
\hline-100 & 2 & 1.55 & 0.7 & 2.45 & 0.3 & & 2 & 1.15 & 1.95 & 1.9 & \\
\hline-98 & 2 & 1.55 & 0.7 & 2.45 & 1.3 & & 2 & 1.25 & 1.95 & 1.9 & \\
\hline-96 & 1.75 & 1.55 & 0.7 & 2.45 & 1.45 & & 2 & 1.25 & 1.75 & 1.9 & \\
\hline-94 & 1.75 & 1.55 & 1.7 & 2.45 & 1.45 & & 2 & 1.25 & 1.75 & 1.9 & \\
\hline-92 & 1.75 & 1.55 & 1.7 & 2.45 & 1.45 & & 2 & 1.25 & 1.75 & 1.9 & \\
\hline-90 & 1.75 & 1.55 & 1.7 & 2.2 & 1.45 & & 2.25 & 1.25 & 1.75 & 1.75 & \\
\hline-88 & 1.75 & 1.55 & 1.7 & 2.2 & 1.45 & & 2.25 & 1.15 & 1.5 & 1.75 & \\
\hline-86 & 1.3 & 1.55 & 1.7 & 2.2 & 1.7 & & 2.25 & 1.15 & 1.5 & 1.75 & \\
\hline-84 & 1.3 & 1.55 & 1.65 & 2.2 & 1.7 & & 2.25 & 1.15 & 1.55 & 1.2 & \\
\hline-82 & 1.3 & 1.55 & 1.65 & 2.2 & 1.7 & & 2.25 & 1.15 & 1.55 & 1.2 & \\
\hline-80 & 1.3 & 1.55 & 1.65 & 1.8 & 1.7 & & 2.15 & 1.15 & 1.55 & 0.4 & \\
\hline-78 & 1.3 & 1.35 & 1.65 & 1.8 & 1.7 & & 2.15 & 2.2 & 1.55 & 0.4 & \\
\hline-76 & 0.7 & 1.35 & 1.65 & 1.8 & 1.8 & & 2.15 & 2.5 & 1.55 & 0.4 & \\
\hline-74 & 0.7 & 1.35 & 1.55 & 1.8 & 1.8 & 0 & 2.15 & 2.5 & 1.6 & 0.4 & \\
\hline-72 & 0.7 & 1.35 & 1.55 & 1.8 & 1.8 & 0 & 2.15 & 2.5 & 1.6 & 0.4 & \\
\hline-70 & 0.7 & 1.35 & 1.55 & 1.5 & 1.8 & 0 & 1.75 & 2.5 & 1.6 & 0 & \\
\hline-68 & 0.7 & 1.35 & 1.55 & 1.5 & 1.8 & 0.15 & 1.75 & 2.5 & 1.6 & 0 & 0.25 \\
\hline-66 & 0.5 & 1.35 & 1.55 & 1.5 & 2.4 & 0.35 & 1.75 & 1.9 & 1.6 & 0 & 0.25 \\
\hline-64 & 0.5 & 1.35 & 1.55 & 1.5 & 2.4 & 1.1 & 1.75 & 1.9 & 1.7 & 0 & 1.5 \\
\hline-62 & 0.5 & 1.35 & 1.55 & 1.5 & 2.4 & 2.2 & 1.75 & 1.9 & 1.7 & 0 & 2.15 \\
\hline-60 & 0.5 & 1.35 & 1.55 & 1.35 & 2.4 & 2.4 & 1.4 & 1.9 & 1.7 & 0 & 2.25 \\
\hline-58 & 0.5 & 1.3 & 1.55 & 1.35 & 2.4 & 2.4 & 1.4 & 1.9 & 1.7 & 0 & 2.25 \\
\hline-56 & 0.15 & 1.3 & 1.55 & 1.35 & 2.25 & 2.4 & 1.05 & 1.2 & 1.7 & 0.65 & 2.25 \\
\hline-54 & 0.15 & 1.3 & 1.5 & 1.35 & 2.25 & 2.15 & 1.05 & 1.2 & 1.65 & 0.65 & 2.25 \\
\hline-52 & 0.15 & 1.3 & 1.5 & 1.35 & 2.25 & 2.15 & 0.7 & 1.2 & 1.65 & 1.1 & 2.1 \\
\hline-50 & 0.15 & 1.3 & 1.5 & 0.85 & 2.25 & 2.15 & 0.7 & 1.2 & 1.65 & 1.1 & 2.1 \\
\hline-48 & 0.15 & 1.2 & 1.5 & 0.85 & 2.25 & 2.15 & 0.3 & 1.2 & 1.65 & 1.3 & 2.2 \\
\hline-46 & -0.4 & 1.2 & 1.5 & 0.85 & 2 & 2.15 & 0.3 & 0.65 & 1.65 & 1.3 & 2.2 \\
\hline-44 & -0.4 & 1.2 & 1.35 & 0.85 & 2 & 1.85 & -0.05 & 0.8 & 1.3 & 1.6 & 2 \\
\hline-42 & -0.8 & 1.2 & 1.35 & 0.85 & 2 & 1.85 & -0.05 & $\begin{array}{l}0.8 \\
\end{array}$ & 1.3 & $\begin{array}{l}1.6 \\
\end{array}$ & 2 \\
\hline-40 & -0.8 & 1.2 & 1.35 & 0.65 & 2 & 1.85 & $\begin{array}{l}-0.3 \\
\end{array}$ & 0.8 & 1.3 & 2.15 & 1.8 \\
\hline-38 & -1 & 1.05 & 1.35 & 0.65 & 2 & 1.85 & -0.3 & 0.8 & 1.3 & 2.15 & 1.8 \\
\hline-36 & -1.15 & 1.05 & 1.35 & 0.3 & 1.4 & 1.85 & -0.4 & 0.7 & 1.05 & 2.15 & 1.7 \\
\hline-34 & $\begin{array}{l}-1.6 \\
\end{array}$ & 1.05 & 1 & 0.3 & 1.4 & 1.7 & \begin{tabular}{l|l|}
-0.4 \\
\end{tabular} & 0.7 & 1.05 & 2.15 & 1.7 \\
\hline
\end{tabular}




\begin{tabular}{|c|c|c|c|c|c|c|c|c|c|c|c|}
\hline-32 & -1.75 & 1.05 & 1 & -0.05 & 1.4 & 1.7 & -0.7 & 0.35 & 0.7 & 2.15 & 1.4 \\
\hline-30 & -2.3 & 0.9 & 1 & -0.05 & 1.4 & 1.4 & -0.7 & 0.35 & 0.7 & 2 & 1.4 \\
\hline-28 & -2.8 & 0.9 & 0.75 & -0.2 & 1.4 & 1.4 & -1 & -0.1 & 0.25 & 2 & 0.6 \\
\hline-26 & -3.1 & 0.05 & 0.75 & -0.2 & 0.4 & 0.4 & -1 & -0.1 & 0.25 & 1.55 & 0.6 \\
\hline-24 & -3.6 & 0.05 & 0.3 & -0.3 & 0.4 & 0.4 & -1.15 & -0.1 & -0.2 & 1.55 & -0.15 \\
\hline-22 & -4.25 & -0.5 & 0.3 & -0.3 & -0.35 & -0.35 & -1.15 & -0.1 & -0.2 & 0.1 & -0.85 \\
\hline-20 & -4.75 & -2 & -0.5 & -0.4 & -0.85 & -1.1 & -1.65 & -0.2 & -0.8 & 0.1 & -1.45 \\
\hline-18 & -5.2 & -2 & -0.5 & -0.4 & -1.3 & -1.8 & -1.65 & -0.45 & -0.8 & -0.5 & -2.05 \\
\hline-16 & -5.45 & -2 & -0.6 & -0.75 & -1.85 & -2.6 & -1.65 & -0.8 & -0.8 & -0.95 & -2.85 \\
\hline-14 & -6 & -2 & -0.6 & -0.75 & -2.3 & -3.4 & -1.65 & -1.25 & -1.25 & -1.5 & -3.7 \\
\hline-12 & -6.45 & -2 & -0.9 & -1.25 & -3.05 & -4.2 & -1.95 & -1.55 & -1.75 & -2.15 & -4.4 \\
\hline-10 & -7.3 & -2 & -0.9 & -1.65 & -3.85 & -5.1 & -2.5 & -1.6 & -2.45 & -2.7 & -5.5 \\
\hline-8 & -8.4 & -2 & -1.35 & -2.6 & -4.65 & -6.25 & -3.55 & -2.7 & -3.65 & -3.7 & -6.45 \\
\hline-6 & -9.1 & -2 & -2.2 & -3.55 & -5.55 & -7.75 & -4.3 & -3.7 & -4.6 & -4.75 & -7.65 \\
\hline-4 & -9.7 & -2 & -3.3 & -4.55 & -6.75 & -8.75 & -4.8 & -4.55 & -5.6 & -5.4 & -8.8 \\
\hline-2 & -9.7 & -2 & -4.4 & -5.4 & -7.95 & -9.25 & -5.55 & -5.35 & -6.55 & -6.7 & -9.5 \\
\hline 0 & -10.2 & -2 & -5.3 & -6.3 & -8.5 & -9.9 & -6 & -6.5 & -7.6 & -7.8 & -10.5 \\
\hline 2 & -10.2 & -2 & -4.3 & -5.75 & -7.9 & -9.5 & -5.65 & -5.75 & -6.7 & -6.8 & -9.2 \\
\hline 4 & -8.95 & -2.85 & -3.25 & -4.6 & -6.65 & -8.6 & -4.8 & -5.15 & -5.8 & -5.45 & -8.1 \\
\hline 6 & -7.45 & -3.5 & -3.2 & -3.55 & -5.2 & -7.4 & -4.15 & -4 & -4.65 & -4.4 & -6.6 \\
\hline 8 & -6.1 & -3.95 & -3.45 & -2.9 & -4.1 & -6.1 & -3.4 & -2.8 & -3.8 & -3.6 & -5.36 \\
\hline 10 & -5.4 & -4.1 & -3.3 & -2.6 & -3.3 & -4.75 & -2.65 & -2.45 & -3.05 & -2.85 & -4.1 \\
\hline 12 & -4.25 & -3.2 & -3.65 & -2.45 & -3 & -3.4 & -2 & -2.3 & -2.45 & -1.75 & -3.25 \\
\hline 14 & -3 & -2.4 & -3 & -2.45 & -2.1 & -2.7 & -1.6 & -1.85 & -1.95 & -0.6 & -2.3 \\
\hline 16 & -1.9 & -2.15 & -2.4 & -2.15 & -0.85 & -1.65 & -1.1 & -1.65 & -1.15 & 0 & -0.95 \\
\hline 18 & -0.6 & -1.95 & -1.8 & -1.6 & 0 & -0.6 & -0.3 & -0.6 & -1.05 & 0 & -0.1 \\
\hline 20 & -0.25 & -1.65 & -1 & -1.25 & 0 & 0 & 0 & -0.15 & -0.3 & & 0 \\
\hline 22 & 0 & -0.6 & -0.2 & -0.9 & 0 & 0 & 0 & 0 & 0 & & \\
\hline 24 & 0 & -0.3 & 0 & -0.2 & & 0 & & 0 & 0 & & \\
\hline 26 & & 0 & 0 & 0 & & & & & & & \\
\hline 28 & & 0 & & 0 & & & & & & & \\
\hline 30 & & & & & & & & & & & \\
\hline
\end{tabular}


Table A.4 - Cross-sections (profiles) of the scour hole for $\mathrm{L}_{\mathrm{a}}=25 \mathrm{~cm}$ (continued)

\begin{tabular}{|c|c|c|c|c|c|c|c|c|c|c|c|}
\hline \multicolumn{12}{|c|}{ Scour Depth for $L_{a}=25 \mathrm{~cm}(\mathrm{~cm})$} \\
\hline \multirow{3}{*}{$\begin{array}{c}X \\
\text { (cm) }\end{array}$} & \multirow{3}{*}{ WithoutCollar } & \multicolumn{5}{|c|}{$\mathrm{B}_{\mathrm{c}}=5 \mathrm{~cm}$} & \multicolumn{5}{|c|}{$B_{c}=2.5 \mathrm{~cm}$} \\
\hline & & \multicolumn{10}{|c|}{$\mathrm{Z}_{\mathrm{c}}(\mathrm{cm})$} \\
\hline & & -2 & -1 & 0 & 1 & 2 & -2 & -1 & 0 & 1 & 2 \\
\hline \multicolumn{12}{|l|}{-146} \\
\hline \multicolumn{12}{|l|}{-144} \\
\hline \multicolumn{12}{|l|}{-142} \\
\hline \multicolumn{12}{|l|}{-140} \\
\hline-138 & & & & & & & & & & & \\
\hline-136 & & & & 1.75 & & & & & & & \\
\hline-134 & & & & 1.75 & & & & & & & \\
\hline-132 & & & & 1.75 & & & & & & & \\
\hline-130 & & & 1.8 & 1.75 & & & & & & & \\
\hline-128 & & & 1.9 & 1.75 & & & & & & & \\
\hline-126 & & & 1.9 & 1.75 & & & & & & & \\
\hline-124 & & & 1.9 & 1.75 & & & & & & & \\
\hline-122 & & & 1.9 & 1.75 & & & & & & & \\
\hline-120 & & & 1.9 & 1.75 & & & 0 & 0 & & & \\
\hline-118 & & & 1.8 & 1.8 & & & 0.3 & 0.7 & & & \\
\hline-116 & & & 1.8 & 1.8 & 0 & & 1.95 & 1.85 & 0 & & \\
\hline-114 & & 1.6 & 1.8 & 1.8 & 1.15 & 0 & 1.6 & 1.5 & 0.4 & & \\
\hline-112 & & 1.2 & 1.8 & 1.8 & 1.1 & 0.5 & 1.6 & 1.5 & 1.9 & & \\
\hline-110 & & 1.2 & 1.8 & 1.8 & 1.1 & 0.5 & 1.6 & 1.5 & 1.85 & & \\
\hline-108 & 0 & 1.2 & 1.75 & 1.8 & 1.55 & 1.65 & 1.6 & 1.25 & 1.85 & & \\
\hline-106 & 0.7 & 1.2 & 1.75 & 1.8 & 1.55 & 1.8 & 1.35 & 1.25 & 1.45 & 0 & \\
\hline-104 & 1.85 & 1.2 & 1.75 & 1.8 & 1.65 & 1.8 & 1.35 & 1.25 & 1.45 & 2 & \\
\hline-102 & 2.15 & 1.2 & 1.75 & 1.8 & 1.7 & 1.6 & 1.35 & 1.25 & 1.45 & 2 & \\
\hline-100 & 2 & 1.2 & 1.75 & 1.8 & 1.7 & 1.6 & 1.35 & 1.25 & 1.45 & 1.6 & \\
\hline-98 & 2 & 1.2 & 1.5 & 1.9 & 1.7 & 1.6 & 1.35 & 1.1 & 1.45 & 1.6 & 0 \\
\hline-96 & 1.75 & 1.2 & 1.5 & 1.9 & 1.7 & 1.6 & 1.25 & 1.1 & 1.1 & 1.6 & 0.1 \\
\hline-94 & 1.75 & 1.2 & 1.5 & 1.9 & 1.7 & 1.65 & 1.25 & 1.1 & 1.1 & 1.6 & 0.1 \\
\hline-92 & 1.75 & 0.8 & 1.5 & 1.9 & 1.7 & 1.65 & 1.25 & 1.1 & 1.1 & 1.6 & 1.6 \\
\hline-90 & 1.75 & 0.8 & 1.5 & 1.9 & 1.7 & 1.65 & 1 & 1.1 & 1.1 & 1 & 2.3 \\
\hline-88 & 1.75 & 0.8 & 1.5 & 1.9 & 1.7 & 1.65 & 1 & 1.25 & 1.1 & 1 & 2.25 \\
\hline-86 & 1.3 & 0.8 & 1.5 & 1.9 & 1.7 & 1.65 & 1 & 1.25 & 0.9 & 1 & 2.25 \\
\hline-84 & 1.3 & 0.8 & 1.5 & 1.9 & 1.6 & 1.65 & 1 & 1.25 & 0.9 & 1 & 1.65 \\
\hline-82 & 1.3 & 0.9 & 1.5 & 2 & 1.6 & 1.5 & 1 & 1.25 & 0.9 & 1 & 1.65 \\
\hline-80 & 1.3 & 0.9 & 1.5 & 2 & 1.6 & 1.5 & 0.7 & 1.25 & 0.9 & 0.65 & 1.65 \\
\hline-78 & 1.3 & 0.9 & 1.5 & 2 & 1.6 & 1.5 & 0.7 & 1.1 & 0.9 & 0.65 & 1.65 \\
\hline-76 & 0.7 & 0.9 & 1.5 & 2 & 1.6 & 1.5 & 0.7 & 1.1 & 0.75 & 0.65 & 1.65 \\
\hline-74 & 0.7 & 0.9 & 1.5 & 2 & 1.5 & 1.5 & 0.7 & 1.1 & 0.75 & 0.65 & 0.9 \\
\hline-72 & 0.7 & 1 & 1.6 & 1.9 & 1.5 & 1.55 & 0.7 & 1.1 & 0.75 & 0.65 & 0.9 \\
\hline-70 & 0.7 & 1 & 1.6 & 1.9 & 1.5 & 1.55 & 0.6 & 1.1 & 0.75 & 0.5 & 0.9 \\
\hline-68 & 0.7 & 1 & 1.6 & 1.9 & 1.5 & 1.55 & 0.6 & 0.8 & 0.75 & 0.5 & 0.9 \\
\hline-66 & 0.5 & 1 & 1.6 & 1.9 & 1.5 & 1.55 & 0.6 & 0.8 & 0.65 & 0.5 & 0.9 \\
\hline-64 & 0.5 & 1 & 1.6 & 1.9 & 1.3 & 1.55 & 0.6 & 0.8 & 0.65 & 0.5 & 0.35 \\
\hline-62 & 0.5 & 1.6 & 1.35 & 1.9 & 1.3 & 2.2 & 0.6 & 0.8 & 0.65 & 0.5 & 0.35 \\
\hline-60 & 0.5 & 1.6 & 1.35 & 2.15 & 1.3 & 2.2 & 0.3 & 0.8 & 0.65 & 0.35 & 0.35 \\
\hline-58 & 0.5 & 1.6 & 1.35 & 2.15 & 1.4 & 2.2 & 0.3 & 0.45 & 0.65 & 0.35 & 0.35 \\
\hline-56 & 0.15 & 1.6 & 1.35 & 2.15 & 1.4 & 2.2 & 0.3 & 0.45 & 0.4 & 0.35 & 0.35 \\
\hline-54 & 0.15 & 1.6 & 1.35 & 2.15 & 1.8 & 2.2 & 0.3 & 0.45 & 0.4 & 0.35 & 0.35 \\
\hline-52 & 0.15 & 1.5 & 1.25 & 2.15 & 1.8 & 2 & 0.3 & 0.45 & 0.4 & 0.35 & 0.35 \\
\hline-50 & 0.15 & 1.5 & 1.25 & 2.05 & 1.85 & 2 & 0 & 0.45 & 0.4 & 0.25 & 0.35 \\
\hline-48 & 0.15 & 1.5 & 1.25 & 2.05 & 1.85 & 2 & 0 & 0.25 & 0.4 & 0.25 & 0.35 \\
\hline-46 & $\begin{array}{l}-0.4 \\
\end{array}$ & 1.5 & 1.25 & 2.05 & 1.7 & 2 & 0 & 0.25 & 0 & 0.25 & 0.35 \\
\hline-44 & -0.4 & 1.5 & 1.25 & 2.05 & 1.7 & 2 & 0 & -0.1 & 0 & 0.25 & 0.1 \\
\hline-42 & -0.8 & 1.15 & 0.9 & 2.05 & 1.7 & 1.75 & 0 & -0.1 & 0 & 0.25 & 0.1 \\
\hline-40 & -0.8 & 1.15 & 0.9 & 1.5 & 1.7 & 1.75 & -0.35 & -0.3 & 0 & 0 & 0.1 \\
\hline-38 & -1 & 0.9 & 0.9 & 1.5 & 1.8 & 1.6 & -0.35 & -0.3 & 0 & 0 & 0.1 \\
\hline-36 & -1.15 & 0.9 & 0.9 & 1.5 & 1.8 & 1.6 & $\begin{array}{l}-0.6 \\
\end{array}$ & $\begin{array}{l}-0.6 \\
\end{array}$ & -0.5 & 0 & -0.45 \\
\hline
\end{tabular}




\begin{tabular}{|c|c|c|c|c|c|c|c|c|c|c|c|}
\hline-34 & -1.6 & 0.15 & 0.9 & 1.5 & 1.55 & 1.35 & -0.6 & -0.6 & -0.5 & -0.2 & -0.45 \\
\hline-32 & -1.75 & 0.15 & 0.6 & 1.5 & 1.55 & 1.35 & -1 & -0.9 & -0.5 & -0.2 & -0.8 \\
\hline-30 & -2.3 & -0.05 & 0.6 & 1 & 0 & 0.9 & -1 & -0.9 & -0.5 & -0.6 & -0.8 \\
\hline-28 & -2.8 & -0.55 & 0.25 & 1 & 0 & 0.9 & -1.25 & -1.15 & -0.7 & -0.6 & -1.3 \\
\hline-26 & -3.1 & -1 & 0.25 & 0.35 & 0.4 & 0.1 & -1.25 & -1.15 & -0.7 & -0.75 & -1.3 \\
\hline-24 & -3.6 & -1.4 & 0 & 0.35 & 0.4 & 0.1 & -1.25 & -1.65 & -0.75 & -1.15 & -1.3 \\
\hline-22 & -4.25 & -1.7 & 0 & -0.15 & -0.1 & -0.7 & -1.7 & -1.65 & -1.05 & -1.45 & -1.8 \\
\hline-20 & -4.75 & -1.9 & -0.4 & -0.85 & -1.15 & -1.2 & -2.25 & -2.35 & -1.55 & -2 & -2.5 \\
\hline-18 & -5.2 & -1.95 & -1 & -1.65 & -1.9 & -2.15 & -2.75 & -2.95 & -2.25 & -2.85 & -3.3 \\
\hline-16 & -5.45 & -2.25 & -1.5 & -2.45 & -2.65 & -3.1 & -3.55 & -3.65 & -3.15 & -3.6 & -3.9 \\
\hline-14 & -6 & -2.5 & -2.1 & -3.3 & -3.15 & -4 & -4.55 & -4.5 & -4.1 & -4.35 & -4.6 \\
\hline-12 & -6.45 & -3 & -2.7 & -4.15 & -4.15 & -4.85 & -5.2 & -5.35 & -5 & -5.25 & -5.4 \\
\hline-10 & -7.3 & -3.6 & -3.5 & -5.15 & -5.25 & -5.85 & -6.3 & -6.15 & -5.6 & -6.05 & -6.35 \\
\hline-8 & -8.4 & -4.65 & -4.5 & -6.2 & -6.35 & -6.9 & -7.05 & -6.9 & -6.55 & -6.9 & -7.2 \\
\hline-6 & -9.1 & -5.5 & -5.55 & -7.45 & -7.45 & -8.6 & -7.7 & -7.65 & -7.6 & -7.8 & -8.3 \\
\hline-4 & -9.7 & -6.5 & -6.8 & -8.45 & -8.2 & -9.2 & -8.65 & -8.7 & -8.5 & -8.85 & -9.35 \\
\hline-2 & -9.7 & -7.35 & -7.8 & -9.2 & -8.6 & -9.5 & -9.3 & -9.2 & -8.75 & -9.65 & -9.7 \\
\hline 0 & -10.2 & -7.8 & -8.3 & -10.2 & -9.8 & -10.6 & -10 & -10.1 & -9.5 & -10.5 & -10.7 \\
\hline 2 & -10.2 & -6.9 & -7.3 & -9 & -8.9 & -9.6 & -9.05 & -9.75 & -9.5 & -9.3 & -10 \\
\hline 4 & -8.95 & -6.1 & -6 & -7.45 & -7.3 & -8.3 & -7.65 & -8.65 & -8.5 & -8.1 & -8.2 \\
\hline 6 & -7.45 & -5.1 & -4.65 & -5.9 & -6.35 & -6.9 & -6.25 & -7.3 & -7.7 & -6.9 & -7 \\
\hline 8 & -6.1 & -3.6 & -3.6 & -4.75 & -5.05 & -6 & -5.15 & -6.15 & -6.4 & -5.4 & -6.45 \\
\hline 10 & -5.4 & -2.65 & -2.4 & -3.45 & -3.75 & -4.35 & -3.95 & -4.45 & -5.6 & -4 & -5.4 \\
\hline 12 & -4.25 & -1.85 & -1.15 & -2.15 & -2.95 & -3 & -2.65 & -3.4 & -4.6 & -3 & -4.15 \\
\hline 14 & -3 & -1.25 & -0.2 & -1.25 & -2.3 & -1.9 & -1.65 & -2.15 & -3.4 & -2.15 & -2.9 \\
\hline 16 & -1.9 & -0.4 & 0 & -0.7 & -1.2 & -0.75 & -0.4 & -1.4 & -2.4 & -0.85 & -1.45 \\
\hline 18 & -0.6 & 0 & 0 & 0 & -0.4 & -0.1 & 0 & -0.4 & -1.5 & -0.3 & -0.4 \\
\hline 20 & -0.25 & 0 & & 0 & 0 & 0 & 0 & 0 & -0.95 & 0 & 0 \\
\hline 22 & 0 & & & 0 & 0 & 0 & & 0 & -0.55 & 0 & 0 \\
\hline 24 & 0 & & & & & & & & -0.4 & & \\
\hline 26 & & & & & & & & & 0 & & \\
\hline 28 & & & & & & & & & 0 & & \\
\hline 30 & & & & & & & & & & & \\
\hline
\end{tabular}


Table A.5 - Cross-sections (profiles) of the scour hole for $\mathrm{L}_{\mathrm{a}}=35 \mathrm{~cm}$

\begin{tabular}{|c|c|c|c|c|c|c|c|c|c|c|c|}
\hline \multicolumn{12}{|c|}{ Scour Depth for $\mathrm{L}_{\mathrm{a}}=35 \mathrm{~cm}(\mathrm{~cm})$} \\
\hline \multirow{3}{*}{$\begin{array}{c}X \\
(\mathrm{~cm})\end{array}$} & \multirow{3}{*}{ WithoutCollar } & \multicolumn{5}{|c|}{$\mathrm{B}_{\mathrm{c}}=10 \mathrm{~cm}$} & \multirow{2}{*}{\multicolumn{5}{|c|}{$\mathrm{B}_{\mathrm{c}}=7.5 \mathrm{~cm}$}} \\
\hline & & \multicolumn{9}{|c|}{$Z_{c}(\mathrm{~cm})$} & \\
\hline & & -2 & -1 & 0 & 1 & 2 & -2 & -1 & 0 & 1 & 2 \\
\hline-152 & & & & & & & & & & & \\
\hline-150 & & & & & 0 & & & & & 0 & \\
\hline-148 & & & & & 0.3 & & & & & 1 & \\
\hline-146 & & & & & 0.3 & & & & & 2.55 & \\
\hline-144 & & 0.8 & & 2.35 & 0.75 & 2.3 & 1.8 & & & 2.6 & \\
\hline-142 & & 0.8 & 1.9 & 2 & 0.75 & 2.3 & 1.7 & 1.7 & 2.1 & 2.4 & \\
\hline-140 & & 0.8 & 1.85 & 2 & 1.2 & 2.3 & 1.7 & 1.8 & 2.05 & 2.4 & 0 \\
\hline-138 & & 0.8 & 1.85 & 2 & 1.2 & 2.3 & 1.7 & 1.8 & 2.05 & 2.4 & 0.9 \\
\hline-136 & & 0.8 & 1.85 & 2 & 1.9 & 2.3 & 1.7 & 1.8 & 2.05 & 2.4 & 2.1 \\
\hline-134 & & 0.8 & 1.85 & 2 & 1.9 & 2.3 & 1.7 & 1.8 & 2.05 & 2.4 & 2.2 \\
\hline-132 & & 0.6 & 1.85 & 1.9 & 1.9 & 2 & 1.55 & 1.8 & 2.05 & 2.1 & 1.9 \\
\hline-130 & & 0.6 & 2.1 & 1.9 & 1.9 & 2 & 1.55 & 1.9 & 1.75 & 2.1 & 1.9 \\
\hline-128 & 0 & 0.6 & 2.1 & 1.9 & 1.9 & 2 & 1.55 & 1.9 & 1.75 & 2.1 & 1.8 \\
\hline-126 & 0.55 & 0.6 & 2.1 & 1.9 & 1.9 & 2 & 1.55 & 1.9 & 1.75 & 2.1 & 1.8 \\
\hline-124 & 2.05 & 0.6 & 2.1 & 1.9 & 1.9 & 2 & 1.55 & 1.9 & 1.75 & 2.1 & 1.8 \\
\hline-122 & 2.1 & 0.25 & 2.1 & 2 & 1.6 & 1.85 & 1.45 & 1.9 & 1.75 & 1.7 & 1.8 \\
\hline-120 & 2.1 & 0.25 & 2.7 & 2 & 1.6 & 1.85 & 1.45 & 1.9 & 1.55 & 1.7 & 1.8 \\
\hline-118 & 2.1 & 0.25 & 2.7 & 2 & 1.6 & 1.85 & 1.45 & 1.9 & 1.55 & 1.7 & 1.7 \\
\hline-116 & 2.1 & 0.25 & 2.7 & 2 & 1.6 & 1.85 & 1.45 & 1.9 & 1.55 & 1.7 & 1.7 \\
\hline-114 & 2.1 & 0.25 & 2.7 & 2 & 1.6 & 1.85 & 1.45 & 1.9 & 1.55 & 1.7 & 1.7 \\
\hline-112 & 1.7 & 0.4 & 2.7 & 2.1 & 1.1 & $\begin{array}{l}1.8 \\
\end{array}$ & 1.55 & 1.9 & 1.65 & 1.6 & 1.7 \\
\hline-110 & 1.7 & 0.4 & 2.8 & 2.1 & 1.1 & 1.8 & 1.55 & 2 & 1.65 & 1.6 & 1.7 \\
\hline-108 & 1.7 & 0.4 & 2.8 & 2.1 & 1.1 & 1.8 & 1.55 & 2 & 1.65 & 1.6 & 1.7 \\
\hline-106 & 1.7 & 0.4 & 2.8 & 2.1 & 1.1 & 1.8 & 1.55 & 2 & 1.65 & 1.6 & 1.7 \\
\hline-104 & 1.7 & 0.4 & 2.8 & 2.1 & 0.8 & 1.8 & 1.55 & 2 & 1.65 & 1.6 & 1.7 \\
\hline-102 & 1.55 & 0.6 & 2.8 & 2.25 & 0.6 & 1.7 & 1.75 & 2 & 1.65 & 1.55 & 1.7 \\
\hline-100 & 1.55 & 0.6 & 2.7 & 2.25 & 0.5 & 1.7 & 1.75 & 2 & 2 & 1.55 & 1.7 \\
\hline-98 & 1.55 & 0.6 & 2.7 & 2.25 & 0.5 & 1.7 & 1.75 & 2 & 2 & 1.55 & 1.65 \\
\hline-96 & 1.55 & 0.6 & 2.7 & 2.25 & 1.45 & 1.7 & 1.75 & 2 & 2 & 1.55 & 1.65 \\
\hline-94 & 1.55 & 0.6 & 2.7 & 2.25 & 1.7 & 1.7 & 1.75 & 2 & 2 & 1.55 & 1.65 \\
\hline-92 & 1.2 & 0.9 & 2.7 & 2.1 & 2.25 & 1.7 & 1.75 & 2 & 2 & 1.6 & 1.65 \\
\hline-90 & 1.2 & 0.9 & 2.4 & 2.1 & 2.25 & 1.7 & 1.75 & 2.1 & 2.25 & 1.6 & 1.65 \\
\hline $\begin{array}{l}-88 \\
\end{array}$ & 1.2 & 0.9 & 2.4 & 2.1 & 2.25 & 1.7 & 1.75 & 2.1 & 2.25 & 1.6 & 1.35 \\
\hline-86 & 1.2 & 0.9 & 2.4 & 2.1 & 2.25 & 1.7 & 1.75 & 2.1 & 2.25 & 1.6 & 1.35 \\
\hline-84 & 1.2 & 0.9 & 2.4 & 2.1 & 2.25 & 1.7 & 1.75 & 2.1 & 2.25 & 1.6 & 1.35 \\
\hline-82 & 0.7 & 1.3 & 2.4 & 1.7 & 2.2 & 2 & 1.75 & 2.1 & 2.25 & 1.9 & 1.35 \\
\hline-80 & 0.7 & 1.3 & 2.2 & 1.7 & 2.2 & 2 & 1.75 & 2.3 & 2.25 & 1.9 & 1.35 \\
\hline-78 & 0.7 & 1.3 & 2.2 & 1.7 & 2.2 & 2 & 1.75 & 2.3 & 2.25 & 1.9 & 1.55 \\
\hline-76 & 0.7 & 1.3 & 2.2 & 1.7 & 2.2 & 2 & 1.75 & 2.3 & 2.25 & 1.9 & 1.55 \\
\hline-74 & 0.7 & 1.3 & 2.2 & 1.7 & 2.2 & 2 & 1.75 & 2.3 & 2.25 & 1.9 & 1.55 \\
\hline-72 & 0.3 & 1.55 & 2.2 & 1.25 & 2.2 & 1.85 & 1.85 & 2.3 & 2.25 & 2.1 & 1.55 \\
\hline-70 & 0.3 & 1.55 & 2.25 & 1.25 & 2.2 & 1.85 & 1.85 & 2.25 & 2.3 & 2.1 & 1.55 \\
\hline-68 & 0.3 & 1.55 & 2.25 & 1.25 & 2.2 & 1.85 & 1.85 & 2.25 & 2.3 & 2.1 & 2 \\
\hline-66 & 0.3 & 1.55 & 2.25 & 1.25 & 2.2 & 1.85 & 1.85 & 2.25 & 2.3 & 2.1 & 2 \\
\hline-64 & 0.3 & 1.55 & 2.25 & 1.25 & 2.2 & 1.85 & 1.85 & 2.25 & 2.3 & 2.1 & 2 \\
\hline-62 & 0.2 & 1.3 & 2.25 & 1.2 & 1.9 & 1.65 & 1.6 & 2.25 & 2.3 & 2.1 & 2 \\
\hline-60 & 0.2 & 1.3 & 2.3 & 1.2 & 1.9 & 1.65 & 1.6 & 2 & 2.1 & 2.1 & 2 \\
\hline-58 & 0.2 & 1.3 & 2.3 & 1.2 & 1.9 & 1.65 & 1.6 & 2 & 2.1 & 2.1 & 1.7 \\
\hline-56 & 0.2 & 1.3 & 2.3 & 1.2 & 1.9 & 1.65 & 1.6 & 2 & 2.1 & 2.1 & 1.7 \\
\hline-54 & 0.2 & 1.3 & 2.3 & 1.2 & 1.9 & 1.65 & 1.6 & 2 & 2.1 & 2.1 & 1.7 \\
\hline-52 & -0.2 & 0.8 & 2.3 & 1.55 & 1.8 & 1.6 & 1.3 & 2 & 2.1 & 1.9 & 1.7 \\
\hline-50 & -0.2 & 0.8 & 1.85 & 1.55 & 1.8 & 1.6 & 1.3 & 1.7 & 1.6 & 1.9 & 1.7 \\
\hline-48 & -0.45 & 0.8 & 1.85 & 1.55 & 1.8 & 1.6 & 1.3 & 1.7 & 1.6 & 1.9 & 1.5 \\
\hline-46 & -0.45 & 0.8 & 1.4 & 1.55 & 1.8 & 1.6 & 1.3 & 1.7 & 1.6 & 1.9 & 1.5 \\
\hline-44 & -1 & 0.8 & 1.4 & 1.55 & 1.8 & 1.6 & 1.3 & 1.7 & 1.6 & 1.9 & 1.5 \\
\hline-42 & -1 & 0.2 & 0.85 & 1.2 & 1.4 & 1.1 & 1.1 & 1.7 & 1.6 & 1.3 & 1.5 \\
\hline-40 & -1.4 & 0.2 & 0.85 & 1.2 & 1.4 & 1.1 & 1.1 & 1.25 & 1 & 1.3 & 1.5 \\
\hline
\end{tabular}




\begin{tabular}{|c|c|c|c|c|c|c|c|c|c|c|c|}
\hline-38 & -1.4 & -0.35 & 0.85 & 1.2 & 1.4 & 1.1 & 0.8 & 1.25 & 1 & 1.3 & 0.6 \\
\hline-36 & -1.65 & -0.35 & 0.85 & 1.2 & 1.4 & 1.1 & 0.8 & 1.25 & 1 & 1.3 & 0.6 \\
\hline-34 & -1.95 & -0.8 & 0.35 & 1.2 & 1.2 & 1.1 & 0.5 & 1.25 & 1 & 1.3 & 0.6 \\
\hline-32 & -2.3 & -0.8 & 0.35 & 0.9 & 1.2 & 0.2 & 0.5 & 1.25 & 1 & 0.9 & 0.6 \\
\hline-30 & -2.6 & -1.2 & 0 & 0.9 & 0.9 & 0.2 & 0 & 0.85 & 0.25 & 0.9 & 0.6 \\
\hline-28 & -3.15 & -1.2 & 0 & 0.3 & 0.9 & -0.3 & 0 & 0.05 & 0.25 & 0.1 & -0.15 \\
\hline-26 & -3.85 & -0.7 & 0 & 0.3 & 0.05 & -1 & -0.5 & 0.05 & 0.25 & 0.1 & -0.8 \\
\hline-24 & -4.45 & -0.7 & 0 & -0.5 & 0.05 & -1.6 & -1.1 & 0.05 & -0.3 & -0.4 & -1.3 \\
\hline-22 & -5.1 & -1.3 & -0.1 & -1.2 & -0.8 & -2.3 & -1.75 & -0.9 & -0.85 & -1.3 & -2 \\
\hline-20 & -5.55 & -1.3 & -0.5 & -2 & -1.6 & -3 & -2.3 & -1.45 & -1.55 & -2.2 & -3 \\
\hline-18 & -6.25 & -1.3 & -0.75 & -2.4 & -2.4 & -3.9 & -2.65 & -1.65 & -2.6 & -3 & -3.75 \\
\hline-16 & -6.9 & -1.6 & -0.95 & -2.95 & -3.4 & -4.6 & -2.75 & -2.05 & -3.5 & -3.8 & -4.5 \\
\hline-14 & -7.5 & -2 & -1.3 & -3.8 & -4.3 & -5.5 & -3.15 & -2.45 & -4.3 & -4.55 & -5 \\
\hline-12 & -8.25 & -2.3 & -1.9 & -4.45 & -5.3 & -6.2 & -3.55 & -3.4 & -5.05 & -5.5 & -5.6 \\
\hline-10 & -9.25 & -3 & -2.65 & -5.2 & -6.2 & -7.4 & -4.1 & -4.3 & -6.05 & -6.6 & -6.3 \\
\hline-8 & -10 & -4.2 & -3.95 & -6.2 & -7.6 & -8.45 & -5.2 & -5.6 & -7.2 & -7.5 & -7.25 \\
\hline-6 & -10.8 & -5.4 & -4.7 & -7.6 & -8.4 & -9.55 & -6.8 & -6.9 & -8.4 & -8.8 & -8.55 \\
\hline-4 & -11.45 & -6.4 & -5.7 & -8.8 & -9.1 & -10.5 & -7.9 & -7.9 & -9.7 & -9.6 & -9.85 \\
\hline-2 & -11.7 & -7.2 & -6.8 & -10.1 & -9.6 & -10.9 & -8.9 & -8.9 & -10.7 & -10.1 & -10.35 \\
\hline 0 & -12.7 & -8.3 & -7.9 & -11.4 & -11.2 & -12.2 & -10.2 & -9.8 & -11.9 & -11.9 & -12 \\
\hline 2 & -11.9 & -7.85 & -7.2 & -10.5 & -10.9 & -11.9 & -9.4 & -9.8 & -11.2 & -11 & -11.6 \\
\hline 4 & -10.8 & -6.85 & -6.3 & -9.7 & -9.7 & -10.7 & -8.5 & -8.6 & -9.8 & -9.7 & -10.75 \\
\hline 6 & -9.3 & -5.7 & -5.2 & -8.3 & -8.6 & -9.55 & -7.25 & -7.3 & -8.65 & -8.55 & -9.4 \\
\hline 8 & -7.85 & -4.7 & -4.1 & -7.15 & -7.8 & -8.25 & -6.05 & -5.75 & -7.35 & -7.35 & -8.25 \\
\hline 10 & -6.65 & -3.9 & -3.4 & -6 & -6.4 & -6.85 & -4.95 & -4.4 & -6.2 & -5.85 & -7 \\
\hline 12 & -5.9 & -3.5 & -3 & -4.9 & -5.1 & -5.4 & -3.55 & -3.35 & -4.8 & -4.8 & -5.4 \\
\hline 14 & -4.7 & -3.15 & -3 & -3.3 & -4 & -4.6 & -2.7 & -2.4 & -3.65 & -3.55 & -4.35 \\
\hline 16 & -3.7 & -2.3 & -2.7 & -2.8 & -2.8 & -3.7 & -2.5 & -1.9 & -2.95 & -2.55 & -3.25 \\
\hline 18 & -2.5 & -2.1 & -2.35 & -2.3 & -1.7 & -2.85 & -1.5 & -1.05 & -2.55 & -1.3 & -2.1 \\
\hline 20 & -1.1 & -1.25 & -1.85 & -2.3 & -0.5 & -1.3 & -0.5 & -0.25 & -1.8 & -0.2 & -1.15 \\
\hline 22 & -0.6 & -0.2 & -1 & -2.2 & -0.2 & -0.4 & -0.3 & 0 & -1.8 & 0 & -0.15 \\
\hline 24 & -0.4 & 0 & -0.2 & -1.7 & -0.2 & -0.25 & 0 & 0 & -1.3 & 0 & 0 \\
\hline 26 & 0 & 0 & 0 & -0.75 & 0 & 0 & 0 & & -0.1 & & 0 \\
\hline 28 & 0 & & 0 & 0 & 0 & 0 & & & 0 & & \\
\hline 30 & 0 & & & & & & & & 0 & & \\
\hline 32 & & & & & & & & & & & \\
\hline
\end{tabular}


Table A.5 - Cross-sections (profiles) of the scour hole for $\mathrm{L}_{\mathrm{a}}=35 \mathrm{~cm}$ (continued)

\begin{tabular}{|c|c|c|c|c|c|c|c|c|c|c|c|}
\hline \multicolumn{12}{|c|}{ Scour Depth for $\mathrm{L}_{\mathrm{a}}=35 \mathrm{~cm}(\mathrm{~cm})$} \\
\hline \multirow{3}{*}{$\begin{array}{c}X \\
\text { (cm) }\end{array}$} & \multirow{3}{*}{ WithoutCollar } & \multicolumn{5}{|c|}{$\mathrm{B}_{\mathrm{c}}=5 \mathrm{~cm}$} & \multicolumn{5}{|c|}{$B_{c}=2.5 \mathrm{~cm}$} \\
\hline & & \multicolumn{10}{|c|}{$\mathrm{Z}_{\mathrm{c}}(\mathrm{cm})$} \\
\hline & & -2 & -1 & 0 & 1 & 2 & -2 & -1 & 0 & 1 & 2 \\
\hline \multicolumn{12}{|l|}{-152} \\
\hline \multicolumn{12}{|l|}{-150} \\
\hline \multicolumn{12}{|l|}{-148} \\
\hline \multirow{2}{*}{\multicolumn{12}{|c|}{$\frac{-146}{-144}$}} \\
\hline & & & & & & & & & & & \\
\hline-142 & & & 1.85 & 2.4 & & & 1.7 & & & & \\
\hline-140 & & & 1.65 & 2.3 & & & 1.75 & & & & \\
\hline-138 & & & 1.65 & 2.3 & & & 1.75 & 1.95 & 2.05 & & \\
\hline-136 & & & 1.65 & 2.3 & & & 1.75 & 1.85 & 1.8 & & \\
\hline-134 & & & 1.65 & 2.3 & & & 1.75 & 1.85 & 1.8 & 0 & \\
\hline-132 & & 2.05 & 1.65 & 2.3 & & & 1.75 & 1.85 & 1.8 & 1.8 & \\
\hline-130 & & 2.05 & 1.65 & 2 & 0 & & 1.85 & 1.85 & 1.8 & 2.05 & \\
\hline-128 & 0 & 2.05 & 1.65 & 2 & 0.9 & & 1.85 & 1.85 & 1.8 & 2.05 & \\
\hline-126 & 0.55 & 2.05 & 1.65 & 2 & 2.4 & & 1.85 & 1.5 & 1.5 & 2 & 0 \\
\hline-124 & 2.05 & 2.05 & 1.65 & 2 & 2.45 & & 1.85 & 1.5 & 1.5 & 2 & 1.45 \\
\hline-122 & 2.1 & 2.05 & 1.65 & 2 & 2.45 & & 1.85 & 1.5 & 1.5 & 2 & 1.95 \\
\hline-120 & 2.1 & 1.85 & 1.65 & 1.45 & 2.45 & 0 & 2.1 & 1.5 & 1.5 & 2 & 1.95 \\
\hline-118 & 2.1 & 1.85 & 1.65 & 1.45 & 2.4 & 0.1 & 2.1 & 1.5 & 1.5 & 2 & 1.95 \\
\hline-116 & 2.1 & 1.85 & 1.65 & 1.45 & 2.4 & 1.45 & 2.1 & 1.15 & 1.4 & 1.5 & 2 \\
\hline-114 & 2.1 & 1.85 & 1.65 & 1.45 & 2.4 & 2.25 & 2.1 & 1.15 & 1.4 & 1.5 & 2 \\
\hline-112 & 1.7 & 1.85 & 1.65 & 1.45 & 2.4 & 2.1 & 2.1 & 1.15 & 1.4 & 1.5 & 2 \\
\hline-110 & 1.7 & 1.5 & 1.65 & 1.65 & 2.4 & 2.1 & 2.1 & 1.15 & 1.4 & 1.5 & 2 \\
\hline-108 & 1.7 & 1.5 & 1.65 & 1.65 & 1.95 & 1.95 & 2.1 & 1.15 & 1.4 & 1.5 & 2 \\
\hline-106 & 1.7 & 1.5 & 1.65 & 1.65 & 1.95 & 1.95 & 2.1 & 0.75 & 1.1 & 1.5 & 2.05 \\
\hline-104 & 1.7 & 1.5 & 1.65 & 1.65 & 1.95 & 1.95 & 2.1 & 0.75 & 1.1 & 1.5 & 2.05 \\
\hline-102 & 1.55 & 1.5 & 1.65 & 1.65 & 1.95 & 1.95 & 2.1 & 0.75 & 1.1 & 1.5 & 2.05 \\
\hline-100 & 1.55 & 1.2 & 1.65 & 1.65 & 1.95 & 1.95 & 1.65 & 0.75 & 1.1 & 1.5 & 2.05 \\
\hline-98 & 1.55 & 1.2 & 1.65 & 1.65 & 1.7 & 1.8 & 1.65 & 0.75 & 1.1 & 1.5 & 2.05 \\
\hline-96 & 1.55 & 1.2 & 1.65 & 1.65 & 1.7 & 1.8 & 1.65 & 0.6 & 1 & 1.3 & 1.85 \\
\hline-94 & 1.55 & 1.2 & 1.65 & 1.65 & 1.7 & 1.8 & 1.65 & 0.6 & 1 & 1.3 & 1.85 \\
\hline-92 & 1.2 & 1.2 & 1.65 & 1.65 & 1.7 & 1.8 & 1.65 & 0.6 & 1 & 1.3 & 1.85 \\
\hline-90 & 1.2 & 0.95 & 1.65 & 1.5 & 1.7 & 1.8 & 0.8 & 0.6 & 1 & 1.3 & 1.85 \\
\hline-88 & 1.2 & 0.95 & 1.65 & 1.5 & 1.2 & 1.05 & 0.8 & 0.6 & 1 & 1.3 & 1.85 \\
\hline-86 & 1.2 & 0.95 & 1.65 & 1.5 & 1.2 & 1.05 & 0.8 & 0.5 & 1 & 0.65 & 1.05 \\
\hline-84 & 1.2 & 0.95 & 1.65 & 1.5 & 1.2 & 1.05 & 0.8 & 0.5 & 1 & 0.65 & 1.05 \\
\hline $\begin{array}{l}-82 \\
\end{array}$ & 0.7 & 0.95 & 1.65 & 1.5 & 1.2 & 1.05 & 0.8 & 0.5 & 1 & 0.65 & 1.05 \\
\hline-80 & 0.7 & 0.95 & 1.6 & 1.45 & 1.2 & 1.05 & 0.35 & 0.5 & 1 & 0.65 & 1.05 \\
\hline-78 & 0.7 & 0.95 & 1.6 & 1.45 & 1.05 & 0.7 & 0.35 & 0.5 & 1 & 0.65 & 1.05 \\
\hline-76 & 0.7 & 0.95 & 1.6 & 1.45 & 1.05 & 0.7 & 0.35 & 0.4 & 0.5 & 0.35 & 0.5 \\
\hline-74 & 0.7 & 0.95 & 1.6 & 1.45 & 1.05 & 0.7 & 0.35 & 0.4 & 0.5 & 0.35 & 0.5 \\
\hline-72 & 0.3 & 0.95 & 1.6 & 1.45 & 1.05 & 0.7 & 0.35 & 0.4 & 0.5 & 0.35 & 0.5 \\
\hline-70 & 0.3 & 1.2 & 1.5 & 1.35 & 1.05 & 0.7 & -0.05 & 0.4 & 0.5 & 0.35 & 0.5 \\
\hline-68 & 0.3 & 1.2 & 1.5 & 1.35 & 1.25 & 0.95 & -0.05 & 0.4 & 0.5 & 0.35 & 0.5 \\
\hline-66 & 0.3 & 1.2 & 1.5 & 1.35 & 1.25 & 0.95 & -0.05 & 0.2 & 0.15 & $\begin{array}{l}0.1 \\
\end{array}$ & 0.3 \\
\hline-64 & 0.3 & 1.2 & 1.5 & 1.35 & 1.25 & 0.95 & -0.05 & 0.2 & 0.15 & 0.1 & 0.3 \\
\hline-62 & 0.2 & 1.2 & 1.5 & 1.35 & 1.25 & 0.95 & -0.05 & 0.2 & 0.15 & 0.1 & 0.3 \\
\hline-60 & 0.2 & 1.55 & 1.7 & 1.2 & 1.25 & 0.95 & -0.2 & -0.25 & 0.15 & 0.1 & 0.3 \\
\hline-58 & 0.2 & 1.55 & 1.7 & 1.2 & 1.3 & 1.1 & -0.2 & -0.25 & 0.15 & 0.1 & 0.3 \\
\hline-56 & 0.2 & 1.55 & 1.7 & 1.2 & 1.3 & 1.1 & -0.4 & -0.45 & -0.3 & -0.15 & 0.05 \\
\hline-54 & 0.2 & 1.55 & 1.7 & 1.2 & 1.3 & 1.1 & -0.4 & -0.45 & -0.3 & -0.15 & 0.05 \\
\hline-52 & -0.2 & 1.55 & 1.7 & 1.2 & 1.3 & 1.1 & -0.5 & -0.85 & -0.3 & -0.3 & $\begin{array}{l}-0.2 \\
\end{array}$ \\
\hline-50 & -0.2 & 1.55 & 1.7 & 1.5 & 1.3 & 1.1 & -0.5 & -0.85 & -0.3 & -0.3 & -0.2 \\
\hline-48 & -0.45 & 1.55 & 1.7 & 1.5 & 1 & 0.95 & $\begin{array}{l}-0.8 \\
\end{array}$ & -1.2 & -0.3 & -0.4 & -0.3 \\
\hline-46 & -0.45 & 1.55 & 1.7 & 1.5 & 1 & 0.95 & \begin{tabular}{|l|}
-0.8 \\
\end{tabular} & -1.2 & -0.6 & -0.4 & -0.3 \\
\hline-44 & -1 & 1.55 & 1.7 & 1.5 & 1 & 0.95 & -1 & -1.5 & -0.6 & -0.6 & -0.5 \\
\hline-42 & -1 & 1.55 & 1.7 & 1.5 & 1 & 0.95 & -1 & -1.5 & -0.6 & -0.6 & -0.5 \\
\hline-40 & -1.4 & 1.5 & 1.35 & 1.2 & 1 & 0.95 & \begin{tabular}{|l|}
-1.3 \\
\end{tabular} & -2 & -0.6 & -0.65 & -0.8 \\
\hline
\end{tabular}




\begin{tabular}{|c|c|c|c|c|c|c|c|c|c|c|c|}
\hline-38 & -1.4 & 1.5 & 1.35 & 1.2 & 1 & 0.8 & -1.3 & -2 & -0.7 & -0.65 & -0.8 \\
\hline-36 & -1.65 & 1.3 & 1.35 & 1.2 & 1 & 0.8 & -1.1 & -2.1 & -0.7 & -1 & -1.05 \\
\hline-34 & -1.95 & 1.3 & 1.35 & 1.2 & 0.85 & 0 & -1.1 & -2.1 & -1 & -1 & -1.35 \\
\hline-32 & -2.3 & 0.85 & 0.9 & 1.2 & 0.85 & 0 & -1.25 & -2.15 & -1 & -1.55 & -1.7 \\
\hline-30 & -2.6 & 0.85 & 0.9 & 0.5 & 0 & -0.75 & -1.25 & -2.4 & -1.1 & -1.55 & -2.35 \\
\hline-28 & -3.15 & 0.35 & 0.2 & 0.5 & 0 & -1.2 & -1.5 & -2.8 & -1.5 & -1.95 & -2.85 \\
\hline-26 & -3.85 & 0.35 & 0.2 & 0.5 & -0.4 & -2.1 & -1.5 & -3.25 & -1.9 & -2.7 & -3.5 \\
\hline-24 & -4.45 & -0.25 & -0.3 & -0.1 & -0.9 & -2.65 & -2.3 & -3.7 & -2.25 & -3.5 & -4 \\
\hline-22 & -5.1 & -0.7 & -1.15 & -0.5 & -1.8 & -3.45 & -2.3 & -4.05 & -2.9 & -4.15 & -4.5 \\
\hline-20 & -5.55 & -1.45 & -2 & -1.5 & -2.4 & -4.1 & -2.85 & -4.5 & -3.5 & -4.9 & -4.9 \\
\hline-18 & -6.25 & -2.55 & -2.9 & -2.4 & -3.25 & -4.55 & -3.45 & -5 & -4.4 & -5.4 & -5.4 \\
\hline-16 & -6.9 & -3.4 & -3.9 & -3.35 & -4.3 & -5.3 & -4.3 & -5.75 & -5.3 & -5.95 & -6.15 \\
\hline-14 & -7.5 & -4.1 & -4.9 & -4.35 & -5.3 & -6.1 & -5.15 & -6.5 & -5.8 & -6.8 & -6.65 \\
\hline-12 & -8.25 & -4.85 & -5.65 & -5.15 & -6.45 & -6.85 & -6.05 & -7.05 & -6.6 & -6.3 & -7 \\
\hline-10 & -9.25 & -5.7 & -6.8 & -6.3 & -7.5 & -7.35 & -6.9 & -7.5 & -7.4 & -8 & -8.1 \\
\hline-8 & -10 & -6.85 & -7.85 & -7.4 & -8.5 & -8.7 & -8.35 & -8.55 & -8.35 & -8.6 & -9.15 \\
\hline-6 & -10.8 & -8.1 & -8.9 & -9.2 & -9.45 & -9.55 & -9.25 & -9.55 & -9.4 & -9.45 & -10.1 \\
\hline-4 & -11.45 & -9.5 & -9.7 & -10.4 & -10 & -10.35 & -10.25 & -10.3 & -10.3 & -10.15 & -10.45 \\
\hline-2 & -11.7 & -10.55 & -10.3 & -10.7 & -10.3 & -10.7 & -10.9 & -11.2 & -11.1 & -11.2 & -10.8 \\
\hline 0 & -12.7 & -11.6 & -11.7 & -11.8 & -11.7 & -12.2 & -12.2 & -12.2 & -12 & -12.7 & -12.2 \\
\hline 2 & -11.9 & -10.7 & -10.7 & -11.2 & -10.9 & -11.4 & -11.6 & -11.55 & -11.6 & -11.65 & -11.4 \\
\hline 4 & -10.8 & -9.4 & -9.7 & -10.25 & -9.95 & -10.1 & -10.2 & -10.4 & -10.4 & -10.4 & -11.25 \\
\hline 6 & -9.3 & -8 & -8.5 & -9.1 & -8.4 & -8.6 & -8.85 & -8.8 & -9.2 & -8.95 & -8.8 \\
\hline 8 & -7.85 & -6.9 & -7.3 & -7.95 & -7.15 & -7 & -7.2 & -7.55 & -7.9 & -7.7 & -7.9 \\
\hline 10 & -6.65 & -5.65 & -5.8 & -6.75 & -5.6 & -6.1 & -6 & -6.3 & -6.6 & -6.75 & -6.5 \\
\hline 12 & -5.9 & -4.8 & -4.6 & -5.4 & -4.9 & -4.7 & -5.2 & -5 & -5.6 & -5.5 & -5.3 \\
\hline 14 & -4.7 & -3.4 & -3.7 & -4.15 & -3.95 & -3.55 & -4.3 & -3.9 & -4.1 & -4.45 & -3.35 \\
\hline 16 & -3.7 & -1.95 & -3 & -3.2 & -3.15 & -2.65 & -3.7 & -2.7 & -2.75 & -3.9 & -2.35 \\
\hline 18 & -2.5 & -1 & -1.9 & -2.85 & -1.8 & -1.6 & -2.75 & -1.65 & -1.8 & -3.1 & -1 \\
\hline 20 & -1.1 & 0 & -1.15 & -2.6 & -0.65 & -0.6 & -1.4 & -0.5 & -1.5 & -1.7 & -0.1 \\
\hline 22 & -0.6 & & -0.35 & -1.85 & -0.15 & -0.2 & -0.3 & -0.2 & -1.1 & -0.65 & 0 \\
\hline 24 & -0.4 & & -0.15 & -1.2 & 0 & 0 & 0 & 0 & -0.4 & -0.1 & \\
\hline 26 & 0 & & 0 & -0.2 & & 0 & 0 & 0 & 0 & 0 & \\
\hline 28 & 0 & & & 0 & & & 0 & & & 0 & \\
\hline 30 & 0 & & & 0 & & & & & & & \\
\hline 32 & & & & & & & & & & & \\
\hline
\end{tabular}

